\title{
WHAT IF WHEN HARRY MET SALLY, SALLY WAS SHY? \\ EXPLORING THE ASSOCIATIONS BETWEEN SHYNESS, ROMANTIC \\ RELATIONSHIP QUALITY, AND WELL-BEING IN EMERGING ADULTHOOD
}

\author{
A thesis submitted to \\ the Faculty of Graduate Studies and Research \\ in Partial Fulfillment of the requirements for the degree
}

Master in Arts

by

H. Claire Rowsell

Department of Psychology

Carleton University

June, 2010

(c)2010 H. Claire Rowsell 


\section{Library and Archives Canada \\ Published Heritage Branch \\ 395 Wellington Street Ottawa ON K1A ON4 Canada}

Bibliothèque et

Archives Canada

Direction du

Patrimoine de l'édition

395, rue Wellington

Ottawa ON K1A 0N4

Canada
Your file Votre référence
ISBN: 978-0-494-71711-0
Our file Notre référence
ISBN: $978-0-494-71711-0$
NOTICE:

The author has granted a nonexclusive license allowing Library and Archives Canada to reproduce, publish, archive, preserve, conserve, communicate to the public by telecommunication or on the Internet, loan, distribute and sell theses worldwide, for commercial or noncommercial purposes, in microform, paper, electronic and/or any other formats.

The author retains copyright ownership and moral rights in this thesis. Neither the thesis nor substantial extracts from it may be printed or otherwise reproduced without the author's permission.
AVIS:

L'auteur a accordé une licence non exclusive permettant à la Bibliothèque et Archives Canada de reproduire, publier, archiver, sauvegarder, conserver, transmettre au public par télécommunication ou par l'Internet, prêter, distribuer et vendre des thèses partout dans le monde, à des fins commerciales ou autres, sur support microforme, papier, électronique et/ou autres formats.

L'auteur conserve la propriété du droit d'auteur et des droits moraux qui protège cette thèse. $\mathrm{Ni}$ la thèse ni des extraits substantiels de celle-ci ne doivent être imprimés ou autrement reproduits sans son autorisation.
In compliance with the Canadian Privacy Act some supporting forms may have been removed from this thesis.

While these forms may be included in the document page count, their removal does not represent any loss of content from the thesis.
Conformément à la loi canadienne sur la protection de la vie privée, quelques formulaires secondaires ont été enlevés de cette thèse.

Bien que ces formulaires aient inclus dans la pagination, il n'y aura aucun contenu manquant. 
Shyness and Romantic Relationships

\begin{abstract}
This study examined associations between shyness, romantic relationship quality, and well-being among emerging adults. The potential role of romantic relationship quality as a protective factor against the detrimental effects of shyness was explored. Participants were $\mathrm{n}=1159$ (Study 1 ) and $\mathrm{n}=400$ (Study 2) undergraduate students ranging in age from 18-26 years. In Study 1, participants completed measures of shyness, romantic relationship status, and relationship quality. In Study 2, students completed measures of shyness, romantic relationship quality, self-esteem, and well-being. Indices of romantic relationship quality included: (1) adult attachment; (2) intimacy; (3) sexual satisfaction; and (4) general romantic relationship satisfaction. Among the results, shyness was negatively related to all indices of romantic relationship quality, self-esteem, and well-being. Moreover, relationship quality appeared to attenuate the negative association between shyness and well-being. However, contrary to expectations, there was some evidence to suggest that more positive relationship quality may actually exacerbate the negative relation between shyness and self-esteem.
\end{abstract}




\section{Acknowledgements}

I would like to thank my advisor, Dr. Robert Coplan for his assistance through every step

of my work. He has been an incredible mentor, collaborator, advisor, and editor. Second, I would like to thank Dr. Janet Mantler, Dr. Anne Bowker, and Dr. Diana Majury for being on my committee. Thank you to Etelle Bourassa of the Department of Psychology for being so understanding and helpful throughout this process. I would like to thank Nikolina Antonacopoulos who answered any question that I had about the SONA System. Thank you to all of the Carleton University undergraduate students who participated in my studies.

Thanks to my lab mates for their ideas and support. Thanks to the friends who spent hours in doing work in coffee shops with me. And thanks to the stats girls for keeping me sane throughout the entire process. Thanks to my family for their endless support and encouragement. Thank you to Luke for giving me the motivation to complete this with the incentive of a trip half way around the world. Finally, thank you to my best friend, my yellow lab, Phoebe who was my constant study partner and who passed away just after helping me complete this piece of work. 


$\begin{array}{lc}\text { Abstract } & \text { ii } \\ \text { Acknowledgements } & \text { iii } \\ \text { Table of Contents } & \text { iv } \\ \text { List of Tables } & \text { vi } \\ \text { List of Figures } & \text { vii } \\ \text { List of Appendices } & 1 \\ \text { Introduction } & 33 \\ \text { Method -Study 1 } & 34 \\ \text { Results -Study 1 } & 40 \\ \text { Method -Study 2 } & 44 \\ \text { Results -Study 2 } & 68 \\ \text { Discussion } & 97 \\ \text { References } & 114 \\ \text { Appendices } & \end{array}$




\section{List of Tables}

Table 1: Descriptive statistics for Study 1 variables

Table 2: Correlations between Study 1 variables

Table 3: Hierarchical regression predicting romantic relationship quality

Table 4: Descriptive Statistics for all Study 2 variables

Table 5: Correlations between demographic variables and study variables

Table 6: Correlations between Study 2 variables

Table 7: Correlations between Study 2 summary variables

Table 8: Hierarchical regression predicting romantic relationship quality and attachment outcome variables from shyness and gender

Table 9: Hierarchical regression predicting well-being from shyness, gender, and romantic relationship quality

Table 10: Hierarchical regression predicting well-being from shyness and romantic relationship quality for males only

Table 11: Hierarchical regression predicting well-being from shyness and romantic relationship quality for females only

Table 12: Hierarchical regression predicting self-esteem from shyness, gender, and romantic relationship quality

Table 13: Hierarchical regression predicting well-being from shyness, gender, and attachment

Table 14: Hierarchical regression predicting self-esteem from shyness, gender, and attachment 


\section{List of Figures}

Figure 1: Simple slopes illustrating the interaction between romantic relationship quality and shyness in the prediction of well-being for females

Figure 2: Simple slopes illustrating the interaction between romantic relationship quality and shyness in the prediction of self-esteem

Figure 3: Simple slopes illustrating the interaction between attachment and shyness in the prediction of well-being

Figure 4: Simple slopes illustrating the interaction 67 between attachment and shyness in the prediction of self-esteem 
List of Appendices

Appendix A: Informed Consent Form

Appendix B: Debriefing Letter to Student

Appendix C: Recruitment Notice

Appendix D: Relationship Measures for Study 1

Appendix E: Demographics for Study 2

Appendix F: Revised Cheek and Buss Shyness Scale

Appendix G: Index of Marital Satisfaction

Appendix H: Experiences in Close Relationships-Revised Questionnaire

Appendix I: Emotional Intimacy Scale

Appendix J: Sexual Satisfaction Scale

Appendix K: Rosenberg Self-Esteem Scale 
What if when Harry met Sally, Sally was shy?

Exploring the associations between shyness, romantic relationship quality, and well-being in emerging adulthood

Adults commonly report that they are shy (Henderson \& Zimbardo, 2008). Shyness is a personality trait that typically involves feelings of apprehension and discomfort in social situations (Coplan \& Armer, 2007; Zimbardo, 1990). There is a well-established empirical link between shyness and problems of psychological well-being. For example, as compared to their less shy counterparts, extremely shy individuals are at greater risk for experiencing lower selfesteem, as well as difficulties with anxiety, depression, and loneliness (Asendorpf \& Wilpers, 1998; Asendorpf, Denissen \& van Aken, 2008; Ashbaugh, Antony, McCabe, Schmidt, \& Swinson, 2005; Brunet \& Schmidt, 2007; Cheek \& Melchoir, 1990; Crozier, 1995; Kalliopuska, 2008; Koydemir \& Demir, 2008; Martin, 1990; Schmidt \& Fox, 1995; Zimbardo, 1990). Notwithstanding, it is certainly not the case that all shy people experience socioemotional and adjustment difficulties. In this regard, researchers have also explored factors that may influence (i.e., moderate) the associations between shyness and negative outcomes, including quality of a variety of important social relationships (Arbeau, Coplan, \& Weeks, 2010; Fordham \& Stevenson-Hinde, 1999; Graham, 2009; Hodges, Boivin, Vitraro, and Bukowski, 1999). However, the potential influence of romantic relationships on the link between shyness and psychological well-being has yet to be been investigated. A better understanding of this process could help those who are shy to develop more fulfilling relationships and healthier lives. As compared to their less shy counterparts, shy individuals are more likely to have poor relationship quality and are less likely to be in a romantic relationship (Asendorpf \& Wilpers, 
1998; Asendorpf et al., 2008; Leck, 2006; Nelson et al., 2008). Only a few researchers have previously investigated the association between shyness and romantic relationships (Asendorpf \& Wilpers, 1998; Caspi et al., 2003; Leck, 2006; Nelson et al., 2008).

Romantic relationship quality may be particularly relevant in the adjustment and wellbeing of shy emerging adults, because romantic relationships are a very central part of people's lives during this developmental period (Arnett, 2000; Kan \& Cares, 2006; Koydemir \& Demir, 2008; Roisman, Masten, Coatsworth, \& Tellegen, 2004). Positive relationships are known to help buffer shy individuals against negative outcomes associated with shyness (Fordham \& Stevenson-Hinde, 1999; Graham, 2009; Griggs, Gagnon, Huelsman, Kidder-Ashley, \& Ballard, 2009; Hodges et al., 1999). The main goal of this thesis research was to examine associations between shyness, romantic relationship quality, and psychological well-being. Specifically, the potential protective role of romantic relationship quality on the possible detrimental effects of shyness was examined in emerging adulthood.

\section{What is Shyness?}

Shyness can be viewed as both a state and a trait. An important distinction between shyness as a state and as a trait must be clarified. State shyness is the immediate experience of heightened anxiety and self-consciousness. Nearly everyone experiences this situational or state shyness at some point in their life (Leary \& Kowalski, 1995; Zimbardo, 1990). State shyness can include a cognitive (e.g., self-consciousness, self-focused), affective (e.g., anxiety, embarrassment), behavioural (e.g., averting eye contact, speaking quietly), and physiological experience (e.g., blushing, sweating, elevated heart rate; Henderson \& Zimbardo, 2008; Schmidt et al., 1999).

On the other hand, shyness as a trait is much more sustaining over time and context. The 
personality trait of shyness involves a more consistent pattern of feelings of wariness and unease in social encounters, instances of perceived social-evaluation, and contexts of social novelty (Coplan \& Armer, 2007; Zimbardo, 1990). Shyness has also been described as a discomfort and/or inhibition in interpersonal situations that impede one's goals, whether they are relational, personal or professional (Henderson \& Zimbardo, 2008). Shy individuals tend to be preoccupied with 'the self' when anticipating and during social interactions (Jones, Briggs, \& Smith, 1986). The most typical situations that arouse reactions of shyness are: performance, perceived social evaluation, novel situations, initiating interactions, and interacting with authorities, strangers, potential romantic or sexual partners, or those of the opposite sex (Henderson \& Zimbardo, 2008).

Shyness is relatively common. Over $80-90 \%$ of people have experienced shyness (Leary \& Kowalski, 1995; Zimbardo, 1990). Nearly 50\% of adults report that they are shy, with $13.3 \%$ reporting they suffer from social anxiety disorder, which is an extreme form of shyness (Zimbardo, 1990). However, the extent of shyness can range considerably from mild discomfort to a clinically-diagnosed social anxiety disorder. Extremely shy individuals are at risk for a host of socio-emotional difficulties, particularly those related to internalizing dimensions (e.g., low self-esteem, depression, anxiety, and loneliness) as well as social isolation, poor health from a lack of social support, earning less money, and even a shorter life span (Cheek \& Melchior, 1990; Kalliopuska, 2008; Koydemir \& Demir, 2008; Zimbardo, 1990). For the purposes of this research, the subsequent focus will be on trait shyness rather than the more transient state shyness.

Shyness is believed to be the later expression of the temperamental trait of behavioural inhibition (BI), a biologically-based highly reactive disposition to novelty (Buss \& Płomin, 
1984). Temperamental characteristics are relatively stable over time and are thought to be the building blocks of later personality (Asendorpf et al., 2008; Caspi \& Silva, 1995; Caspi et al., 2003; Kagan, 1988). Behavioural inhibition is defined as avoidance, withdrawal, and fear in the presence of novelty (Rubin \& Coplan, 2004). Inhibition in infancy may lead to shyness in childhood and adulthood. However, this is not always the case. Environmental factors, such as: parental styles, attachment to primary caregiver, influence of a sibling, family conflicts, peer relations, the school environment, or social activities can influence the development of shyness, (Arbeau, et al., 2010; Duggan \& Brennan, 1994; Fordham \& Stevenson-Hinde, 1999; Graham, 2009; Henderson \& Zimbardo, 2008). Relationship quality with significant people may influence the extent of shyness and the negative implications that are associated with it. Correlates and Outcomes of Shyness

Shyness has been described as involving multiple components, including behavioural, physiological, and socio-emotional. Correlates of shyness in each of these areas will be discussed, with particular emphasis on social relationships and psychological well-being.

There are several physiological reactions that occur with the experience of shyness and distress in novel/social situations, such as; blushing, dry mouth, sweating, trembling, feeling dizzy and accelerated heart rate (Henderson \& Zimbardo, 2008; Schmidt et al., 1999). Shyness is associated with increased autonomic nervous system response and increased cortisol levels to novelty (Kagan, Reznick \& Snidman, 1987; Kagan, Snidman, \& Arcus, 1993).

In terms of behavioural correlates, shyness is associated with displays of gaze aversion, reduced speaking, decreased use of body language and more frequent automanipulatives (i.e., hair twirling, finger biting; Coplan, Hughes, \& Rowsell, 2009; Henderson \& Zimbardo, 2008; Pilkonis, 1977a, 1977b). It is also associated with avoidance of social interactions. If highly shy 
individuals are unable to avoid social interactions or escape from them, they tend to act withdrawn and guarded, smile less, talk less, speak quietly, make less eye contact, behave in anxious ways; overall making the social interaction poor and awkward (Bruch, 2001; Crozier, 2001).

Forming relationships. It has been suggested that those who are shy are caught in a conflict between wanting to approach social situations, and simultaneously experiencing avoidance and anxiety over these situations (Coplan, Prakash, O’Neil, \& Armer, 2004; Rubin \& Asendorpf, 1993). This makes social interactions and relationships difficult and anxiety-inducing for highly shy individuals.

As well, those who are chronically shy fear negative evaluation from others much more than the average person, and feel less competent with social skills and in social interactions (Bruch, 2001; Henderson \& Zimbardo, 2008; Miller, 2001). A "self-fulfilling prophecy" can occur for shy individuals, who may fear that others will not like them or will judge them negatively. Consequently, shy people may either avoid interacting completely or prevent interaction or judgment from occurring by acting withdrawn, cold or unfriendly (Bradshaw, 2006). In turn, this withdrawn and timid behaviour often leads others to form a negative impression of them or not notice them at all - confirming the shy individual's initial fear and expectation.

Social avoidance and withdrawal makes it difficult for shy people to meet people and make friends (Bradshaw, 2006). Highly shy individuals also report difficulties in establishing, and maintaining interpersonal relationships, having less gratifying social relationships, more dysfunctional relationship beliefs, and lower relationship quality with parents and romantic partners, and having fewer romantic relationships (Coplan et al., 2004; Crozier, 1979; Fordham 
\& Stevenson-Hinde, 1999; Garcia-Coll, Kagan \& Reznick, 1984; Koydemir \& Demir, 2008;

Leck, 2006; Nelson et al., 2008; Rubin, Wojslawowicz, Rose-Krasnor, Booth-LaForce, \& Burgess, 2006; Zimbardo, 1990).

Psychological well-being. Shyness has been associated with a host of socio-emotional difficulties, particularly among the internalizing dimension (e.g., low self-esteem, depression, anxiety, low self-confidence, loneliness) and in terms of the establishment and maintenance of social relationships (e.g., social withdrawal, social isolation, having fewer close friends; Asendorpf \& Wilpers, 1998; Asendorpf, Denissen \& van Aken, 2008; Ashbaugh et al., 2005; Brunet \& Schmidt, 2007; Cheek \& Melchoir, 1990; Crozier, 1995; Eisenberg, Fabes, \& Murphy, 1995; Heiser, Tumer, \& Beidel, 2002; Kalliopuska, 2008; Koydemir \& Demir, 2008; Martin, 1990; Schmidt \& Fox, 1995; Zimbardo, 1990). As compared to their less shy peers, chronically shy individuals also show less interest in others, have more negative self-beliefs and thoughts, are more self-conscious, have difficulty expressing themselves and see themselves as unattractive (Crozier, 1995; Henderson \& Zimbardo, 2008; Martin, 1990; Zimbardo, 1990).

Shy individuals often attempt to hide their anxiety and emotions from others. This is an unhealthy way to deal with stress (Eisenberg et al., 1995). They also tend to be overly critical of their performance, negatively evaluated their ability to function in social situations, blame themselves for poor social interactions, and generally experience more negative thoughts than those who are less shy (Bruch, Gorsky, Collins, \& Berger, 1989; Henderson \& Zimbardo, 2008; Koydemir \& Demir, 2008; Wichmann, Coplan, \& Daniels, 2004). Self-blaming can lead to negative biases and views of the self. These negative cognitive biases about the self and social interactions lead to an increased avoidance or inhibition in future social interactions (Henderson \& Zimbardo, 2008). 
A number of studies have specifically demonstrated a negative relation between shyness and indices of self-esteem and self-regard (e.g., Bruch et al., 1989; Cheek \& Melchior, 1990; Crozier, 1995; Kalliopuska, 2008; Koydemir \& Demir, 2008). Rosenberg (1965) defines selfesteem as a stable sense of global personal worth. Self-esteem is considered to be an integral component and critical indicator of psychological well-being and adjustment (Fox \& Wilson, 2008; Leary \& Tangney, 2003). It has a strong link to overall happiness, well-being and may be a buffer against stress (Baumeister, Campbell, Krueger, \& Vohs, 2003; Fox \& Wilson, 2008; Leary \& Tangney, 2003). Fordham and Stevenson-Hinde (2003) reported that shyness was negatively correlated with global self-worth in a sample of school-aged children.

Overall, shyness is a risk factor for many negative outcomes; of major importance are the poor self-esteem and overall poor psychological well-being that are associated with shyness. These problems do not simply disappear with age; shyness is a risk factor for developing internalizing problems and poor psychological well-being throughout adolescences and adulthood (Cheek \& Melchior, 1990; Kalliopuska, 2008; Koydemir \& Demir, 2008).

To note, not all shy individuals develop these negative outcomes. Many adjust appropriately and lead fulfilling lives. However, for some, shyness is debilitating and negatively influences their health, relationships, and overall quality of their lives. The impact of shyness depends on other factors as well, such as the individual's family life, social resources, social support, social environment, quality of close relationships, and coping strategies (Arbeau et al., 2010; Duggan \& Brennan, 1994; Fordham \& Stevenson-Hinde, 1999; Graham, 2009; Henderson \& Zimbardo, 2008; Prakash \& Coplan, 2003). Therefore, shyness is only a risk factor, and not the sole determinant, for the negative outcomes discussed above. 


\section{Shyness in Emerging Adulthood}

Emerging adulthood is the life phase in between adolescence and adulthood, generally eighteen years till the mid-twenties (18-26 years of age). According to Arnett (2000), this is a stage that is defined by instability, exploration, and becoming an adult. This is the time that people generally experiment with their career, schooling, world views, peers, and relationships (Arnett, 2000). Such a transitional period of development allows young people to have an extended opportunity to explore and develop their own identity.

Emerging adulthood is relatively new area of study within developmental and lifespan development psychology. It is generally considered to be a culturally defined developmental stage that is exhibited primarily in Western society (Arnett, 2000). Arnett (2010) has argued that in the past half century, the transition between adolescence and adulthood has been extended, with it lasting about as long as adolescence itself (Arnett, 2010). With the increased emphasis on culture, diversity, and lifespan development within psychology, emerging adulthood is finding its place in the academic world of psychology (Vartanian, in press). Textbooks and conferences on emerging adulthood are on the rise (Arnett, 2010). For example, the Society for the Study of Emerging Adulthood has held four bi-yearly conferences to date. In the past few years, emerging adulthood has also begun infiltrating the field of developmental psychology with a number of articles and special issues on emerging adulthood being published in prominent developmental psychology journals (Eisenberg, 2007; Mortimer, 2009).

The development of Erikson's (1950) "intimacy versus isolation" stage overlaps with the emerging adulthood years. This is the time that people learn to develop enduring, committed, and intimate relationships (Erikson, 1950), making romantic relationships central and important in this stage. However, Erikson's stage theory was developed before emerging adulthood became a 
Shyness and Romantic Relationships 9

developmental phase. Therefore, it may not be the most appropriate conceptual basis. Despite this discrepancy, there are several similarities that still exist between these two concepts. Of importance, romantic relationships were important in Erikson's "intimacy versus isolation" stage and remain important in emerging adulthood phase of development. Relationships with romantic partners also become increasingly central throughout adolescence, becoming one of the most important relationships in emerging adulthood (Lanz \& Tagliabue, 2007). Romantic relationships in emerging adulthood are more serious, intimate, and committed than those in adolescence (Arnett, 2000; Montgomery, 2005; Seiffge-Krenke, 2003). The establishment and maintenance of romantic relationships are important developmental steps in emerging adulthood (Arnett, 2000; Kan \& Cares, 2006; Koydemir \& Demir, 2008; Roisman et al., 2004). Berscheid and colleagues (1989) found that college students considered their romantic relationships to be their closest relationships.

Emerging adulthood may also be a particularly important time period to study shyness. There are many novel and life changing situations that emerging adults encounter including attending university or college, getting a new job, and meeting many unfamiliar people. During this transitional time, shyness may hinder social adjustment and personal well-being. Therefore, shyness may negatively impact the successful development in adulthood and the maintenance of psychological well-being. For example, it has been suggested that shyness may inhibit people from experimenting and trying new things when it comes to jobs, schooling, and relationships (Caspi, Bem, \& Elder, 1988; Caspi et al., 2003; Nelson et al., 2008). This may impede the development of strong social bonds, and slow advances in careers or the pursuit higher education - further holding shy adults back from living a pleasurable and social life and maintaining psychological health. 
In a study of an American sample, Caspi and colleagues (1988) reported differences between shy and non-shy children later in life on a variety of variables; in age of marriage, having children, and entering stable careers. As compared to their non-shy counterparts, shy boys went on to marry an average of three years later, had children four years later, and entered a stable occupation three years later. Shy girls went on to marry men with high occupational statuses and were in the workforce for less time than non-shy girls. These findings are from a 1928 birth cohort study. Therefore, the results are a reflection of the society and life in the mid 1900s. At this time men were expected to be assertive, excel in the workplace and be the breadwinner of the family. It was much more common for women to not work outside the home. Therefore, these findings are difficult to draw conclusions from for shy boys and girls in this day and age.

A replication of this study was done in Sweden from 1955-1958 by Kerr, Lambert, and Bem (1996). The results from this study approximately replicated those of the previous study for both males and females. Unlike the American boys in Caspi and colleagues`(1988) sample, shy Swedish boys did not differ from those of non-shy boys when it came to career. An additional finding was that shy females attained a lower level of education after controlling for IQ.

A second and more recent replication of this study was done by Asendorpf and colleagues (2008). The results in this study were somewhat different from those of the previous two studies. The delayed progression through the milestone stages of young adulthood (i.e., marriage, having children) was replicated not only for shy males, but for shy females as well. This finding is representative of present day society's expectation for both males and females to attain higher education, be a part of the workforce and have a family. Additionally, shy participants had fewer (about half as many) stable romantic relationships when compared to the non-inhibited 
participants. Moreover, the stable romantic relationships of shy individuals were formed an average of eight months later non-shy peers. Therefore, the gender differences appear to be lessening, but the effect of shyness on significant life transitions, outcomes, and relationships has not. Shy emerging adults may be missing out on critical elements of development within the emerging adult years leading them on a path to reduced psychological well-being and socioemotional problems.

An earlier study done by Asendorpf and Wilpers (1998) noted several interesting effects of shyness within an emerging adult sample. They followed students during their first 18 months of university. They found that shyness was related to several social and romantic relationship measures, including: number of new peer relationships, time it takes to make new friends, perceived social support and closeness, being in love with a partner, having a steady sexual partner, frequency of sexual activity with partner (Asendorpf \& Wilpers, 1998). Specifically, shy students reported fewer peer relationships than non-shy students throughout the 18 months. However, near the end of the study the number of peer relationships for shy individuals was only slightly less than that of those who were not shy. This suggested that shyness was associated with slow adaptation to the new social world of university, but that eventually shy individuals "catch up" with their less shy peers. Shy students also reported lower perceived support and closeness in their peer relationships, even though they reported equal interpersonal conflict to non-shy students.

In terms of romantic relationships, shy students (35\%) were two times less likely to be 'in love' than non-shy students. Twenty percent of shy students reported being in a steady sexual relationship; which was half that of those who were not shy. Interestingly, the shy students who were in a steady sexual relationship reported having sex more often than non-shy students in 
steady sexual relationships (Asendorpf \& Wilpers, 1998). The authors noted two potential reasons for this unexpected finding. One, shy individuals may have felt obligated to engage in more frequent sexual activities with their partners in order to maintain their relationship and ensure their partner does not leave. Alternatively, it is also possible the shy individuals may form more intense partnerships. Studying sexual satisfaction in conjunction with shyness may assist in further understanding of this result.

Because of their heightened importance in emerging adulthood, romantic relationships may be of particular significance to shy emerging adults (Berscheid, Snyder, \& Omoto, 1989; Koydemir \& Demir, 2008; Lanz \& Tagliabue, 2007; Myers, 2000; Reis, Collins, \& Buerscheid, 2000; Rogers, 1951; Seiffge-Krenke, 2003; Tanner, 2006). Close relationships protect against many of the risks associated with shyness, including, social isolation, loneliness, poor self-worth, anxiety, depression, and low self-esteem (Fordham \& Stevenson-Hinde, 1999; Hartup, 1995; Parker \& Asher, 1993; Weiss, 1974). Therefore, an understanding of the influence of romantic relationships during this developmental period is necessary in order to understand the effect it may have on the association between shyness and psychological well-being.

\section{Shyness and Close Relationships}

Relatively little is known about shyness within romantic relationships. Accordingly, an overview of shyness within friendship relationships is presented first. Much of this research is potentially applicable to romantic relationships, which can be considered a unique form of friendship. Both romantic partnerships and friendships are reciprocal and voluntary relationships that must be agreed upon by both members (Hays, 1988). Friendships are necessary for learning how to form and maintain intimate, loyal and long-lasting relationships. Thus, friendship can also be construed as a precursor to romantic relationships (Erikson, 1950). 
Shyness and Romantic Relationships 13

In late adolescence, involvement in romantic relationships is associated with emotional and behavioural well-being, and good same-sex friendships (Seiffige-Krenke, 2003). During adolescence and beyond, self-disclosure and intimacy increase considerably (Buhrmester \& Furman, 1987). These are two areas in which shy individuals have difficulty (Rubin et al., 2006). Having a close group of same-sex friends in later adolescence predicted friendships with the opposite sex, which then predicted romantic relationships in the future (Connolly, Furman, \& Konarski, 2000). Connolly and colleagues (2000) also found that quality of friendship is predictive of current and later romantic relationship satisfaction. Friendships are very important for development and protecting against negative outcomes, such as internalizing problems (Fordham \& Stevenson-Hinde, 1999). They are a means of validating self-worth and assisting in the development of interpersonal confidence, self-esteem, and self-definition (Fordham \& Stevenson-Hinde, 1999; Parker \& Gottman, 1989). Individuals with friendships characterized by lower quality tend to have more socio-emotional adjustment problems, including, low selfesteem, anxiety, depression, loneliness, and social dissatisfaction (Fordham \& Stevenson-Hinde, 1999; Hartup, 1995; Parker \& Asher, 1993).

Shy people are thought to desire close friendships, but their anxiety may encourage behaviours that interfere with the development and maintenance of such relationships (Asendorpf \& Wilpers, 1998; Bruch 2001; Miller, 2001). Much of the literature on the association between shyness and friendship has been focused on children. Several researchers have found that shy children are less likely to have friends than non-shy children (Coplan et al., 2004; Parker \& Seal, 1996). For instance, Coplan and colleagues (2004) found that shy children had fewer friends and were more likely to play alone than non-shy children. However, there is some opposing literature that suggests that this is not necessarily the case. Ladd and Burgess 
(1999) found that shy children are as likely to have a best friend as those who were not shy (Ladd \& Burgess, 1999). However, since this was a very young sample, shyness may be less likely to impact friends or be noticed by the other children.

There is some evidence to suggest that shyness is associated with lower relationship quality within best friendships. For example, the friendships of shy individuals are characterized by having less intimacy, fun, helpfulness, guidance, care and validation (Rubin et al., 2006). Shy adults make friends much more slowly than people who are not shy (Asendorpf \& Wilpers, 1998). Bradshaw (2006) found that shy adults tend to be lonelier and form friendships that are less supportive and satisfying than those who are less shy.

Overall, shyness is associated with more difficulty establishing friendships, lower prevalence of friendships and lower friendship quality (Asendorpf \& Wilpers, 1998; Bradshaw, 2006; Coplan et al., 2004; Parker \& Seal, 1996; Rubin et al., 2006; Ward \& Tracey, 2004). Shyness and Romantic Relationships

Romantic relationships are a unique form of dyadic friendship. Friendship is a mutual and voluntary personal relationship that offers intimacy and help, with both individuals in the partnership spending time with one another and exhibiting reciprocal mutual affection (Fehr, 1996). Romantic relationships include these friendship qualities plus a few more: sexual desire, greater fascination with partner, a greater desire for exclusivity, and more defined social norms (Giordano, Manning, \& Longmore, 2006). Additional to these, within romantic relationships there tends to be more time spent together and more expression of positive emotions than in other relationships (Fehr, 1996). Another component of a romantic relationship is behavioural interdependence; the mutual influence that the partners have on each other (Berscheid et al., 1983). Couple's lives are intertwined and affected by each other. Behaviour by either partner 
Shyness and Romantic Relationships 15

impacts that of them self and their partner.

There are some gender differences in the types and quality of close relationships that men and women form. For one, women report having more friendships and are more likely to have a best friend when compared to men. Women also tend to have more intimate and close friendships (Adams \& Blieszner, 1995; Birditt \& Antonucci, 2007). However, women also report more negative and lower quality close relationships (Birditt \& Antonucci, 2007). This may occur because women may be more emotionally involved in their close relationships and this can lead to feeling burdened by others' problems (Birditt \& Antonucci, 2007).

The majority of previous research on shyness and romantic relationships has focused on the prevalence of dating and being in relationships. Several studies have found that shyness is negatively associated with dating and being in a committed romantic or sexual relationship (Asendorpf \& Wilpers, 1998; Leck, 2006; Nelson et al., 2008). Even though shy and socially anxious individuals may have a strong desire to date, their anxiety in social interactions may prevent them from initiating and maintaining interactions with potential dating partners. As for romantic relationships, shy people reported half as many as those who were not shy. In addition, those who are shy fall in love much less than average and have fewer friendships (Asendorpf \& Wilpers, 1998; Asendorpf et al., 2008).

Despite the majority of research suggesting that shyness is associated with reduced dating, there is one study that found no such relation (Erwin 2007). In a sample of university students, Erwin (2007) found no significant association between shyness and romantic relationship status. However, this study did find that the "love style" of shy individuals differed from those who were not shy. High shyness scores were associated with two of the six love styles, storge and mania. Storge is the love style that is associated with affectionate love and 
develops slowly out of friendship. Mania is an obsessive and volatile love style which is associated with low self-esteem (Erwin, 2007). This combination of love styles suggests that shy individuals are more likely to emphasize the friendship aspect of their relationship, while also being more possessive of and dependent on their partners (Erwin, 2007).

As previously mentioned shyness is associated with a lag in time before marriage or being in a committed romantic relationship (Asendorpf \& Wilpers, 1998; Asendorpf et al., 2008; Caspi et al., 1988; Kerr et al., 1996). Nelson and colleagues (2008) found that shy emerging adults had lower romantic relationship quality when compared to non-shy peers, which is consistent with the friendship literature on shyness in childhood (Rubin et al., 2006). They also reported that shyness was associated with more difficulty with dating.

A couple of studies have found that shyness is associated with negative romantic relationship and well-being constructs, such as self-blaming, lower self-esteem, negative beliefs, and detrimental attributions (Johnson, Aikman, Danner \& Elling, 1995; Koydemir \& Demir, 2008). As mentioned earlier, many other studies that have linked shyness to poor well-being, low self-esteem, and internalizing behaviours (e.g., Asendorpf et al., 2008; Ashbaugh et al., 2005; Brunet \& Schmidt, 2007; Kalliopuska, 2008; Zimbardo, 1990).

Koydemir and Demir (2008) studied the relations between shyness, self-esteem, and cognitive distortions in the context of romantic relationships in a sample of Turkish emerging adults. Shyness was found to be negatively associated with self-esteem and dysfunctional relationship beliefs including, interpersonal rejection, unrealistic relationship expectations, interpersonal misperceptions, and interpersonal cognitive distortions. Shy individuals tended to hold high expectations for relationships, and think that having close relationships may cause problems. The shy participants in the study were more also concerned with making a good 
impression on others and not receiving negative evaluations than the less shy participants (Koydemir \& Demir, 2008).

In a study of attributions within romantic relationships, it was found that shy individuals tend to attribute causality in the same negative, self-blaming ways typically associated with depression (Johnson et al., 1995). This finding is similar to that of Wichmann and colleagues (2004), who reported that shy children self-blame for negative social experiences. This is a further link in the similarity between not only romantic relationships and friendships, but the outcomes and perceptions of shy individuals within both types of relationships.

Overall, shyness is associated with more negative relationship and well-being outcomes. However, as mentioned earlier, it must be emphasized that not all shy individuals form negative social relationships and experience negative outcomes. There are many factors that may socioemotional outcomes of shy individuals. Of particular interest for the current research, the quality of close relationships has been shown to have a significant influence on the psychological wellbeing of shy individuals (Arbeau et al., 2010; Fordham \& Stevenson-Hinde, 1999; Graham, 2009; Hodges et al., 1999). Therefore, romantic relationship quality may significantly influence the association between shyness and psychological well-being. Potentially, high quality romantic relationship may have a protective effect against poor well-being and low self-esteem that are associated with shyness. In the following sections, a closer look at what factors may contribute to the quality of romantic relationships is provided.

\section{Components of Romantic Relationship Quality}

Romantic relationship quality is the term used to describe the subjective assessment of the quality of a romantic relationship for those involved (Hassebrauck \& Fehr, 2002). Marital quality was defined by Spanier and Lewis (1980) as the subjective evaluation of a couple's 
relationship on several dimensions. Marital quality and romantic relationship quality are one in the same, except that marital quality refers specifically to married couples (Hassebrauck \& Fehr, 2002). When discussing relationship quality, the subjective experience that an individual has within their own relationship is their perception of reality. This subjective perception is what is important for the individual's health and well-being, making it what is generally focused on in studies concerned with relationship quality (Cheung \& Hudson, 1982; Hassebrauck \& Fehr, 2002; Spanier \& Lewis, 1980).

The quality of romantic relationships has been operationalized to include several different facets. For example, Fletcher and colleagues (2000) found six main components of perceived relationship quality; satisfaction, commitment, trust, closeness or intimacy, passion, and love. In addition, Furman and Wehner (1997) determine that attachment, sexual behavioural systems, and intimacy are key elements in romantic relationships for young adults. Intimacy, sexual satisfaction and attachment are prominent constructs within romantic relationship quality (Fletcher, Simpson, \& Thomas, 2000; Furman \& Wehner, 1997; Hassebrauck \& Fehr, 2002; Penhollow \& Young, 2008; Young Denny, Luquis, \& Young, 1998). These are three vital aspects of romantic relationships that influence the overall quality of the relationship.

For the purpose of the present research, romantic relationship quality encompassed four separate components: (1) relationship satisfaction/quality and degree of problems within the relationship; (2) intimacy; (3) sexual satisfaction; (4) and romantic attachment.

Shyness has been related to lower romantic relationship quality and generally, less positive relationship outcomes (Fordham \& Stevenson-Hinde, 1999; Koydemir \& Demir, 2008; Leck, 2006; Nelson et al., 2008; Zimbardo, 1990). For example, shyness is related to lower intimacy and more negative attachment (higher anxious and avoidant attachment; Bartholomew 
Shyness and Romantic Relationships 19

\& Horowitz, 1991; Duggan \& Brennan, 1994; Kalliopuska, 2008; Rubin et al., 2006). Intimacy and attachment are critical aspects of relationships that if inadequate, can both have significant and detrimental effects on relationships and well-being (Collins, Ford, Guichard, \& Allard, 2006; Nofle \& Shaver, 2006; Ornish, 1998; Rubin et al., 2004; Sinclair \& Dowdy, 2005; Wood, Emmerson, \& Cowan, 2004). Therefore, these are two areas of romantic relationship quality that may be of particular importance in the psychological well-being of shy individuals. Additionally, sexual satisfaction may be significantly influential on well-being for shy individuals because it is so closely tied to overall romantic relationship quality and a significant aspect of a romantic relationship (Giordano, Manning, \& Longmore, 2006; Penhollow \& Young, 2008).

Overall, positive relationships tend to lead to better well-being whereas more negative relationships are predictive of poorer well-being. Associations between close relationship quality and psychosocial functioning have been found many times over (Adams \& Blieszner, 1995; Baumeister et al., 2003; Birditt \& Antonucci, 2007; Collins et al., 2006; Lanz \& Tag, 2007; Noftle \& Shaver, 2006). Relationship quality is associated with psychological well-being, and negatively associated with socio-emotional problems including low social competence, poor selfesteem, depression, anxiety, loneliness, peer rejection, and social isolation (Fordham \& Stevenson-Hinde, 1999; Hartup, 1995; Lanz \& Tagliabue, 2007; Parker \& Asher, 1993; Rubin et al., 2004; Segrin, Powell, Givertz, \& Brackin, 2003; Weiss, 1974; Wood et al., 2004). Interestingly, relationships with spouses and significant others are thought to be the most strongly predictive of well-being (Birditt \& Antonucci, 2007).

Marital quality is related to a number of psychological and physical aspects of well-being (Adams \& Blieszner, 1995; Birditt \& Antonucci, 2007). Low marriage quality and marriage distress have been associated with depressive symptoms and depression (Whiffen, 2006). A few 
studies have found similar connections in dating partners (Fiske \& Peterson, 1991; Segrin et al., 2003). Fiske and Peterson (1991) found that dissatisfaction and anger within a dating relationship were associated with depression. Segrin and colleagues (2003) found that romantic relationship quality was negatively associated with depressive symptoms and loneliness in a sample of dating couples. This finding was similar in both males and females (Segrin et al., 2003).

Within marital relationships, some studies have found a gender difference in relationship functioning and depression. In a couple of studies females were found to have a stronger association between relationship dissatisfaction and depression (Dehle \& Weiss, 1998; Fincham, Beach, Harold, \& Osborne, 1997). However, this is not always the case (Segrin et al., 2003). This gender difference may be due to the fact that females' self-esteem is generally more closely tied to and influenced by their romantic relationship functioning and feel that romantic acts are more important, when compared to men (Culp \& Beach, 1998; Maltby \& Day, 2000; Segrin et al., 2003).

Poor relationship quality has been linked to low self-esteem in both romantic relationships and friendships (Baumeister et al., 2003; Lanz \& Tagliabue, 2007; Rubin et al., 2004; Thomas \& Daubman, 2001). Lanz and Tagliabue (2007) found that emotional support from a romantic partner was predictive of self-esteem in an Italian emerging adult sample. In another study, self-esteem was positively correlated with cross-gendered friendship for adolescent females (Thomas \& Daubman, 2001). Interestingly self-esteem did not appear to be related to cross-gendered friendship for boys at this age.

Low social self-esteem has been linked to involuntary minimal dating for both men and women (Leck, 2006). Social self-esteem is an individual's view of their personal worth and competence in social situations (Leck, 2006). Additionally, Murray and colleagues (2001) found 
Shyness and Romantic Relationships 21

that those with low self-esteem do not believe that their partner truly cares for them and loves them. Alternatively, not all studies have found that self-esteem is linked with duration or quality of relationships. Baumeister and colleauges (2003) suggest that this may be because those who are very high in self-esteem may be narcissists, which over time can be a negative quality that drives others away. However, relatively high self-esteem is healthy and has been correlated with relationship quality. In addition, people with high self-esteem report that they are more likable, attractive, and have better interpersonal relationships and relationship success, than those with low self-esteem (Baumeister et al., 2003).

Romantic relationship quality can be conceptually broken down into two levels, general and specific. At the specific level of the current romantic relationship, intimacy and sexual satisfaction are important indicators of romantic relationship quality within a current partner (Burleson, Trevathan, \& Todd, 2007; Fletcher et al., 2000; Furman \& Wehner, 1997;

Hassebrauck \& Fehr, 2002; Penhollow \& Young, 2008; Young et al., 1998). At the general level, adult attachment is a great indicator of the relationship quality that an individual tends to have within romantic relationships. This is quite stable from relationship to relationship (Bowlby, 1973). For the present study, romantic relationship quality was assessed at both of these levels, with intimacy, sexual satisfaction and an overall measure of current relationship satisfaction as measures of specific relationship quality, and attachment as a measure of general relationship quality.

Intimacy. Intimacy is the closeness and interdependence, the affection and warmth, and the extent of self-disclosure within a relationship (Perlman \& Fehr, 1987). It is a core part of all close relationships. The definition of intimacy includes the following: support, understanding, communication, comfort, and sharing, with self-disclosure and responsiveness being two of its 
Shyness and Romantic Relationships 22 key components (Sternberg, 1987). Emotional intimacy involves a perception of closeness to a partner, self-disclosure of personal feelings by both partners, and understanding, caring and acceptance of one another (Sinclair \& Dowdy, 2005). It simply focuses on the emotional rather than physical intimacy. Self-disclosure and responsiveness are two key components of intimacy (Laurenceau et al., 2004; Reis, 2007). Sustained intimacy is not possible without either of these.

Self-disclosure is the process of telling another person about oneself. Both partners need to engage in self-disclosure to one another in order to be considered intimate (Laurenceau et al., 2004). Those who mutually self-disclose are happier within their current romantic relationship (Sprecher \& Hendrick, 2004). Self-disclosure is related to liking for a number of reasons. Those who disclose more are liked more than those who disclose only a little (Sprecher \& Hendrick, 2004). People like others who they have already self-disclosed to, and those who we like are the ones we tend to disclose to. People who self-disclose also tend to be liked more than those who do not. Individuals feel important and trusted by one who discloses to them (Collins \& Miller, 1994). Complete self-disclosure is not necessary or healthy for any relationship, platonic or romantic.

A balance of intimate self-disclosure and some privacy is needed for marital satisfaction (Finkenauer \& Hazam, 2000). Some level of privacy is healthy for a relationship. However, avoiding certain conversations and not opening up when appropriate breeds decreased satisfaction. The more topics that couples avoid discussing and disclosing about, the less satisfying their relationship tends to be (Caughlin \& Afifi, 2004).Responsiveness is necessary in an intimate relationship because when we self-disclose private information about ourselves we need to feel that our partner cares and is supportive of us. Perceived responsiveness is a measure of validation, care, and understanding that an individual feels that they get from their romantic 
partner (Reis, 2006).

Intimacy is related to a number of indices of well-being. Emotional intimacy was negatively associated with perceived stress, helplessness, and negative pain coping behaviours (Sinclair \& Dowdy, 2005). Emotional intimacy has been found to influence both psychological and physical well-being, and incidence of chronic illnesses (Ornish, 1998; Sinclair \& Dowdy, 2005).

Intimacy is lacking in friendships in which at least one member is shy (Rubin et al., 2006). Since shy individuals are less likely to self-disclose and are low on support, warmth, and responsiveness, this limited intimacy does not breed trust, affection or commitment between partners and can lead to lower relationship satisfaction (Kalliopuska, 2008; Rubin et al., 2006). Within the context of romantic relationships, the association between shyness and intimacy has not yet been investigated.

Sexual satisfaction. Sexual satisfaction can be defines as the thoughts, feelings, personal and socio-cultural attitudes and beliefs, and biological variables combine to be the experience of sexual satisfaction for an individual (Penhollow \& Young, 2008). Sexual satisfaction is subjective. The specifics of one's sexual relationship is not important, it is the way people feel about it that is influential. It is their perception that determines their satisfaction (Miller \& Perlman, 2009). Many studies have shown that intimacy, relationship satisfaction and sexual satisfaction are positively associated (Byers, Demmon, \& Lawrance, 1998; Byers \& Demmons, 1999; Cupach \& Comstock, 1990; Henderson-King \& Veroff, 1994; Sprecher, 2002; Young et al., 1998). Sexual and relationship satisfaction are not separate entities. They tend to be highly correlated with one another, and it is difficult to determine which causes which. Since this association is near impossible to tease apart, it may in fact be bidirectional (Byers, 2005). Those 
who are content with their sexual interactions tend to be content with their relationship. These two types of satisfaction build on each other, both causing the other to increase or decrease accordingly (Burleson et al., 2007). This association has been found in marriage and long-term relationships (Cupach \& Comstock, 1990; Henderson-King \& Veroff, 1994).

Much of the studies on sexual satisfaction are conducted on long-term or married samples. However, Sprecher (2002) found that sexual satisfaction and relationship satisfaction were significantly correlated for premarital couples as well. The participants were mainly university students, with a mean age of 20 years. She also found that sexual satisfaction was positively correlated with love, relationship stability and commitment, for both males and females. In addition, Byers and colleagues (1998) found that sexual satisfaction and relationship satisfaction were correlated in an undergraduate sample.

Sexual satisfaction is an important factor in maintaining and improving psychological well-being, self-esteem, health, and happiness (Davison, Bell, LaChina, Holden, \& Davis, 2009; Taleporos, Dip, \& McCabe, 2002). It is a key part of most intimate relationships (Penhollow \& Young, 2008). Penhollow and Young (2008) found that sexual satisfaction was negatively correlated with body image in a sample of undergraduate students. This association was stronger for females than males. Davison and colleagues (2009) found that sexual satisfaction was related to women's well-being; however this study did not investigate this relation for men. Sexual satisfaction was found to be a strong predictor of self-esteem (positive relation) and depression (negative relation) in a sample of disabled and able-bodied participants (Taleporos et al., 2002).

The link between shyness and sexual satisfaction has been vastly overlooked. Some research has reported that those who are shy are more inhibited with members of the opposite sex and less likely to be involved in a sexual relationship (Asendorpf \& Wilpers, 1998; Henderson \& 
Shyness and Romantic Relationships 25

Zimbardo, 2008). However, there are no studies to date that examine the relation between shyness and sexual satisfaction. Sexual satisfaction is a strong component of romantic relationship quality and is positively associated with relationship quality in emerging adults and adults (Penhollow \& Young, 2008). Therefore, sexual satisfaction may be negatively related to shyness and particularly to the well-being of shy individuals.

Adult attachment. Adult attachment is an important determinant of relationship quality in close relationships (Beinstein Miller \& Hoicowitz, 2004; Noftle \& Shaver, 2005). Attachment is defined as the bond between an individual and an attachment figure (Bowlby, 1969). Adult attachment is an extension of the original attachment theory by Bowlby and Ainsworth (Bowlby, 1973; Hazan \& Shaver, 1987; Noftle \& Shaver, 2006). Its purpose is to explain individual differences in feelings, thoughts, and behaviour for adults or adolescents within close relationships (Hazen \& Shaver, 1987; Nofle \& Shaver, 2006).

In early childhood the attachment figure is generally the primary caregiver (Bowlby, 1969, 1973). Early attachment to primary caregivers has lasting effects on later close relationships, because it creates a belief system about being cared for and expected behaviour (Bowlby, 1973). Experiences in later close relationships can influence the belief system to a certain degree, but are generally relatively stable (Bowlby, 1973).

Attachment researchers use the term internal working models to describe the cognitiveaffective representations that people form of the bond they have with their attachment figure and the expectations within these relationships. These representations are mainly of the intimacy, interdependence, and trust within these attachment bonds (Bowlby, 1973). These internal working models have two dimensions: attachment anxiety and attachment avoidance (Bartholomew \& Horowitz, 1991). The dimension, anxiety, refers to anxiety about rejection, 
abandonment, and not being loved, and relational self-worth and acceptance. The dimension, avoidance, refers to avoidance of intimacy and dependence, and the extent of comfort that they have with intimacy and interdependence with others (Bartholomew \& Horowitz, 1991; Collins et al., 2006). Both dimensions of attachment (anxiety and avoidance) have negative effects on close relationships, including romantic relationships. Specifically, high anxiety is negatively correlated with relationship quality, and high avoidance is negatively correlated with relationship length and quality for both friendships and romantic relationships (Beinstein Miller \& Hoicowitz, 2004).

Lower levels of both anxiety and avoidance are optimal for having satisfying and close relationships (Beinstein Miller \& Hoicowitz, 2004). This is referred to as secure attachment. Secure attachment is associated with high self-esteem, high sociability, and high relationship satisfaction. Thus, they feel positively about themselves and others (Bartholomew \& Horowitz, 1991; Noftle \& Shaver, 2005; Pietromonaco \& Barrett, 1997).

Higher scores on one or both of the attachment dimensions are considered evidence of insecure attachment (Bartholomew \& Horowitz, 1991; Collins et al., 2006). Insecure attachment is correlated with less adaptive/beneficial responses to both positive and negative events within the context of a close relationship. As well, it is related to aversive emotional and cognitive patterns which increase the risk of negative relationship outcomes (Collins et al., 2006).

High anxious attachment (and low avoidant attachment) is characterized with a need for high levels of intimacy and acceptance from their partners and more negative beliefs about themselves and their partner, high dependency, and desire for contact with others. It is associated with low trust for a partner, self-blame for a partner's transgressions, and a belief of inadequacy as a partner (Bartholomew \& Horowitz, 1991; Collins et al., 2006; Pietromonaco \& Barrett, 
1997). Those who are high in avoidance (and low on anxiety) tend to be less interested in developing close relationships and instead desire a stronger degree of independence. This attachment style is linked with positive self-views and negative other-views (Bartholomew \& Horowitz, 1991; Pietromonaco \& Barrett, 1997).

Being high on both anxiety and avoidance is associated with lower levels of trust and emotional expression, and negative views of the self and others (Bartholomew \& Horowitz, 1991). Individuals with this attachment pattern tend to desire intimacy, yet they get scared when they begin to get close to someone. They are fearful of intimacy, yet have a high level of dependence. Those who are high on both dimensions of attachment have a combination of the negative characteristics described for both anxious attachment and avoidant attachment. High anxiety and avoidance is potentially the most detrimental of all possible combinations of attachment dimensions (Bartholomew \& Horowitz, 1991).

Attachment styles have been linked to expectations of the social world, relationship satisfaction and length, and functioning within close relationships (Beinstein Miller \& Hoicowitz, 2004; Noftle \& Shaver, 2006; Rubin et al., 2004). Individual differences such as attachment style have been linked to predispose people to have adaptive/maladaptive attributions within close relationships which lead to positive/negative long-term consequences, including, relationship stability and relationship quality (Beinstein Miller \& Hoicowitz, 2004; Collins et al., 2006; Kirkpatrick \& Hazan, 1994; Noftle \& Shaver, 2006).

Secure attachment is associated with greater satisfaction and duration of romantic relationships, when compared to insecure attachment (Beinstein Miller \& Hoicowitz, 2004; Collins et al., 2006; Kirkpatrick \& Hazan, 1994; Pietromonaco \& Barrett, 1997). Specifically, Beinstein Miller and Hoicowitz (2004) found that attachment anxiety limited relationship quality 
Shyness and Romantic Relationships 28

and attachment avoidance limited both length and quality of the relationship. Since secure attachment is low on both the anxiety and avoidance dimensions, these people are at less of a risk for relationship disintegration or poor quality (Beinstein Miller \& Hoicowitz, 2004; Collins et al., 2006.

Attachment models and relationship quality influence well-being and socio-emotional functioning. For instance, insecure attachment is also predictive of internalizing problems and poor well-being in children, adolescents and adults (Collins et al., 2006; Noftle \& Shaver, 2006; Rubin et al., 2004; Wood et al., 2004). Simons and colleagues (2001) found that secure attachment was related to higher self-esteem in children. Rubin and colleagues (2004) reported that secure attachment predicted socio-emotional adjustment in adolescence.

Shyness is associated with the combination of high anxious-attachment and high avoidance-attachment (Bartholomew \& Horowitz, 1991; Duggan \& Brennan, 1994). This high anxiety and high avoidance is precisely the approach/avoid struggle that shy people struggle with (Coplan et al., 2004; Rubin \& Asendorpf, 1993). This suggests that anxiety and fear are the reason for the high social avoidance for these individuals rather than unsociability (Duggan \& Brennan, 1994). Since shyness is higher among those who are both anxiously and avoidantly attached, then these maladaptive forms of attachment may be a significant reason for the reduced relationship satisfaction among shy individuals.

Shyness is associated with insecure attachment. Shyness is also associated with negative well-being outcomes. This suggests that attachment may play a significant role in the influence of shyness on well-being. The link between shyness and poorer psychological well-being may be moderated by the adult attachment style. Thus - positive attachment may attenuate the negative association between shyness and well-being, and more negative attachment may strengthen this 
association.

\section{The Protective Role of Close Relationships for Shy Individuals}

According to Werner (1990), protective factors shield "at risk" individuals from negative outcomes. As described earlier, shy individuals are at increased risk for several negative outcomes, particularly along the internalizing dimension (e.g., Asendorpf et al., 2008; Zimbardo, 1990). However, not all shy people have problems later on. Since relationships throughout development are critical for well-being and adjustment, these positive relationships may act as protective factors for shy individuals.

Relationships that are central to people's lives are very important with respect to wellbeing, health, self-esteem and socio-emotional functioning (Adams \& Blieszner, 1995; Birditt \& Antonucci, 2007; Fiske \& Peterson, 1991; Leck, 2006; Whiffen, 2006). The influence and protective role of positive relationships for shy individuals has been studied with respect to teachers, peers, siblings and parents (Arbeau et al., 2010; Fordham \& Stevenson-Hinde, 1999; Graham, 2009; Hodges et al., 1999). However, the protective role of a positive relationship with a romantic partner has not been studied in conjunction with shyness.

Arbeau and colleagues (2010) recently studied the buffering role of positive teacher-child relationship in the links between shyness and socio-emotional adjustment in childhood. They found evidence to suggest that closer teacher-child relationships attenuated associations between shyness and loneliness, peer problems and internalizing difficulties. This suggests that there is a potential buffering role of the teacher-child relationship on the adjustment of shy children. Graham (2009) studied the buffering effect of sibling relationship quality among preschoolers in relations between shyness and negative socio-emotional functioning. It was found that warm and supportive sibling relationships may buffer shy children against negative socio-emotional 
outcomes, such as loneliness and anxious-fearful behaviour (Graham, 2009).

The influence of quality of relationships shy children's well-being has also been studied within the context of close friendships. For shy and withdrawn children, having a best friend may help protect them from potential negative outcomes, including internalizing and externalizing problems, victimization, and similar problems in the future (Hodges et al., 1999). Fordham and Stevenson (1999) found that friendship quality may act as a protective factor for shy ten year olds, buffering them against detrimental correlates of shyness, specifically internalizing problems, perception of lack of social support, anxiety and low global self-worth.

Theoretically, it would make sense that given the importance and centrality of romantic relationships during emerging adulthood, that the quality of these relationships would have a similar influence on the individual's well-being and socio-emotional functioning as other central relationships. However, the protective role of romantic relationship quality on the relation between shyness and well-being has not been examined.

\section{The Current Study}

The current thesis research examined the associations between shyness, romantic relationship quality, and psychological well-being in emerging adults. In addition, the potential moderating effect of relationship quality on the associations between shyness and indices of subjective well-being was explored. Finally, potential gender differences in these associations were examined. Two separate studies were conducted to address these aims.

There were several reasons to explore these associations in emerging adulthood. For one, this is the developmental time period in which individuals are developing and forming their selfidentity (Arnett, 2000; Nelson et al., 2008). Second, during this time, romantic relationships are a significant part of the developmental process of becoming an adult and are important for 
Shyness and Romantic Relationships 31

adjustment and well-being (Arnett, 2000; Lanz \& Tagliabue, 2007; Rogers, 1951; Seiffge-

Krenke, 2003; Tanner, 2006). They are becoming more serious and central to individuals' lives

(Reis et al., 1993). Third, the study of shyness during this developmental stage is quite limited.

Therefore, this study adds to the literature in this new area of study. Finally, the potential

buffering effect of romantic relationship quality on the detrimental effects of shyness may be

significant in this transition period since romantic relationships are one of the most significant -if

not the most significant - relationship for emerging adults (Berscheid et al., 1989). Overall,

shyness may negatively impact the successful development in this transitional stage and romantic relationships may influence this.

A very limited amount of previous research has been done on the association between shyness and romantic relationship quality. There have been no studies to date investigating the relation between shyness and intimacy in emerging adults. Moreover, previous literature about the sexuality of shy adults has only assessed the quantity of sexual encounters and number of partners. The quality of their sexual relationships has been left unstudied.

Romantic relationship quality was assessed with an overall measure of quality, as well as with assessments of specific components, including adult attachment, sexual satisfaction and intimacy. The study examined romantic relationship quality from both a general and specific to the current relationship view. General relationship quality is the relationship quality that a person would tend to have with any partner - and was assessed via a measure of adult attachment. Specific relationship qualities that pertain to a current partner were assessed with measures of romantic relationship satisfaction, intimacy and sexual satisfaction.

The present study also examined the moderating role of romantic relationship quality on the link between shyness and psychological well-being. Romantic relationship quality has been 
studied in conjunction with both, shyness and well-being separately (Adams \& Blieszner, 1995; Asendorpf \& Wilpers, 1998; Birditt \& Antonucci, 2007; Fiske \& Peterson, 1991; Nelson et al., 2008; Whiffen, 2006). However, it has yet to be studied in conjunction with both shyness and well-being simultaneously. In the current research, well-being was assessed with measures of global self-esteem and general psychological well-being scales.

The following specific hypotheses were put forward:

(1) Individuals who were currently in a romantic relationship would report lower levels of shyness when compared to those who were not in a romantic relationship; (2) Among individuals that did have a current romantic partner, shyness would be negatively associated with general romantic relationship quality, intimacy, and sexual satisfaction; (3) Among individuals that did have a current romantic partner, shyness would be positively associated with both an anxious and avoidant adult attachment style; (4) Overall - shyness would be negatively related to psychological well-being and self-esteem; (5) Romantic relationship quality would moderate the association between shyness and well-being (i.e., psychological well-being, self-esteem). Specifically, as romantic relationship quality increases, the negative relation between shyness and well-being would become attenuated; (6) Shy males would be less likely to be in a romantic relationship than shy females; (7) Negative relations between shyness and indices of both relationship quality and well-being would be stronger for males than females; and finally; (8) Although highly speculative in nature, it was also postulated that the moderating role of romantic relationship quality in the associations between shyness and indices of well-being would be stronger for females than for males (i.e., 3-way interaction effect). 
Shyness and Romantic Relationships 33

Method - Study 1

\section{Participants}

A total of 1159 participants ( $n=795$ females; $n=364$ males) were recruited using Mass Testing in undergraduate psychology classes at Carleton University. Participants ranged in age from 18-26 years $(M=19.56, S D=1.88)$. Approximately half of the participants were presently in a romantic relationship (50.1\%). Of the participants in a romantic relationship, the majority were in their relationship for more than one year $(60.3 \%)$, with $15.0 \%$ being in a relationship for 6-12 months, $11.8 \%$ in a relationship for 3-6 months, and $12.9 \%$ in a relationship for less than three months.

\section{Measures}

Shyness. Shyness was assessed using the Revised Cheek and Buss Shyness Scale (RCBSS, Cheek \& Buss, 1981 -see Appendix F). This self-report measure contains 13 items assessing the personality trait of shyness. Participants were instructed to decide to what extent each item is characteristic of their feelings and behaviour using a five-point Likert scale was used ( 1 = very uncharacteristic or untrue, strongly disagree, $2=$ uncharacteristic, $3=$ neutral, $4=$ characteristic, and $5=$ very characteristic or true, strongly agree). Higher scores are indicative of higher levels of shyness. The RCBS has been previously shown to display strong internal consistency $(\alpha=.90)$ and good test-retest reliability for a 45-day period ( $r=.88$; Hopko, Stowell, Jones, Armento, \& Cheek, 2005). The internal consistency for the $R C R S$ for the present sample was $\alpha=.75$.

Relationship Status. A two item measure was used to assess relationship status (see Appendix D). One item is used to determine if participants are currently in a relationship, “Are you currently involved in a romantic relationship?" There were two answer options: $1=$ Yes and $2=$ No. If they answered 'yes' to the previous question, participants were asked, "How long have 
you been in this current romantic relationship?" There are four answer options: $1=$ less than 3 months, $2=3-6$ months, $3=6-12$ months, and $4=$ over one year.

Relationship Quality. Three items from the Social Provisions Questionnaire (Carbery \& Buhrmeister, 1998 -see Appendix D) were used to assess the perceived quality of various social relationships and can be applied to romantic partners, friends, and parents. A 5-point Likert scale is used (ranging from $1=$ Little to none, to $5=$ The most). An example of one of the items used is, "How satisfied are you with your relationship with this person?" Nelson et al. (2008) reported high internal consistency this measure $(\alpha=.98)$. The internal consistency for these three items in the current sample was $\alpha=.92$.

$$
\text { Results - Study } 1
$$

\section{Preliminary Analyses}

The purpose of Study 1 was to investigate the association between shyness and relationship status, the effect of shyness and gender on relationship status, and the association between shyness and romantic relationship quality.

The data were screened for outliers using scatterplots. Cases that were more than three standard deviations above or below the mean were considered to be outliers and initially removed. However, there was not a significant change in the results with the removal of these outliers. Therefore, these cases are included in the following results. The data were also screened for missing values. Missing data in the form of unanswered items were prorated if less than $25 \%$ of the items for a subscale were missing for a measure. The data were tested for general analyses of variance assumptions (independence, linearity, homogeneity of variance, normality). Homogeneity of variance was not violated according to Levene's Statistic, $F(3,1109)=.194, p<$ .900 for shyness by gender and relationship status. The romantic relationship quality scale score 
Shyness and Romantic Relationships 35

from the Social Provisions Questionnaire displayed significant levels of both skewness (-1.04) and kurtosis (1.396; i.e., more than two times the standard error of both skewness and kurtosis; Tabachnick \& Fidell, 2007). Therefore, a reverse square root transformation was performed for this measure - which appropriately corrected these issues and allowed this variable to meet the assumption of normality. The term was then reversed so higher scores indicated higher levels of romantic relationship quality. See Table 1 for descriptive statistics for all Study 1 variables.

Correlations among all study variables are presented in Table 2. Among the results, relationship quality was significantly and negatively related to shyness. However, neither age nor relationship length were significantly related to shyness. Relationship length was significantly correlated with relationship quality. As such, relationship length was controlled for it in subsequent analyses.

A chi-squared test of independence was performed to evaluate the relation between gender and relationship status. The relation between these variables was significant, $\square^{2}(1, N=$ $1159)=14.87, p<.001$; indicating that females were more likely to be in a romantic relationship when compared to males. An independent-samples $t$ test was conducted to evaluate whether relationship status differed by age. The test was significant, $t(1159)=-5.31, p<.001$, indicating participants in relationships $(M=19.85, S D=2.05)$ were significantly older than those who were not in a relationship $(M=19.27, S D=1.64)$.

Shyness \& Relationship Status

A $2 \times 2$ ANOVA was conducted to evaluate gender and relationship status differences in participants' shyness. Results indicated a significant main effect of relationship status $(F(1,1109)$ $=23.196, p<.001$, partial $\left.\eta^{2}=.020\right)$, but no significant main effect of gender $(F(1,1109)=.006$, $p=.938$, partial $\eta^{2}=.000$ ). Participants who were currently in a relationship rated themselves as 
Table 1

Descriptive statistics for Study 1 variables

\begin{tabular}{ccccccc}
\hline Variable & $\mathrm{N}$ & Range & Mean & SD & Skewness & Kurtosis \\
\hline Shyness & 1113 & $1-4.23$ & 2.92 & .392 & -.077 & .768 \\
$\begin{array}{c}\text { Romantic } \\
\text { Relationship } \\
\text { Quality }\end{array}$ & 584 & $1-5.00$ & 4.18 & .805 & -1.04 & 1.396 \\
$\begin{array}{c}\text { Romantic } \\
\text { Relationship } \\
\text { Quality }\end{array}$ & 584 & $1-2.24$ & 1.32 & .285 & .606 & -.124 \\
\hline
\end{tabular}

Note. Shyness = Revised Cheek and Buss Shyness Scale, 5-point scale; Romantic Relationship Quality = items from the Social Provisions Questionnaire, 3-point scale; Romantic Relationship Quality = items from the Social Provisions Questionnaire (after Reverse Square Root Transformation), 3-point scale. 


\section{Table 2}

Correlations between Study 1 variables

\begin{tabular}{cccc}
\hline & Age & $\begin{array}{c}\text { Relationship } \\
\text { Length }\end{array}$ & $\begin{array}{c}\text { Relationship } \\
\text { Quality }\end{array}$ \\
\hline Shyness & .032 & -.069 & $-.149^{* * *}$ \\
Age & - & $.174^{* * *}$ & -.014 \\
$\begin{array}{c}\text { Relationship } \\
\text { Length }\end{array}$ & - & - & $.257^{* * *}$ \\
\hline
\end{tabular}

${ }^{*} \mathrm{p}<.05,{ }^{* *} \mathrm{p}<.01,{ }^{* * *} \mathrm{p}<.001$ 
Shyness and Romantic Relationships 38

significantly less shy $(M=2.87, S D=.380)$ than participants not in a relationship $(M=2.98, S D$ $=.396)$. The interaction between gender and relationship status was not significant, $F(1,1109)=$ $.783, p=.377$, partial $\eta^{2}=.001$.

\section{Shyness \& Relationship Quality}

To determine if shyness and gender interacted in the prediction of romantic relationship quality (among individuals currently in a relationship), a hierarchical regression analysis was conducted with shyness and gender as independent variables, and relationship quality as the dependent variable. Since relationship length was significantly correlated with relationship quality, this variable was controlled for in the regression analysis. Thus, relationship length was entered in Step 1, standardized "main effect" variables (shyness and gender) were entered into Step 2, and at Step 3, the interaction term (shyness x gender) was entered. Results are presented in Table 3. Shyness was significantly and negatively related to relationship quality. Neither gender nor any of the interaction terms were significant predictors of relationship quality.

Study 1 was conducted to replicate and confirm findings from previous research that indicated that shyness was negatively associated with being in a romantic relationship, and for those in a relationship; poor romantic relationship quality. The findings of this study are consistent with that of previous research. Shyness scores were significantly lower in those who were in a relationship compared to those who were not. Shyness negatively impacts romantic relationship quality. These findings provided sufficient evidence to further explore the negative impact of shyness on romantic relationship quality. Therefore a second study was conducted to evaluate the negative associations between shyness, several facets of romantic relationship quality, and additional measures including well-being and self-esteem. 
Shyness and Romantic Relationships 39

Table 3

Hierarchical regression predicting romantic relationship quality from shyness and gender

\begin{tabular}{|c|c|c|c|c|c|c|}
\hline Enter & $\mathrm{R}^{2}$ & $\mathrm{~F}$ & $\Delta \mathrm{R}^{2}$ & $\Delta \mathrm{F}$ & SE & $\beta$ \\
\hline Step 1 & .061 & $36.70 * * *$ & & & & \\
\hline Relationship Length & & & & & .011 & $.248 * * *$ \\
\hline Step 2 & .077 & $15.53 * * *$ & .015 & $4.70^{* *}$ & & \\
\hline Shyness & & & & & .011 & $-.124 * *$ \\
\hline Gender & & & & & .011 & -.014 \\
\hline Step 3 & .077 & $11.66^{* * * *}$ & .000 & .145 & & \\
\hline Shyness x Gender & & & & & .012 & -.016 \\
\hline
\end{tabular}

${ }^{*} \mathrm{p}<.05,{ }^{* *} \mathrm{p}<.01,{ }^{* * *} \mathrm{p}<.001$ 


\section{Method - Study 2}

\section{Participants}

Participants for Study 2 were $n=400$ undergraduate students ( 336 females, 62 males, 2 participants not specifying gender) ranging from 18 to 26 years of age $(M=19.62, S D=1.950)$. Students were recruited through the SONA System at Carleton University. The requirements for participation in this study were that individuals must be (1) currently in a romantic relationship; and (2) between the ages of 18 to 26 years. The majority of the participants were Caucasion (74.7\%), with the remaining participants self-identifying as Asian or Pacific Islander (7.8\%), Biracial (3.8\%), African (2.8\%), Hispanic/Latino (1.5\%), Native American (1.0\%), and Other (7. 3\%). Participants ranged from being in their first year (58.9\%) to in their fifth year $(1.3 \%)$ of their undergraduate degree $(M=1.61, S D=.900)$. Participants were predominantly in exclusive relationships with a boyfriend/girlfriend, engaged, or committed to marry $(97.7 \%)$, with the remaining participants being married (2.3\%). Romantic relationship length for participants ranged from less than two weeks $(1.5 \%)$ to more than five years $(4.0 \%)$ with the majority of relationships being more than one year, but less than five (57.1\%), and the remaining $30.8 \%$ were together for more than two months, but less than one year. The majority of the participants were living in the same city as their romantic partner (73.7\%), $14.8 \%$ of which were living with their romantic partners.

\section{Procedure}

The study was conducted online using the SONA System. Initially participants read the Informed Consent Form (see Appendix A). Participants who consented then began the online questionnaire. They complete the following measures (see Appendices E-L). Once they had completed the questionnaire, the participants were given a Debriefing to read (see Appendix B). 


\section{Measures}

Relationship Status. A three item measure was used to assess relationship status (Nelson et al., 2008 -see Appendix E). For the first item, "Which best describes your current dating status". There were four answer options: $\mathrm{A}=$ Married, $\mathrm{B}=$ Have a boy/girlfriend (in an exclusive relationship, Engaged, or Committed to marry, $\mathrm{C}=$ casual/occasional dating and $\mathrm{D}=$ Not dating at all. If participants answer $\mathrm{C}$ or $\mathrm{D}$, then they were not able to continue to in the study. Those who answered A or B continued. The second item, "How long have you been in this current romantic relationship?" had seven options for response: $1=$ less than 2 weeks, $6=$ more than 5 years. The third item, which was not derived from the demographics used by Nelson and colleagues (2008), "What is your living arrangement?" had three response options, $A=$ living with romantic partner, $\mathrm{B}=$ live in same city as romantic partner, $\mathrm{C}=$ do not live in same city as romantic partner.

Shyness. As in Study 1, the Revised Cheek and Buss Shyness Scale (RCBSS, Cheek \& Buss, 1981 - see Appendix F) was used to measure shyness. The internal consistency of this measure was $\alpha=.91$ in the current sample.

Romantic Relationship Satisfaction. The Index of Marital Satisfaction (IMS; Cheung \& Hudson, 1982 - see Appendix G) was used to measure overall perceived romantic relationship quality and satisfaction in a current romantic relationship. Although this measure was originally designed for use with married couples, it has been revised and more recently used with unmarried couples in committed romantic relationships (Cheung \& Hudson, 1982). For the present study one item was changed slightly to ensure that they are most appropriate for the emerging adult sample. "I feel that I should never have married my partner" was changed to, "I feel that I should never have started a relationship with my partner". The IMS contains 25 items 
(e.g., "My partner is affectionate enough", "My partner treats me badly", and "I feel that I cannot rely on my partner") assessed on a five-point Likert scale ( $1=$ Rarely or none of the time, $2=\mathrm{A}$ little of the time, $3=$ Sometimes, $4=$ A good part of the time, $5=$ Most or all of the time), with some responses reverse-coded. The reliability of the IMS has been previously demonstrated to be strong, with a Cronbach's $\alpha$ of 0.96 (Touliatos, Perlmutter, \& Straus, 2001). For the IMS, internal consistency was found to be $\alpha=.95$ in the current sample. The $I M S$ total score was reverse coded so that a higher score indicated greater relationship satisfaction.

Adult Attachment. The Experiences in Close Relationships -Revised Questionnaire (ECR$R$; Fraley et al., 2000 -see Appendix $\mathrm{H}$ ) was used to measure adult romantic attachment. The ECR-R is a self-report measure with two 18 item subscales. The anxiety subscale assesses fear of abandonment or rejection (e.g., "I'm afraid that I will lose my partner's love"). The avoidant subscale assesses discomfort with closeness and discomfort in depending on others (e.g., "I find it difficult to allow myself to depend on romantic partners"). This measure uses a 7-point Likert scale $(1=$ strongly agree and $7=$ strongly disagree $)$. Participants were instructed to decide how strongly they agree or disagree with each item. High scores on both subscales indicate high levels of anxiety or avoidant attachment, respectively. However, for the present study, the $E C R-R$ was reverse coded. Therefore, higher scores indicate more positive attachment style, keeping it in line with the other measures of relationship quality. Both subscales and the total ECR-R scale scores range from 1-7, for the present study. The internal consistency of the $E C R-R$ was previously reported as $\alpha=.91$ (Fraley, 2005) and in the current study was $\alpha=.93$.

Intimacy. The Emotional Intimacy Scale (EIS; Sinclair \& Dowdy, 2005 - see Appendix I) was used to assess intimacy in participants' current romantic relationships. It is a five-item scale that measures the perception of closeness, understanding, and caring within a close relationship, 
Shyness and Romantic Relationships 43

with a higher score indicating greater intimacy. Example items are "This person completely accepts me as I am" and "My thoughts and feelings are understood and affirmed by this person". The internal consistency has been found to be strong $(\alpha=.88)$ and the test-retest reliability for a six-week period was found to be high $(r=.85$; Sinclair \& Dowdy, 2005). In the present study, the internal reliability of the $E I S$ was strong $(\alpha=.88)$.

Sexual Satisfaction. The Sexual Satisfaction Scale (SSS; Young et al., 1998 - see Appendix J) was used to assess sexual satisfaction within each participant's current romantic relationship. A minor change was made to the wording of this scale (changing the word 'spouse' to 'partner') to make this scale more suitable for this age group. This ten item measure uses a five-point Likert scale $(1=$ Strongly Disagree, $2=$ Disagree, $3=$ Undecided, $4=$ Agree , and $5=$ Strongly Agree). Sample items include, "After sex I feel relaxed and fulfilled", "I have very good communication with my spouse about sex", and "I am sexually attracted to my partner". Higher scores reflect higher sexual satisfaction. The internal consistency of the SSS was previously reported as $\alpha=.93$ (Young et al., 1998) and in the present sample was $\alpha=.91$.

Global Self-Esteem. The Rosenberg Self-Esteem Scale (Rosenberg, 1965 - see Appendix K) was used to assess global self-esteem. This measure has ten items assessed on a four-point Likert scale $(0=$ Strongly Agree, $1=$ Agree, $2=$ Disagree, and $3=$ Strongly Disagree $)$. Participants were instructed to decide to what extent they agree with each item, with higher scores indicated higher global self-esteem. Example items are "On the whole, I am satisfied with myself" and "I am able to do things as well as most other people". The internal consistency of this measure has been previous reported as $\alpha=.88$ (Rosenberg, 1965). Internal consistency for this measure was also strong $(\alpha=.90)$ in the current sample.

Psychological well-being. Goldberg's (1972) General Health Questionnaire (GHQ) was 
used to measure psychological well-being (see Appendix L). The 12-item scale (Cronbach's alpha $=.86$, Goldberg, 1972) asked about participants' mental health over the past few weeks. Example items are "During the past few weeks, have you been feeling reasonably happy, all things considered?" and "During the past few weeks, have you lost much sleep over worry?" The items were responded to using 4-point Likert scales $(1=$ more so than usual to $4=$ much less than usual and, $1=$ not at all to $4=$ much more than usual). For the present study, $G H Q$ scores were reverse coded such that higher scores indicated better mental health. Internal reliability was $\alpha=.72$ in the current sample.

\section{Results - Study 2}

\section{Preliminary Analyses}

The goal of Study 2 was to investigate the associations between shyness, romantic relationship quality, attachment, and psychological well-being in an emerging adult sample.

The data were first screened for outliers. Extreme scores that were more than three standard deviations above or below the mean were identified and initially removed. However, the removal of these outliers did not significantly change the results of subsequent statistical analyses. Therefore, these cases were included in the results to follow. The data were also screened for missing values. Missing data in the form of unanswered questions was again prorated as needed (if less than $25 \%$ missing data from a subscale measure).

The assumptions of hierarchical regression were tested (e.g., normality, independence, homodasticity, and linearity). To check the assumptions of homoscedasticity and independence, separate scatterplots were examined with each variable on case number. Case number did not appear to influence scores, therefore homoscedasticity was not violated. Bivariate scatterplots of all possible combinations of variables were examined to test for linearity. To test the assumption 
Shyness and Romantic Relationships 45 of normality, the statistical test for normality, skewness and kurtosis values, and histograms and boxplots for each of the variables were examined.

The Emotional Intimacy Scale (EIS), the Sexual Satisfaction Scale (SSS), and the General Health Questionnaire $(G H Q)$ were transformed because of a lack of normality. Reflect and square root transformations were done to both SSS and EIS because they were both negatively skewed. A square root transformation was done to the GHQ. Higher scores on each of these indicate higher intimacy, higher sexual satisfaction, and higher psychological well-being, respectively. Descriptive statistics for all of the measures are displayed in Table 4.

$T$-tests were conducted to evaluate whether males or females differed in terms of shyness, relationship quality, attachment, psychological well-being or self-esteem. The only significant gender difference was for self-esteem, $t(395)=-2.11, p<.05$, indicating that males $(M=3.59$, $S D=.918)$ reported higher levels of self-esteem than females $(M=3.32, S D=.839)$.

Correlations among variables. The inter-correlations of the demographic variables and study measures are depicted in Table 5. Unexpectedly, results indicated that participant age was significantly and positively (albeit modestly) related to shyness. However, since the inclusion of Age as a covariate did not alter any of the results from subsequent analyses, results are presented without controlling for age.

In Table 6 the correlations among the main study variables are presented. As expected, all measures of relationship-specific romantic relationship quality (i.e., relationship satisfaction, intimacy, sexual satisfaction) were highly inter-correlated. Accordingly, these measures were standardized and aggregated together to form a composite score of romantic relationship quality (for participants' current romantic relationship). A second composite measure of general relationship quality (i.e., attachment) was created by aggregating the two subscales of the 
Table 4

Descriptive Statistics for all Study 2 variables

\begin{tabular}{ccccccc}
\hline Variable & $\mathrm{N}$ & Range & Mean & SD & Skewness & Kurtosis \\
\hline Shyness & 400 & $1.00-4.54$ & 2.47 & .760 & .323 & -.302 \\
$\begin{array}{c}\text { Romantic } \\
\text { Relationship } \\
\text { Satisfaction }\end{array}$ & 400 & $1.20-5.00$ & 3.86 & .843 & -.688 & -.693 \\
$\begin{array}{c}\text { Emotional } \\
\text { Intimacy }\end{array}$ & 400 & $1.00-5.00$ & 4.36 & .643 & -1.500 & 4.030 \\
$\begin{array}{c}\text { Emotional } \\
\text { Intimacy }\end{array}$ & 400 & $1.00-2.24$ & 1.26 & .235 & .848 & .927 \\
$\begin{array}{c}\text { Sexual } \\
\text { Satisfaction }\end{array}$ & 366 & $1.70-5.00$ & 4.20 & .676 & -1.081 & 1.150 \\
$\begin{array}{c}\text { Sexual } \\
\text { Satisfaction }\end{array}$ & 366 & $1.00-2.07$ & 1.32 & .241 & .656 & .002 \\
$\begin{array}{c}\text { Anxious } \\
\text { Attachment }\end{array}$ & 400 & $1.00-5.94$ & 2.85 & 1.024 & .509 & -.194 \\
$\begin{array}{c}\text { Avoidant } \\
\text { Attachment }\end{array}$ & 400 & $1.06-5.39$ & 3.00 & 1.055 & .438 & -.929 \\
$\begin{array}{c}\text { Overall } \\
\text { Attachment }\end{array}$ & 400 & $1.11-5.08$ & 2.92 & .860 & .145 & -.778 \\
$\begin{array}{c}\text { Self-Esteem } \\
\text { Well-Being } \\
\text { Well-Being }\end{array}$ & 399 & $.50-5.00$ & 3.37 & .858 & .136 & -.328 \\
\hline & 398 & $.33-3.22$ & 1.46 & .477 & .038 & 1.581 \\
\hline & & & & & & \\
\hline
\end{tabular}


Note. Shyness = Revised Cheek and Buss Shyness scale, 5-point scale; Romantic Relationship Satisfaction = Index of Marital Satisfaction, 5-point scale; Emotional Intimacy = Emotional Intimacy Scale, 5-point scale; Emotional Intimacy = Emotional Intimacy Scale (after Reverse Square Root Transformation), 5-point scale; Sexual Satisfaction = Sexual Satisfaction Scale, 5 point scale; Anxious Attachment = dimension of Experiences in Close Relationships-Revised Questionnaire, 7-point scale; Avoidant Attachment = dimension of Experiences in Close Relationships-Revised, 7-point scale; Overall Attachment = Experiences in Close RelationshipsRevised Questionnaire, 7-point scale; Self-Esteem = Rosenberg Self-Esteem Scale, 6-point scale; Psychological Well-Being = General Health Questionnaire, 5-point scale; Psychological WellBeing = General Health Questionnaire (after Square Root Transformation), 5-point scale. 
Table 5

Correlations between demographic variables and study variables

\begin{tabular}{cccc}
\hline & Age & $\begin{array}{c}\text { Year of } \\
\text { University }\end{array}$ & $\begin{array}{c}\text { Dating } \\
\text { Length }\end{array}$ \\
\hline Shyness & $.108^{*}$ & .096 & .063 \\
$\begin{array}{c}\text { Romantic Relationship } \\
\text { Satisfaction }\end{array}$ & -.082 & -.060 & .029 \\
$\begin{array}{c}\text { Emotional Intimacy } \\
\text { Sexual Satisfaction }\end{array}$ & -.001 & -.053 & $.165^{* *}$ \\
$\begin{array}{c}\text { Anxious Attachment } \\
\text { Avoidant }\end{array}$ & -.062 & -.035 & .035 \\
Attachment & -.054 & -.052 & .182 \\
$\begin{array}{c}\text { Overall Attachment } \\
\text { Self-Esteem }\end{array}$ & -.064 & -.031 & .180 \\
Psychological \\
Well-Being
\end{tabular}

${ }^{*} \mathrm{p}<.05, * * \mathrm{p}<.01$ 
Shyness and Romantic Relationships 49

Table 6

Correlations between Study 2 variables

\begin{tabular}{|c|c|c|c|c|c|c|c|}
\hline & 2 & 3 & 4 & 5 & 6 & 7 & 8 \\
\hline 1. Shyness & $-.149 * *$ & $-.155^{* *}$ & $-.202 * * *$ & $-.385 * * *$ & $-.169 * * *$ & $-.371 * * *$ & $-.167^{* *}$ \\
\hline $\begin{array}{l}\text { 2. Romantic } \\
\text { Relationship } \\
\text { Satisfaction }\end{array}$ & - & $.466 * * *$ & $.393 * * *$ & $.371 * * *$ & $.792 * * *$ & $.458 * * *$ & $.290 * * *$ \\
\hline $\begin{array}{l}\text { 3.Emotional } \\
\text { Intimacy }\end{array}$ & - & - & $.470 * * *$ & $.426 * * *$ & $.413 * * *$ & $.255 * * *$ & $.205^{* * *}$ \\
\hline $\begin{array}{l}\text { 4. Sexual } \\
\text { Satisfaction }\end{array}$ & - & - & - & $.308 * *$ & $.258 * * *$ & $.231 * * *$ & $.140 * *$ \\
\hline $\begin{array}{l}\text { 5. Anxious } \\
\text { Attachment }\end{array}$ & - & - & - & - & $.370^{* * *}$ & $.405 * * *$ & $.260 * * *$ \\
\hline $\begin{array}{l}\text { 6. Avoidant } \\
\text { Attachment }\end{array}$ & - & - & - & - & - & $.468 * *$ & $.214 * *$ \\
\hline $\begin{array}{l}\text { 7. Self- } \\
\text { Esteem }\end{array}$ & - & - & - & - & - & - & $.385 * * *$ \\
\hline 8. Well-Being & & & & & & & \\
\hline
\end{tabular}

$* \mathrm{p}<.05, * * \mathrm{p}<.01, * * \mathrm{p}<.001$ 
attachment measure (with higher scores indicating more "secure" attachment). Although dating length was significantly associated with emotional intimacy, it was not significantly correlated with the composite measure of romantic relationship quality. Therefore, this measure was not controlled for in subsequent analyses.

Correlations between shyness, the newly created composite relationship quality measures, and the two outcome measures are displayed in Table 7. Shyness was expected to be negatively associated with all indices of romantic relationship quality (e.g., romantic relationship satisfaction, emotional intimacy, and sexual satisfaction) for individuals who are currently in a romantic relationship. Shyness was found to be significantly and negatively associated with the composite measure of romantic relationship quality. Shyness was also negatively correlated with romantic relationship satisfaction, emotional intimacy and sexual satisfaction.

Shyness was predicted to be negatively correlated with secure attachment, and positively correlated with both anxious and avoidant adult attachment style. Since these measures were reversed in order to have high scores indicate better, healthier 'secure' attachment styles, shyness was negatively correlated with each of them, which indicates that it is positively correlated with negative attachment and both, anxious and avoidant attachment. Shyness was associated with more maladaptive (i.e., secure) attachment styles.

It was also hypothesized that shyness would be negatively correlated with both selfesteem and psychological well-being. Results from the correlation analyses indicate that shyness was significantly and negatively associated with both self-esteem and psychological well-being (see Table 6).

Shyness, Gender, and Relationship Quality/Attachment

To determine if shyness and gender interacted in the prediction of the indices of romantic 
Table 7

Correlations between Study 2 summary variables

\begin{tabular}{lccc}
\hline & Shyness & Self-Esteem & $\begin{array}{c}\text { Psychological } \\
\text { Well-Being }\end{array}$ \\
\hline $\begin{array}{c}\text { Romantic Relationship } \\
\text { Quality }\end{array}$ & $-.209^{* * *}$ & $.390^{* * *}$ & $.258^{* * *}$ \\
Secure Attachment & $-.334^{* * *}$ & $.528^{* * *}$ & $.284^{* * *}$ \\
\hline
\end{tabular}

${ }^{*} \mathrm{p}<.05,{ }^{* *} \mathrm{p}<.01, * * \mathrm{p}<.001$ 
relationship quality (i.e., relationship satisfaction, intimacy, and sexual satisfaction) or attachment, a series of separate hierarchical regression analyses were conducted with shyness and gender as independent variables, and the constructs relationship quality as the dependent variable. Standardized "main effect" variables (shyness and gender) were entered into Step 1, and at Step 2, the interaction term (shyness $\mathrm{x}$ gender) was entered.

Results are presented in Table 8. Shyness was a significant (negative relation) predictor of all constructs of romantic relationship quality and attachment. Neither gender nor the interaction between shyness and gender were significant predictors of the relationship constructs.

\section{Shyness, Relationship Quality/Attachment, and Outcome Variables}

A series of hierarchical regression analyses was computed to determine if romantic relationship quality and/or attachment moderated relations between shyness and psychological well-being and self-esteem. Specifically, it was predicted that the negative relation between shyness and well-being (both, psychological well-being and self-esteem) would be stronger at lower levels of romantic relationship quality and weaker at high levels of romantic relationship quality. Additionally, it was predicted that the negative relation between shyness and well-being (both, psychological well-being and self-esteem) would be stronger at lower levels of attachment (more negative attachment) and weaker at high levels of attachment (more positive attachment). Four separate hierarchical regression analyses were conducted, two predicting self-esteem (from shyness and romantic relationship quality or attachment) and two predicting psychological wellbeing (from shyness and romantic relationship quality or attachment).

For each equation, standardized "main effect" variables were entered at Step 1 (shyness, gender, and romantic relationship quality or attachment). Two-way interaction terms (e.g., shyness $\mathrm{x}$ gender, gender $\mathrm{x}$ romantic relationship quality or gender $\mathrm{x}$ attachment, shyness $\mathrm{x}$ 
Table 8

Hierarchical regression predicting romantic relationship quality and attachment outcome variables from shyness and gender

\begin{tabular}{|c|c|c|c|c|c|}
\hline $\begin{array}{l}\text { Outcome } \\
\text { Variable }\end{array}$ & $\begin{array}{l}\text { Predictor } \\
\text { Variable }\end{array}$ & $\Delta \mathrm{R}^{2}$ & $\Delta \mathrm{F}$ & SE & $\beta$ \\
\hline $\begin{array}{l}\text { Relationship } \\
\text { Satisfaction }\end{array}$ & $\begin{array}{r}\text { Step } 1 \\
\text { Shyness } \\
\text { Gender }\end{array}$ & .024 & 4.82 & $\begin{array}{l}.050 \\
.050\end{array}$ & $\begin{array}{l}-.146 * * \\
-.051\end{array}$ \\
\hline & $\begin{array}{l}\text { Step } 2 \\
\quad \text { Shyness x Gender }\end{array}$ & .001 & .388 & .050 & -.031 \\
\hline $\begin{array}{l}\text { Emotional } \\
\text { Intimacy }\end{array}$ & $\begin{array}{r}\text { Step } 1 \\
\text { Shyness } \\
\text { Gender }\end{array}$ & .032 & $7.53 * *$ & $\begin{array}{l}.050 \\
.049\end{array}$ & $\begin{array}{l}-.177 * * * \\
-.076\end{array}$ \\
\hline & $\begin{array}{l}\text { Step } 2 \\
\quad \text { Shyness x Gender }\end{array}$ & .004 & 1.76 & .051 & -.066 \\
\hline $\begin{array}{c}\text { Sexual } \\
\text { Satisfaction }\end{array}$ & $\begin{array}{r}\text { Step } 1 \\
\text { Shyness } \\
\text { Gender }\end{array}$ & .046 & $8.57 * * *$ & $\begin{array}{l}.051 \\
.052\end{array}$ & $\begin{array}{l}-.212 * * * \\
-.020\end{array}$ \\
\hline & $\begin{array}{l}\text { Step } 2 \\
\quad \text { Shyness x Gender }\end{array}$ & .001 & .335 & .053 & .030 \\
\hline Attachment & $\begin{array}{l}\text { Step } 1 \\
\text { Shyness } \\
\text { Gender }\end{array}$ & .108 & $23.83 * * *$ & $\begin{array}{l}.048 \\
.047\end{array}$ & $\begin{array}{c}-.329 * * * \\
.011\end{array}$ \\
\hline & $\begin{array}{l}\text { Step } 2 \\
\quad \text { Shyness x Gender }\end{array}$ & .001 & .383 & .049 & -.030 \\
\hline
\end{tabular}

$* \mathrm{p}<.05, * * \mathrm{p}<.01, * * \mathrm{p}<.001$ 
romantic relationship quality or shyness $\mathrm{x}$ attachment) were entered at Step 2, followed by the three-way interaction term (e.g., shyness $\mathrm{x}$ gender $\mathrm{x}$ romantic relationship quality or shyness $\mathrm{x}$ gender $\mathrm{x}$ attachment) in Step 3 . The $N$ s for each computation vary slightly due to missing data.

Shyness, relationship quality, and well-being. Results for the prediction of psychological well-being from shyness and relationship quality are displayed in Table 9. Both shyness (negative relation) and romantic relationship quality (positive relation) were significant predictors of psychological well-being. None of the two-way interaction terms (i.e., romantic relationship quality $\mathrm{x}$ shyness, gender $\mathrm{x}$ shyness, and romantic relationship quality $\mathrm{x}$ gender) were significant. However, the $F$-change at Step 3 was significant; indicating that the three-way interaction term of romantic relationship quality by shyness and gender was a significant predictor of psychological well-being. To decompose this interaction, the regression equations were computed separately by gender.

Results for males are shown in Table 10. No significant main effects or interaction were observed. That is, neither relationship quality, shyness, nor their interaction, were significant predictors of psychological well-being for males.

Results for females are displayed in Table 11. Results also indicated no significant main effects for shyness or relationship quality for females. However, there was a significant two-way interaction between romantic relationship quality and shyness. This significant interaction was explored using simple slopes analyses (Preacher, Curran, \& Bauer, 2006). Results can be seen in Figure 1. Among women with lower levels of romantic relationship quality, shyness was negatively related to well-being $(\beta=-.135, p=.074)$. However, at higher levels of romantic relationships quality, the negative association between shyness and well-being was attenuated, 
Shyness and Romantic Relationships 55

Table 9

Hierarchical regression predicting well-being from shyness, gender, and romantic relationship quality

\begin{tabular}{|c|c|c|c|c|c|c|}
\hline Enter & $\mathrm{R}^{2}$ & $\mathrm{~F}$ & $\Delta \mathrm{R}^{2}$ & $\Delta \mathrm{F}$ & $\mathrm{SE}$ & $\beta$ \\
\hline Step 1 & .080 & $10.30 * * *$ & & & & \\
\hline Shyness & & & & & .010 & $-.118 *$ \\
\hline Gender & & & & & .010 & .067 \\
\hline $\begin{array}{c}\text { Romantic Relationship } \\
\text { Quality }\end{array}$ & & & & & .004 & $.232 * * *$ \\
\hline Step 2 & .087 & 5.57 & .007 & .847 & & \\
\hline Shyness x Gender & & & & & .010 & -.082 \\
\hline $\begin{array}{c}\text { Shyness x Relationship } \\
\text { Quality }\end{array}$ & & & & & .004 & .013 \\
\hline Gender x Relationship Qua & & & & & .004 & -.011 \\
\hline Step 3 & .100 & $5.54 * * *$ & .013 & $5.03 *$ & & \\
\hline $\begin{array}{c}\text { Shy x Gender x } \\
\text { Relationship Quality }\end{array}$ & & & & & .004 & $.117^{*}$ \\
\hline
\end{tabular}

${ }^{*} \mathrm{p}<.05, * * \mathrm{p}<.01, * * * \mathrm{p}<.001$ 
Shyness and Romantic Relationships 56

Table 10

Hierarchical regression predicting well-being from shyness and romantic relationship quality for males only

\begin{tabular}{|c|c|c|c|c|c|c|}
\hline Enter & $\mathrm{R}^{2}$ & $\mathrm{~F}$ & $\Delta \mathrm{R}^{2}$ & $\Delta \mathrm{F}$ & SE & $\beta$ \\
\hline Step 1 & .059 & 1.64 & & & & \\
\hline Shyness & & & & & .170 & -.089 \\
\hline $\begin{array}{c}\text { Romantic Relationship } \\
\text { Quality }\end{array}$ & & & & & .058 & .211 \\
\hline Step 2 & .106 & 2.01 & .046 & 2.64 & & \\
\hline $\begin{array}{c}\text { Shyness x Relationship } \\
\text { Quality }\end{array}$ & & & & & .056 & .215 \\
\hline
\end{tabular}

$* \mathrm{p}<.05, * * \mathrm{p}<.01, * * * \mathrm{p}<.001$ 
Shyness and Romantic Relationships 57

Table 11

Hierarchical regression predicting well-being from shyness and romantic relationship quality for females only

\begin{tabular}{|c|c|c|c|c|c|c|}
\hline Enter & $\mathrm{R}^{2}$ & $\mathrm{~F}$ & $\Delta \mathrm{R}^{2}$ & $\Delta \mathrm{F}$ & $\mathrm{SE}$ & $\beta$ \\
\hline Step 1 & .001 & .076 & & & & \\
\hline Shyness & & & & & .071 & -.023 \\
\hline $\begin{array}{l}\text { Romantic Relationship } \\
\text { Quality }\end{array}$ & & & & & .031 & -.005 \\
\hline Step 2 & .040 & $4.16^{* *}$ & .039 & $12.34 * *$ & & \\
\hline $\begin{array}{c}\text { Shyness x Relationship } \\
\text { Quality }\end{array}$ & & & & & .029 & $.199 * *$ \\
\hline
\end{tabular}

$* \mathrm{p}<.05, * * \mathrm{p}<.01, * * * \mathrm{p}<.001$ 
Figure 1

Simple slopes illustrating the interaction between romantic relationship quality and shyness in the prediction of well-being for females

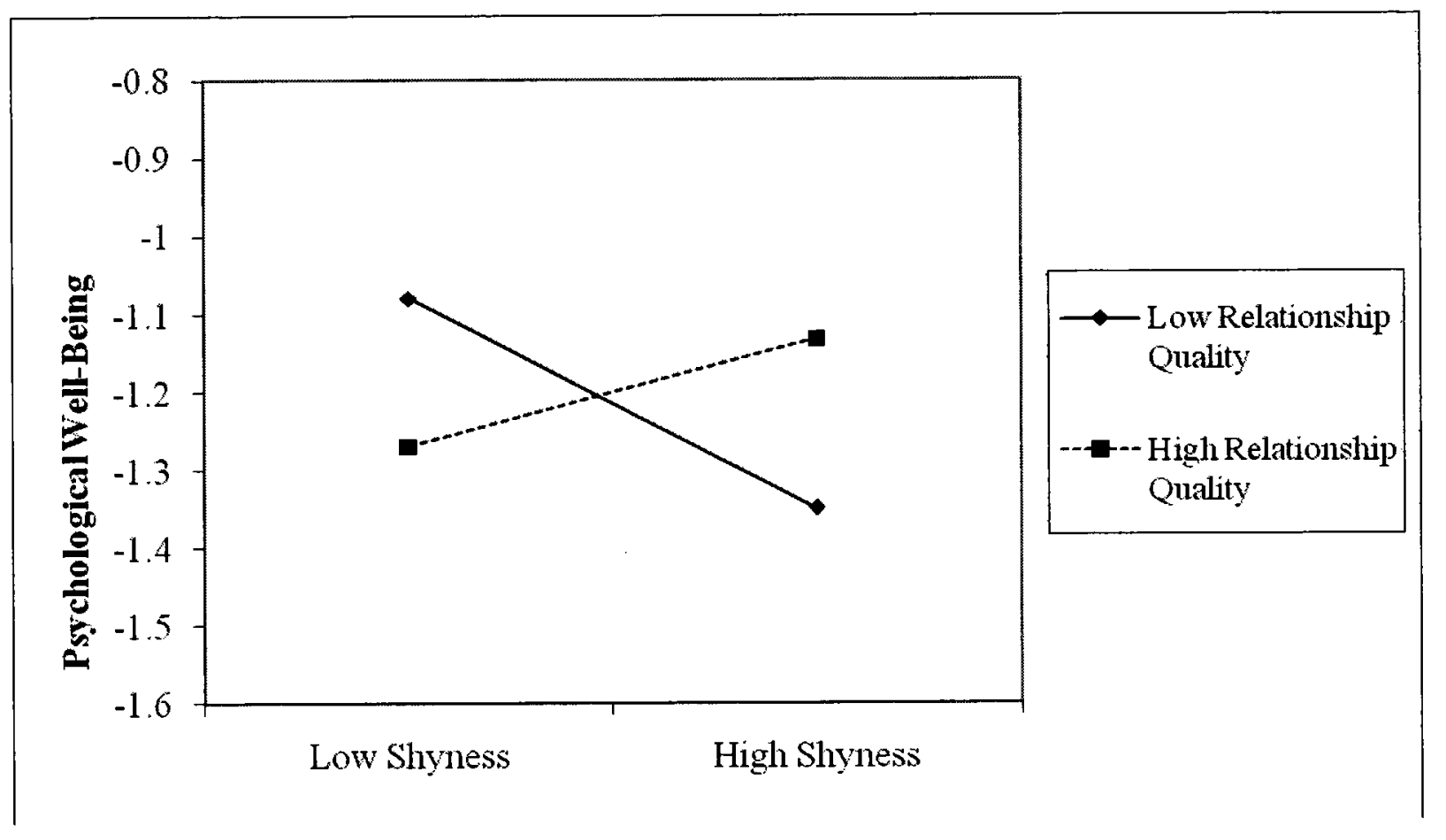


eventually becoming positive in sign $(\beta=.069, p=.364)$. This result suggests that having a more positive romantic relationship "buffers" shy woman against problems with well-being. However, it must also be noted that the smaller sample size for males may have been a contributing factor to the lack of a significant two-way interaction between shyness and romantic relationship quality.

Shyness, relationship quality, and self-esteem. Results of the hierarchical regression examining the predictive ability of romantic relationship quality on self-esteem are presented in Table 12. Significant main effects were found for shyness (negative relation), gender (males > females) and romantic relationship quality (positive relation). There was also a significant relationship quality $\mathrm{x}$ gender interaction, and the relationship quality $\mathrm{x}$ shyness interaction approached significance. There were no other significant two-way or three-way interactions.

The significant interaction term of romantic relationship quality by gender was explored by splitting the data by gender to analyse the effect of romantic relationship quality on selfesteem. Results indicated that relationship quality significantly predicted self-esteem for both males, $\beta=.594, t(52)=5.53, p<.001$, and females, $\beta=.286, t(303)=5.51, p<.001$, but the strength of the association between these variables was stronger among males.

The marginally significant interaction term of romantic relationship quality by shyness was explored using simple slopes analyses. Results can be seen in Figure 2. Among participants with lower romantic relationship quality, shyness was negatively associated with self-esteem ( $\beta=$ $-.214, p<.001)$. However, relationship quality did not appear to buffer the negative association between shyness and self-esteem, with the strength of this negative relation actually increasing slightly with higher levels of relationships quality $(\beta=-.27, p<.001)$. However, it should be noted that this unexpected results was only marginally statistically significant. 
Table 12

Hierarchical regression predicting self-esteem from shyness, gender, and romantic relationship quality

\begin{tabular}{|c|c|c|c|c|c|c|}
\hline Enter & $\mathrm{R}^{2}$ & $\mathrm{~F}$ & $\Delta \mathrm{R}^{2}$ & $\Delta \mathrm{F}$ & $\mathrm{SE}$ & $\beta$ \\
\hline Step 1 & .252 & $40.18 * * *$ & & & & \\
\hline Shyness & & & & & .040 & $-.288 * * *$ \\
\hline Gender & & & & & .039 & $.122 *$ \\
\hline $\begin{array}{c}\text { Romantic Relationship } \\
\text { Quality }\end{array}$ & & & & & .017 & $.345^{* *}$ \\
\hline Step 2 & .269 & $21.72 * * *$ & .017 & $2.68 *$ & & \\
\hline Shyness x Gender & & & & & .040 & .042 \\
\hline $\begin{array}{c}\text { Shyness x Relationship } \\
\text { Quality }\end{array}$ & & & & & $\begin{array}{l}.016 \\
.015\end{array}$ & $-.079+$ \\
\hline Gender x Relationship Qua & & & & & & \\
\hline Step 3 & .269 & $18.56 * * *$ & .000 & .001 & & \\
\hline $\begin{array}{c}\text { Shy x Gender x } \\
\text { Relationship Quality }\end{array}$ & & & & & .014 & -.002 \\
\hline
\end{tabular}

${ }^{*} \mathrm{p}<.05, * * \mathrm{p}<.01, * * * \mathrm{p}<.001,+\mathrm{p}<.1$ 
Figure 2

Simple slopes illustrating the interaction between romantic relationship quality and shyness in the prediction of self-esteem

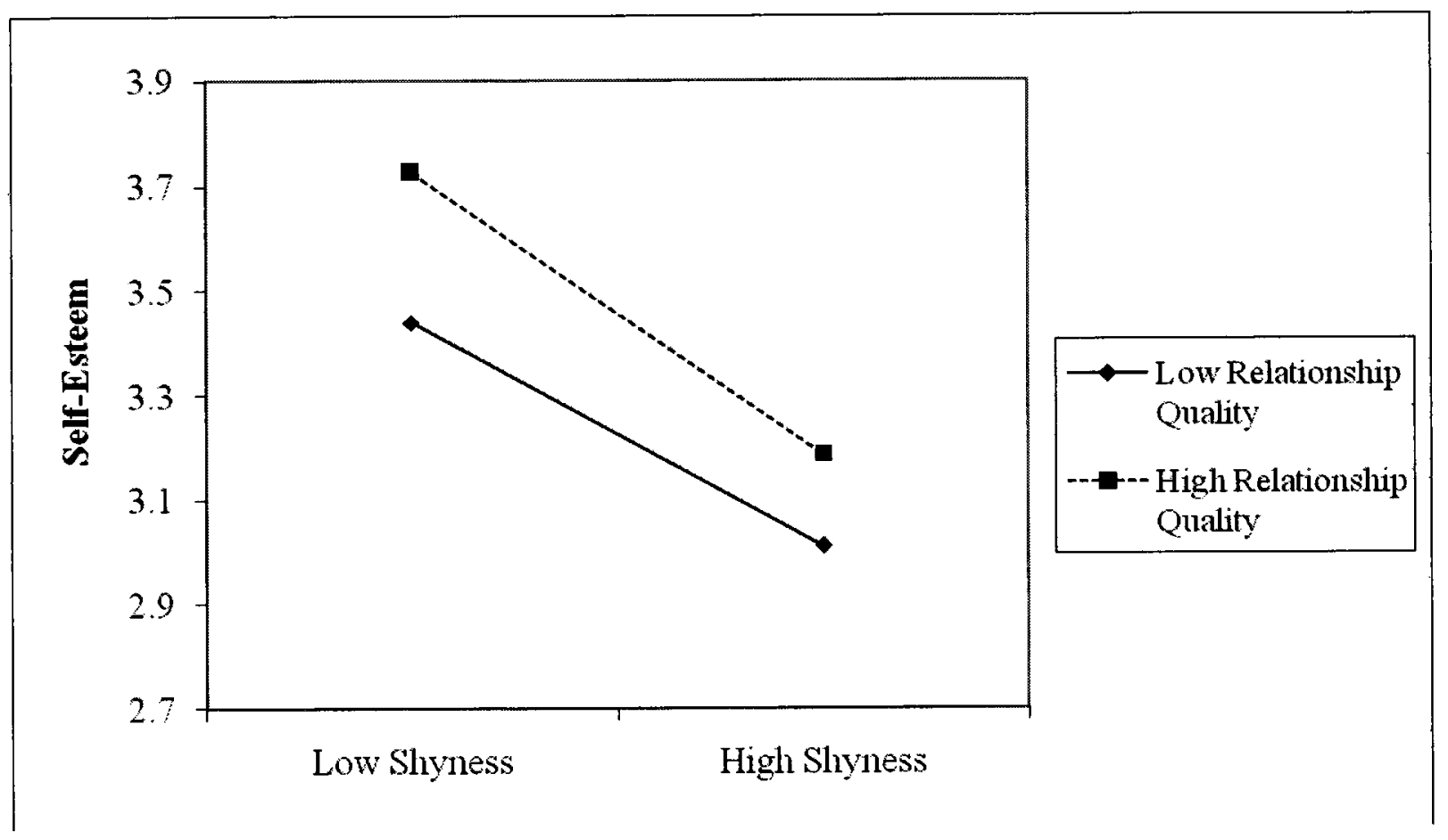


Shyness and Romantic Relationships 62

Table 13

Hierarchical regression predicting well-being from shyness, gender, and attachment

\begin{tabular}{|c|c|c|c|c|c|c|}
\hline Enter & $\mathrm{R}^{2}$ & $\mathrm{~F}$ & $\Delta \mathrm{R}^{2}$ & $\Delta \mathrm{F}$ & SE & $\beta$ \\
\hline Step 1 & .088 & $12.52 * * *$ & & & & \\
\hline Shyness & & & & & .010 & -.088 \\
\hline Gender & & & & & .009 & .070 \\
\hline Attachment & & & & & .010 & $.248 * * *$ \\
\hline Step 2 & .108 & $7.78^{* * *}$ & .020 & $2.86^{*}$ & & \\
\hline Shyness x Gender & & & & & .010 & $-.118 *$ \\
\hline Shyness x Attachment & & & & & .009 & $.093+$ \\
\hline Gender x Attachment & & & & & .009 & -.023 \\
\hline Step 3 & .110 & $6.80 * * *$ & .002 & .93 & & \\
\hline Shy $\mathrm{x}$ Gender $\mathrm{x}$ Attachment & & & & & .008 & .049 \\
\hline
\end{tabular}

$* \mathrm{p}<.05, * * \mathrm{p}<.01, * * * \mathrm{p}<.001,+\mathrm{p}<.1$ 
Shyness and Romantic Relationships 63

Shyness, attachment, and well-being. Results for the prediction of psychological well-being from shyness and attachment are displayed in Table 13. Attachment was a significant predictor of psychological well-being. Neither shyness nor gender were significant predictors of well-being. There was a significant shyness $\mathrm{x}$ gender interaction, and the attachment $\mathrm{x}$ shyness interaction approached significance. There were no other significant two-way or three-way interactions.

The significant interaction term of shyness by gender was explored by splitting the data file by gender to analyse the effect of shyness on well-being. Results indicated that shyness significantly and negatively predicted psychological well-being for males, $\beta=-.333, t(58)=$ $2.71, p<.001$, but not for females, $\beta=.043, t(328)=-.77, p=.442$.

The marginally significant interaction term of attachment by shyness was explored using simple slopes analyses. Results are displayed in Figure 3. Among participants with lower (i.e., less secure) attachment beliefs, shyness was negatively related to psychological well-being ( $\beta=$ $.037 p<.01$ ). However, at higher (i.e., more secure) levels of attachment, there was no significant association between shyness and well-being $(\beta=-.001, p=.940)$. Thus, it appeared that the negative relation between shyness and well-being was attenuated among individuals with more secure attachment beliefs about romantic attachment relationships.

Shyness, attachment, and self-esteem. Results for the hierarchical regression examining the predictive ability of attachment and shyness on self-esteem are presented in Table 14. Significant main effects of gender (males $>$ females), attachment (positive relation) and shyness (negative relation) were found. There were significant attachment $\mathrm{x}$ shyness and attachment $\mathrm{x}$ gender interactions. No other two-way or three-way interactions were present.

The significant interaction term of attachment by gender was explored by splitting the data file by gender to examine the effect of attachment on self-esteem. Results indicate that 
Figure 3

Simple slopes illustrating the interaction between attachment and shyness in the prediction of well-being

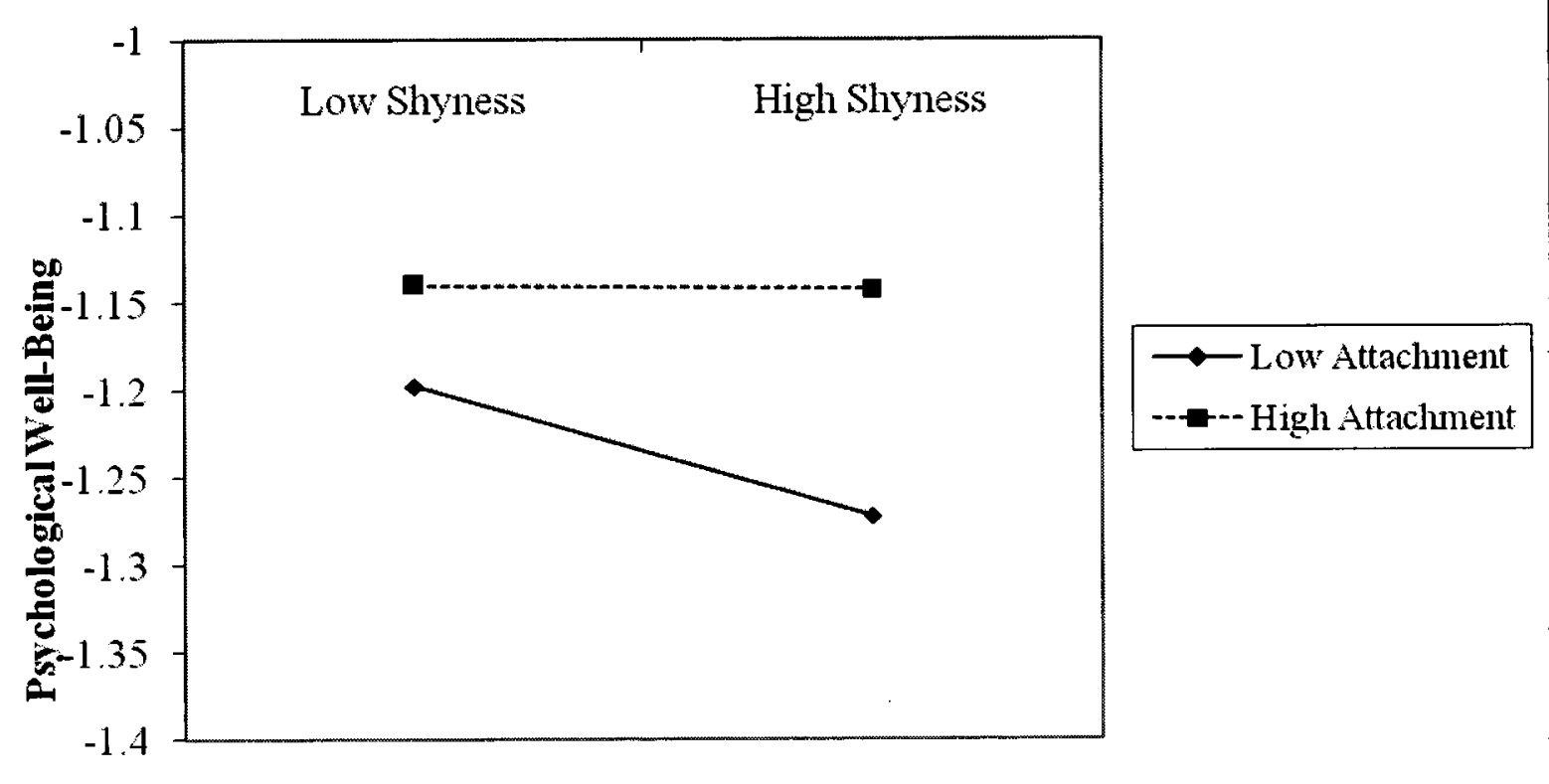


Table 14

Hierarchical regression predicting self-esteem from shyness, gender, and attachment

\begin{tabular}{|c|c|c|c|c|c|c|}
\hline Enter & $\mathrm{R}^{2}$ & $\mathrm{~F}$ & $\Delta \mathrm{R}^{2}$ & $\Delta \mathrm{F}$ & SE & $\beta$ \\
\hline Step 1 & .330 & $64.07 * * *$ & & & & \\
\hline Shyness & & & & & .037 & $-.217 * * *$ \\
\hline Gender & & & & & .035 & $.107^{*}$ \\
\hline Attachment & & & & & .038 & $.453^{* * *}$ \\
\hline Step 2 & .350 & $34.78 * * *$ & .020 & $3.97 * *$ & & \\
\hline Shyness x Gender & & & & & .038 & .050 \\
\hline Shyness x Attachment & & & & & .034 & $-.103 *$ \\
\hline Gender x Attachment & & & & & .033 & $.100^{*}$ \\
\hline Step 3 & .350 & $29.72 * * *$ & .000 & .04 & & \\
\hline Shy $x$ Gender $x$ Attachment & & & & & .030 & .008 \\
\hline
\end{tabular}

${ }^{*} \mathrm{p}<.05, * * \mathrm{p}<.01, * * * \mathrm{p}<.001$ 
Shyness and Romantic Relationships 66

attachment significantly and positively predicted self-esteem for males, $\beta=.710, t(59)=7.83, p$ $<.001$, and females, $\beta=.395, t(330)=7.98, p<.001$, but the strength of the association between variables was stronger among males.

The significant attachment by shyness interaction effect was again explored using simple slopes analyses. Results are displayed in Figure 4. Among participants with lower levels of attachment, shyness was negatively related with self-esteem $(\beta=-.097, p=.061)$. However, contrary to expectations, attachment did not appear to buffer the negative association between shyness and self-esteem, with the strength of this negative relation actually increasing with higher levels of secure attachment $(\beta=-.267, p<.001)$. 
Figure 4

Simple slopes illustrating the interaction between attachment and shyness in the prediction of self-esteem

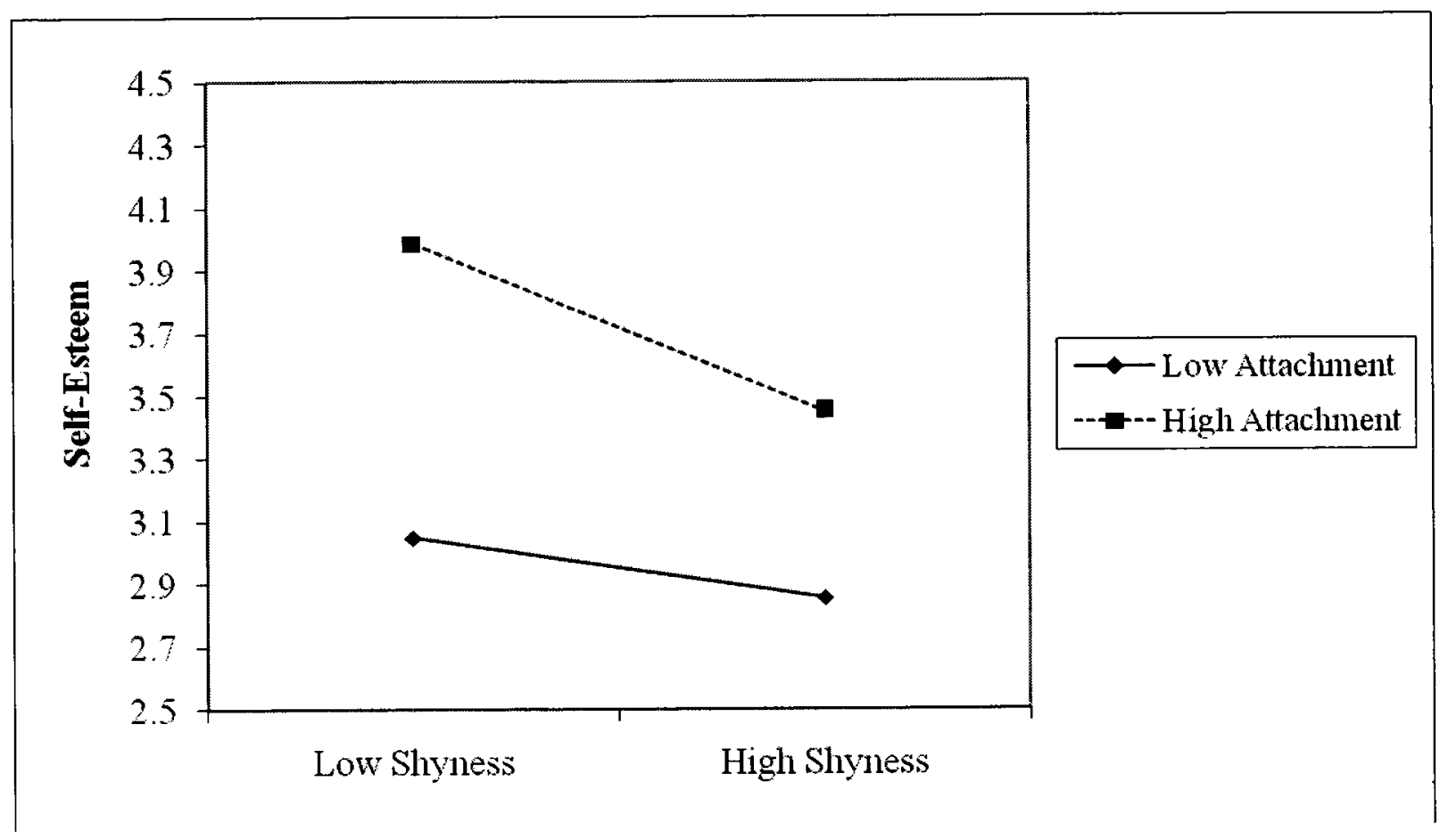




\section{Discussion}

The purpose of this research was to investigate associations between shyness, romantic relationship quality, and psychological well-being among a sample of emerging adults. In particular, these studies sought to examine the potential moderating effect of romantic relationship quality in the associations between shyness and indices of general well-being. It was hypothesized that emerging adults who were in romantic relationships would report lower levels of shyness when compared to those who were not in a relationship. Moreover, among those currently in a relationship, shyness was expected to be negatively associated with indices of romantic relationship quality and attachment-related attitudes about relationships. As well, although shyness was predicted to be negatively related to aspects of well-being, romantic relationship quality was expected to moderate these relations and act as a protective (i.e., buffering) factors among shy emerging adults.

Overall, the majority of these hypotheses were supported in the present study. Young adults currently in a romantic relationship reported being less shy than those who were still "single". Among those in relationships, shyness was negatively related to reported intimacy, sexual satisfaction, and general relationship quality. As well, shyness was negatively related to more global and positive attachment-related attitudes towards relationships. Shyness was found to be negatively associated with self-esteem and psychological well-being. Some moderating effects were found. Both romantic relationship quality and attachment appeared to "buffer" the negative relation between shyness and psychological well-being. However, results regarding the prediction of self-esteem were not as predicted. For example, contrary to expectations, at higher levels of relationship quality and among adults with more positive attachment-related attitudes, shyness appeared to be more strongly negatively associated with self-esteem. Finally, some 
gender effects were also noted. For example, shyness among males was more strongly negatively associated with indices of well-being than for females. The implications of each of these results are now discussed in more detail.

\section{Shyness and Relationship Status}

Results from Study 1 indicated that shyness differed significantly among those in and not in a romantic relationship. Overall, those who were currently in a romantic relationship scored lower on shyness as compared to those not in a relationship. This finding is in line with results from several previous studies. For instance, Leck (2006) found that shyer individuals were less likely to be in a romantic relationship and tended to date less frequently. Additionally, Asendorpf and colleagues (2008) reported that shy emerging adults had about half as many romantic relationships as compared their less-shy counterparts. Finally, shy emerging adults have been previously found to report having fewer peer relationships, being less likely to be 'in love', and being less likely to be in a steady sexual relationship than those who were not shy (Asendorpf \& Wilpers, 1998).

If shy people are less likely to be in a romantic relationship during the important developmental phase of emerging adulthood, this may in turn affect their socio-emotional development and impact them throughout adulthood. Romantic relationships are a significant relationship in emerging adulthood and are a key part of healthy emerging adulthood (Arnett, 2000; Kan \& Cares, 2006; Koydemir \& Demir, 2008). There are several implications of this finding. To begin with, relationships at this time are a great way to explore social interactions, figure out what qualities and characteristics you are looking for in a partner (and what characteristics you are not). Relationships in this stage of development also help people to understand what relationships entail; including both the ups and the downs. All of these points 
Shyness and Romantic Relationships 70 have direct implications on future relationships. Those who do not explore different relationships or experience being in a relationship may not know what qualities and characteristics they desire in a partner, may not fully understand what a healthy relationship entails, or how to communicate effectively in a relationship.

Second, relationships among emerging adults assist them in developing and implementing the appropriate social skills, relationship skills, and patterns that come with being in a serious relationship (Arnett, 2000; Kan \& Cares, 2006; Koydemir \& Demir, 2008; Roisman et al., 2004). Those who do not experience romantic relationships during this time may lag behind in the acquisition of these skills and be delayed in their development as an adult. Shyness may put people at risk for delayed social and relationship learning experiences and potentially keep them from missing these experiences completely. In turn, this may negatively influence the well-being of people who are shy, because they may lack adequate social support, which is essential for positive psychological and physical health (Turner, 1981). Thus, by not learning how to develop strong intimate bonds with others at the stage in life that their peers are, shy individuals may miss out on learning the necessary skills and detrimental interpersonal, psychological, and health outcomes may ensue.

Alternatively, it must also be noted that the lack of involvement in romantic relationships in emerging adulthood may not negatively impact all shy people. For instance, positive and close relationships with peers and parents may provide adequate opportunity for shy people who do not date or who date minimally to explore and figure out what they are looking for in a close relationship and to understand how to have a fulfilling, healthy intimate relationship. The relationships that parents have with each other may provide a model of romantic relationships for their children. Therefore, if the romantic relationship of parents appears to be fulfilling and 
healthy, their offspring may learn through observation what a healthy relationship is, how partners interact with each other, and what a healthy relationship looks like. On a similar note, those who date minimally may learn vicariously through the romantic relationships of their friends. Friendships are very important relationships in emerging adulthood (Arnett, 2000; Arnett, 2010) and may help shy individuals learn what they would want and what they would not want from a relationship of their own. Thus, although some shy emerging adults may be at a disadvantage in terms of their future relationships because of their lack of dating, the negative outcomes of this discrepancy in dating may not significantly impact their social development or life outcomes later on.

Gender differences. Some gender differences did emerge. For example, females in the present study were more likely than males to be in a romantic relationship and males reported higher self-esteem than females. The finding that males reported higher global self-esteem is consistent with previous research (Kling, Hyde, Showers, \& Buswell, 1999; Twenge \& Campbell, 2001). Within specific domains of self-esteem, self-esteem differences depending on gender (Gentile et al, 2009). For instance, males had higher self-esteem in physical appearance, athletics, personal self, and self-satisfaction; whereas females had higher behavioural conduct and moral-ethical self-esteem.

No other study variables (e.g., shyness, romantic relationship quality, attachment, psychological well-being) differed due to gender. For females, romantic relationship quality buffered the negative relation between shyness and well-being. However, for males there was no significant relation between shyness and romantic relationship quality.

Contrary to predictions, shyness levels among those in and not in a relationship did not differ between males and females. This finding provides further evidence for the narrowing of 
differences in outcomes between males and females, in terms of shyness. The delayed progression through milestones of the early years of adulthood continue to be found for shy individuals; however the gender difference between shy males and females appears to be lessening (Asendorpf et al., 2008). In recent years, the pressures of being assertive and extroverted in order to succeed and adapt within a Western society have been increasingly placed on females, while still continuing to be placed on males. Additionally, the expectations of attaining higher education and working outside the home have become increasingly normal for not only males, but females as well. In the past, when women were expected to be homemakers and stay at home, shy females were suitable partners. However, with women working outside the home more and more, shyness is becoming less and less of a favourable quality in a female partner. Women are now expected to be successful and in western society, success is negatively associated with shyness.

Thus, it can be speculated that shyness is becoming a less desirable quality in females. Since shyness is negatively associated with being assertive and extroverted, it may make succeeding in both, relationships and career more difficult. The negative impact of shyness is increasingly becoming evident for females not only males. This negative view of shyness used to be common only for males; however, this research supports the growing trend that the negative relationship outcomes of shyness are becoming prevalent for females as well. In sum, these findings suggest that for both female and male, being in a relationship is more common for those who are less shy.

Shyness and Aspects of Relationship Quality

Since romantic relationships are important (if not the most important - Berscheid et al., 1989) relationship in emerging adulthood, it is perhaps not surprising that the positive 
associations between all relationship quality indices and both well-being constructs were found.

Across both studies and across multiple indicators, shyness was robustly negatively related to romantic relationship quality. In Study 1 , shyness was negatively related to a general measure of quality in a romantic relationship. In Study 2, shyness was negatively correlated with several indices of romantic relationship quality, including relationship satisfaction, emotional intimacy, and sexual satisfaction. These results support previous research indicating that shyer individuals tend to form relationships characterised as less positive in quality (e.g., Koydemir \& Demir, 2008; Nelson et al., 2008). The current findings also add to the extant literature in several ways. To begin, intimacy within romantic relationships has not been studied in conjunction with shyness. Second, the association between shyness and sexual satisfaction had not been previously investigated. Therefore, this study provides two new findings about shyness - shyness is negatively correlated with intimacy and with sexual satisfaction within an emerging adult romantic relationship.

In Study 1, relationship quality was measured using three items taken from the Social Provisions Questionnaire (Carbery \& Buhmeister, 1998), which is a somewhat basic and "quick" measure. Interestingly, this quick measure provided similar findings to the longer (25-item) Index of Marital Satisfaction (Cheung \& Hudson, 1982) measure used in Study 2. Remarkably, the 3item measure provided precisely the same degree of association between shyness and quality as did the IMS $(r=-.149)$ and very similar findings to the Composite measure of relationship quality $(r=-.209)$. The implications of this negative association found between shyness and romantic relationship quality will be discussed in the following section.

Relationship length was correlated with romantic relationship quality in Study 1. In Study 2, relationship length was only correlated with one construct of relationship quality: emotional 
intimacy. Conceptually this makes sense, since intimacy is strengthened by self-disclosure, understanding, acceptance, and responsiveness, all of which increase over time in a relationship (Laurenceau et al., 2004; Perlman \& Fehr, 1987; Reis, 2007). Therefore, as relationship length increases, the opportunity for intimacy increases as well.

Shyness was not significantly correlated with relationship length. This is of interest because it indicates that despite the fact that those with higher levels of shyness are less likely to form relationships, and when they do they are less satisfying, but not any shorter than those of less shy individuals. Therefore, the decrease in relationship status is not because their relationships are shorter than their less shy peers.

As expected, relationship length was predictive of relationship quality; however, this was no different for participants who were more and less shy. Since intimacy is a significant part of relationship quality (Fletcher et al., 2000; Furman \& Wehner, 1997), it is not unexpected that factors that increase intimacy, such as relationship length, should also increase relationship quality.

In Study 1, there were no gender differences in terms of shyness' influence on romantic relationship quality. Again, in Study 2, there were no gender differences in terms of the influence of shyness on any of the indices of romantic relationship quality or attachment. In other words, against predictions, males with high levels of shyness were no more likely to report lower relationship quality than females with higher levels of shyness.

Sexual satisfaction. The previous study of shyness in terms of sexual relationships has been very limited. In fact, this study is the first to investigate sexual satisfaction in association with shyness. It was perhaps not surprising that shyness was negatively related to sexual satisfaction, since it was negatively related to both intimacy and relationship quality, which are 
highly correlated with sexual satisfaction (Byers, 2005, Renaud, Byers, \& Pan, 1997). This association makes theoretical sense given that the characteristics that define shyness can be construed as being "opposite" to those that characterized sexual satisfaction. For instance, shyness is associated with feeling uncomfortable in novel and social interactions, reduced intimacy, difficulty communicating, reduced self-disclosure, feeling inhibited and nervous when with members of the opposite sex or in dating situations, anxiety, and self-consciousness (Henderson \& Zimbardo, 2008; Pilkonis, 1997b; Rubin et al., 2006). In contrast, sexual satisfaction is associated with expressing one's opinion, assertiveness, intimacy, self-disclosure, and open communication (Byers \& Demmons, 1999; Cupach \& Comstock, 1990; Cupach and Metts, 1991; Haavio-Manila, 1997). Therefore, characteristics of shyness can be conceptualized as being in direct opposition to those that improve sexual satisfaction!

Accordingly, since open communication and intimacy are so important for sexual satisfaction (Byers \& Demmons, 1999; Cupach \& Comstock, 1990; Haavio-Mannila \& Kontula, 1997; Rathus et al, 2007) and shyness is associated with difficulty communicating, especially about personal matters, and decreased responsiveness (Bradshaw, 2006; Koydemir \& Demir, 2008; Rubin et al., 2006; Zimbardo, 1990), shyer individuals would seem more likely to report less sexual satisfaction. Open discussion about preferences and experiences-via self-disclosure and active listening-encourages cooperation between partners and allows them to incorporate what they both find satisfying (Cupach and Metts, 1991). Self-disclosure, which is an essential part of communication, includes revealing likes, dislikes, desires, etc. When self-disclosure is not present, frustration, miscommunication and decreased sexual and relationship satisfaction will be present (Byers, 2005). Open communication about one's private beliefs and preferences, especially sexual preferences promotes sexual and relationship satisfaction (Byers \& Demmons, 
1999; Metts \& Cupach, 1991).

Responsiveness and non-verbal communication are also important for sexual and relationship satisfaction. When self-disclosure is accompanied with active listening and responsiveness, the result is higher satisfaction in the relationship (Byers, 1999). In addition, communication through touch is positively related with sexual and relationship satisfaction in couples (Renaud et al., 1997). Also, public identification, such as holding hands or hugging, strengthens commitment within partnerships (Brehm, 1992). Self-disclosure, responsiveness and overall communication are issues that pose challenges to those who are shy (Bruch, 2001; Croizer, 1995; Henderson \& Zimbardo, 2008; Rubin et al., 2006). They tend to be self-conscious and intimidated, making communication strained or absent (Bradshaw, 2006; Bruch, 2001; Crozier, 2001). Those who are self-conscious will not likely feel comfortable expressing their opinions and preferences. Therefore, it is not surprising that shyness is associated with decreased sexual satisfaction.

Intimacy. The negative relation between shyness and intimacy has been found within the context of children's friendships (Rubin et al., 2006), however, this is the first study to make the link within the context of a romantic relationship. This finding is not surprising, because shyness is associated with lower self-disclosure, warmth, and responsiveness, which are key components of intimacy (Kalliopuska, 2008; Laurenceau et al., 2004; Reis, 2006; Rubin et al., 2006). Therefore, this study provides evidence that this negative association is not only present in children's friendships, but also in older samples (i.e., emerging adults) and in other close relationships.

Similar to sexual satisfaction, the negative association between shyness and intimacy may be due to the fact that the factors that contribute to intimacy (i.e., open communication, self- 
disclosure, responsiveness, warmth, expressiveness) are often the most difficult for shy people to express. For instance, shyness is associated with feeling self-consciousness, inhibited, reticence, decreased use of body language, anxiety in social interactions, poor communication, and perceptions of reduced social skills (Bruch, 2001; Henderson \& Zimbardo, 2008; Miller, 2001; Pilkonis, 1977a; Pilkonis, 1977b). These factors do not bode well for creating intimacy within relationships. Expressions of warmth and affection, sharing of personal information, trust, feeling comfortable with each other, and openness in communication are key components of intimacy (Perlman \& Fehr, 1987; Sternberg, 1987). Since several characteristics of shyness work in stark contrast to improving intimacy, the negative association found between these two concepts seems reasonable.

This reduced intimacy is likely a substantive contributor towards the negative links between shyness and both overall relationship quality as well as sexual satisfaction. Intimacy is a key component in both of these constructs and therefore must play a role in this association. Therefore, one of the implications of this association is the influence it has on the other constructs of relationship quality. People who are shyer are at risk of not only reduced intimacy, but also reduced sexual satisfaction and reduced relationship quality in romantic relationships. A second implication of this is that if shy people have trouble developing intimacy in one of their closest relationships, perhaps their other relationships are not fairing overly well either. Romantic relationships are characterized as being the most expressive of all relationships (Fehr, 1996). Therefore, other relationships (i.e., relationships with friends, coworkers, and parents) may have even lower levels of intimacy than their romantic relationship. If this were the case then this lack of adequate relationships could put shy individuals at risk for a host of negative outcomes, such as poor social support, lower well-being, internalizing problems. 
Shyness and Romantic Relationships 78

Implications. There are many implications of the finding that shyer individuals tend to form less positive romantic relationships. For one, if a romantic relationship (which is often one of the closest and most intimate of relations) has poorer quality, then additional relationships of other types might also have reduced intimacy and quality. Previous research has found that shy emerging adults had lower quality relationships with both romantic partners and parents (Koydemir \& Demir, 2008; Nelson et al., 2008). Additionally, shyness has been linked with reduced quality and intimacy in friendships (Fordham \& Stevenson-Hinde, 1999; Rubin et al., 2006). Therefore, this negative association may be of even greater concern since it may infiltrate all of the close relationships that an individual has.

Another potential consequence of poorer quality relationships for shy individuals is that social support may be reduced. Social support networks are important for everyone's well-being. However, they are of particular importance for shy individuals since they are more at risk for negative health and well-being outcomes (Eisenberg et al., 1995; Henderson \& Zimbardo, 2008; Kalliopuska, 2008; Koydemir \& Demir, 2008). Therefore, the association between shyness and reduced relationship quality may have some serious implications on their social support, and ultimately their well-being. If shy individual do not have intimate relationships with their romantic partners, then they may not be getting adequate social support from them. If they do not have other close relationships that are providing this needed social support, they may be at risk of loneliness and other negative health outcomes that come with poor social support.

Furthermore, lower relationship quality may make shy individuals more apprehensive about getting into future relationships. To begin with, shyness is associated with feeling nervous when interacting with potential dating partners or people of the opposite sex (Henderson \& Zimbardo, 2008). Additionally, during emerging adulthood, people learn about what to expect 
Shyness and Romantic Relationships 79

from relationships and what relationships entail. These relationships likely become models for future relationships. Therefore, for shy individuals, dating is already likely going to be a challenging difficult and potentially stressful experience. However, with the addition of having a poor quality and low intimacy relationship as a model, shy people may be less likely to pursue future relationships. They may expect that these future relationships will also have poor quality and they will feel uncomfortable in them, making relationships seem not very appealing.

They may blame also themselves for the failures of their relationships or lack of relationship quality. In fact, shy individuals tend to self-blame in negative ways for failed social interactions and problems in romantic relationships (Johnson et al., 1995; Wichmann et al., 2004). Indeed, it has long been argued that early intimate relationships set the precedence for future relationships (Bowlby, 1973; Connolly et al., 2000). These initial relationships set expectations and can become the model for future relationships. If during emerging adulthood, shy individuals do not have high quality, comfortable, and intimate close relationships, then this inadequacy may be carried forward into future romantic relationships.

The reduced quality, intimacy and satisfaction of relationship may also cause relationship difficulties in the future since sexual satisfaction and intimacy are key components of happiness in a relationship and are related to relationships staying intact (Fletcher, Simpson, \& Thomas, 2000; Furman \& Wehner, 1997; Hassebrauck \& Fehr, 2002; Penhollow \& Young, 2008; Young Denny, Luquis, \& Young, 1998). For instance, if an individual does not develop the positive patterns of open communication with a partner, this unhealthy and limited communication may be carried forward into future relationships. Alternatively, for shy individuals who do open up and develop intimacy with their partners, this experience of sharing personal information and expressing warm and interest in one another may have a positive effect and carry over into other 
Shyness and Romantic Relationships 80

relationships and future relationships. It may help them to open up and gain all of the benefits that come along with a healthy romantic relationship.

\section{Shyness and Romantic Attachment Style}

The notion that past relationships form the building blocks for future relationships is a cornerstone of attachment theory (e.g., Bowlby, 1973). In the present study, more positive attachment was significantly related to psychological well-being and self-esteem, similar to past research (Bartholomew \& Horowitz, 1991; Simons et al., 2001). These relatively stable bonds that are formed between individuals and their partners are significant predictors of self-esteem, well-being, and socio-emotional functioning (Collins et al., 2006; Noftle \& Shaver, 2006; Rubin et al., 2004; Simons et al., 2001; Wood et al., 2004).

In the present study, shyness was associated with more negative romantic attachment styles. Shyness was related to anxious and avoidant attachment style, but more strongly related to anxious attachment. This is in line with previous research (Bartholomew \& Horowitz, 1991; Duggan \& Brennan, 1994). Being more anxiously and avoidantly attached is correlated with wanting to be intimate with others, while at the same time being afraid of being close to others (Bartholomew \& Horowitz, 1991). Shyness is associated with the approach/avoidance paradigm of wanting to be social and have interpersonal relationships, yet at the same time avoiding these situations because of heightened anxiety about it (Coplan et al., 2004; Rubin \& Asendorpf, 1993).

There are several implications of the association between shyness and poor attachment style. For one, both shyness and insecure attachment are negatively related to being in a relationship (Beinstein Miller \& Hoicowitz, 2004; Leck, 2006; Noftle \& Shaver, 2006). Therefore, those who are shy and are insecurely attached may be even less likely to be in a 
Shyness and Romantic Relationships 81

romantic relationship. These individuals may avoid pursuing and forming relationships because they are anxious about not being loved, being rejected, and avoidant of becoming intimate with another.

In a similar vein, shy and insecurely attached individuals who are in romantic relationships may not be able to sustain their relationships. They may sabotage the relationship because they are scared that if they open up, their partners will not love them and will reject them. Therefore, sabotaging the relationship before this happens may be used as a form of selfpreservation to prevent them from not getting hurt by someone else. Or they may sabotage the relationship inadvertently. Their insecurities, lack of trust, overdependence, and unwillingness to become intimacy with others may prevent their relationships from progressing and lead to the relationship's demise.

Additionally, the lower levels of trust and emotional expression that characterize insecure attachment (high on anxious and avoidant attachment) may be one of the factors that lead to reduced relationship quality. Insecure attachment has been linked to reduced relationship quality and stability (Beinstein Miller \& Hoicowitz, 2004; Collins et al., 2006; Kirkpatrick \& Hazan, 1994; Pietromonaco \& Barrett, 1997). It is difficult to develop and maintain a quality relationship when having a fear of intimacy while at the same time as having a strong need for dependence (Bartholomew \& Horowitz, 1991). Overall, poor attachment styles tend to make it difficult for individuals to pursue, develop, and maintain romantic relationships. Therefore, since shyness is associated with negative attachment styles, those who are shyer may be less likely to form healthy relationships.

Shyness and Well-being

Overall, as predicted, shyness was negatively correlated with both psychological well- 
Shyness and Romantic Relationships 82

being and self-esteem. This finding is in keeping with the results of a growing number previous research indicating associations between shyness and indices of socio-emotional maladaptation (Asendorpf \& Wilpers, 1998; Bruch et al., 1989; Cheek \& Melchior, 1990; Kalliopuska, 2008; Koydemir \& Demir, 2008). This study provides additional support for the fact that these negative correlates of shyness are also evident during emerging adulthood. Thus, the potential negative implications of shyness in childhood and adolescence appear to continue not only through emerging adulthood, but may also persist throughout adulthood.

Continuing to feel poorly about oneself, unhappy, and anxious can take its toll on the body and mind (DeLongis, Folkman, Lazarus, 1988; Last, 1991; Stordal, Bjelland, Dahl, \& Mykletun, 2003). This may ultimately put shyer individuals at greater risk for more serious health issues. DeLongis and colleagues (1988) found that there was a significant relationship between stress and health problems. In addition they found that participants with low self-esteem and unsupportive social relationships were more likely to have physical and mental health problems when dealing with daily hassles than those who were high in social support and selfesteem.

Shy individuals' negative and self-conscious beliefs may be reinforced and repeated, leading them to become more engrained, automatic, and difficult to change (Bandura, 1997). This would suggest that it is important to stop these negative thought patterns and actively improve the self-esteem of shy individuals before this way of thinking become more engrained and therefore more difficult to change. Shy emerging adults may also have never developed adequate coping mechanisms for their shyness and anxiety, allowing their shyness to continue to have a negative impact on their self-concept and well-being. Burgress and colleagues (2006) found that shy/withdrawn children were most likely to use avoidant and non-assertive coping 
strategies when confronted with social stressors. As such, it is important for shy individuals to learn at an early stage how to cope effectively with the anxiety, worry and stress that are associated with shyness. Otherwise it will continue to be a problem later in life. Positive coping methods could be tools for shy individuals to deal with their reduced well-being and at the same time actively improve their well-being.

Shyness was a negative predictor for males, but not for females. This indicates that males who are higher in shyness suffer when it comes to their well-being. This gender difference may be because shyness is still seen as a more negative trait in males than in females. This gender difference is narrowing, however, this provides evident to suggest that it still exists.

There was a significant gender difference in terms of the predictability of romantic relationship quality on self-esteem. Unexpectedly, romantic relationship quality was a stronger predictor for males than for females. However, higher levels of romantic relationship quality did predict higher levels of self-esteem for both genders. This gender difference does not support previous research that suggests that the quality of a romantic relationship is more influential for females' self-esteem than males' (Culp \& Beach, 1998; Maltby \& Day, 2000; Segrin et al., 2003). Romantic relationship quality and attachment were strong predictors of self-esteem for both genders, but stronger predictors for males than females.

A potential explanation for the gender difference seen in the predictability of self-esteem by gender interactions (i.e., romantic relationship quality $\mathrm{x}$ gender, attachment $\mathrm{x}$ gender) may be because males reported higher levels of self-esteem than females. This elevated level of selfesteem may have caused the association to appear stronger; however, it may just be because overall, males reported higher self-esteem. Alternatively, this gender difference may be a result of the unequal male and female sample sizes. 
Shyness and Romantic Relationships 84

\section{Moderating Role of Romantic Relationships}

It was of particular interest in the present research to explore the potential moderating role of romantic relationships in the associations between shyness and indices of well-being. In this regard, the findings were somewhat mixed. Indeed, a strikingly different pattern of results was indicated for the two outcome variables of interest (i.e., well-being and self-esteem). This is particularly difficult to explain given that well-being and self-esteem were positive correlated with each other and displayed a similar (and theoretically consistent) pattern of associations with other study variables.

Well-being. To begin with, in the links between shyness and general well-being, both romantic relationship quality and positive attachment styles appeared to serve a protective role. That is, the findings suggested that higher quality romantic relationships and more positive attachment beliefs attenuated the negative association between shyness and well-being. This buffering effect of romantic relationship quality was expected. This provides support for the importance of romantic relationships on well-being, especially for those who are at risk for negative well-being outcomes. This finding adds to the growing body of research suggesting that positive and close relationships can attenuate the link between shyness and reduced well-being (Arbeau et al., 2010; Fordham \& Stevenson-Hinde, 1999; Graham, 2009; Hodges et al., 1999). Within emerging adulthood, romantic relationships may be of particular importance to shy individuals' well-being, just like close relationships with friends, teachers, siblings, and parents are for children.

Interestingly, for relationship-specific quality, gender also appeared to play a role. For males, there was no moderating influence of romantic relationship quality on shyness and wellbeing. However, for females, romantic relationship quality did influence this association. 
Specifically, at lower relationship quality, shyness was negatively related to well-being, and at higher levels of relationship quality, this negative association was attenuated. Therefore, as predicted, romantic relationship quality did moderate this association for females. Higher relationship quality buffered the negative effects of shyness on well-being, but at lower relationship quality, the negative relation between shyness and well-being was still present. With a larger sample size of males, a similar buffering role of relationship quality may have been found for males as well.

Alternatively, it may be that relationship quality does not serve this role for shy men. Potentially, for shy males, things are so stacked against them because of societal expectations that not even a good romantic relationship can protect them against poorer outcomes Attachment was also a (marginally statistically significant) moderator of the relation between shyness and psychological well-being (and in this case for both genders). As hypothesized, at lower levels of attachment (i.e., less secure), there was a negative association between shyness and well-being. At higher levels of attachment (i.e., more secure), this negative relation was attenuated. In other words, higher levels of attachment buffered the negative influence of shyness on psychological well-being. This buffering effect of attachment is similar to that of romantic relationship quality reported previously. Since adult attachment is a significant determinant of relationship quality, it is not surprising that attachment had a similar buffering effect (Beinstein Miller \& Hoicowitz, 2004; Noftle \& Shaver, 2005). This finding supports past research that suggests attachment plays a significant role in health and well-being outcomes (Collins et al., 2006 Noftle \& Shaver, 2006; Rubin et al., 2004; Wood et al., 2004). Positive, intimate relationships and social support are essential for positive well-being and development, and secure attachment is necessary to form and maintain these close relationships 
(Adams \& Blieszner, 1995; Baumeister et al., 2003; Birditt \& Antonucci, 2007; Collins et al., 2006; Noftle \& Shaver, 2006; Wood et al., 2004). Therefore, the positive influence of attachment style on psychological well-being makes theoretical sense.

Self-esteem. Admittedly, results concerning the prediction of self-esteem were somewhat surprising. Overall, an opposite pattern of results was found in terms of the interaction effect between shyness and relationship quality/attachment in predicting self-esteem as compared to well-being. As previously described romantic relationship quality and secure attachment beliefs appeared to buffer shy individuals from negative well-being. In contrast, the negative relation between shyness and self-esteem appeared to be strongest at higher levels of romantic relationship quality and more secure levels of attachment beliefs. In other words, better quality relationships seemed to exacerbate the negative relation between shyness and self-esteem.

To begin with, it is possible that the result was spurious, and was an unintended artefact of the measure of self-esteem employed. Clearly, this finding needs to be replicated before its implications can be substantively considered.

Notwithstanding, there are some possible conceptual interpretations of this unexpected finding. For example, it may be that among individuals with poorer relationships, there is a strong link to poor self-esteem, regardless of shyness levels. Indeed, the association between attachment and self-esteem was quite strong ( $r=.528)$. In contrast, among individuals with more positive relationships, there is considerably more variability in self-esteem, allowing the negative relation between shyness and self-esteem to emerge more strongly. In other words, there may be a "saturation" point at which relationship quality is "good enough", and factors, such as temperamental factors (e.g., shyness) become stronger predictors.

It is also possible that the different pattern of results emerged because of the distinct 
Shyness and Romantic Relationships 87

nature of the constructs of self-esteem and psychological well-being. Although the broader construct of psychological well-being includes self-esteem, self-worth and self-beliefs, it also includes general cognitive functions (i.e., ability to concentrate, ability to make decisions), quality of sleep (i.e., losing sleep over worrying), and generally being able to enjoy life (i.e., feeling under strain, ability to enjoy your day-to-day activities (Goldberg, 1972; Rosenberg, 1965). Accordingly, personality and relationship factors may influence self-esteem and wellbeing in different ways. The findings of the current study could be interpreted to suggest that self-esteem may be more influenced by personality characteristics (i.e., shyness), whereas wellbeing may be more influenced by social and relationship factors.

In this regard, it can be further speculated that overall, good relationship quality will foster feelings of happiness and decrease feelings of depression or stress. However, even when in a positive and healthy relationship, people who are shy may still suffer from negative beliefs and cognitions about themselves. For instance, shy people in a healthy relationship with high quality may feel happy, and be able to focus and sleep, and not be depressed or stressed. However, they may still feel that they are incompetent and not as good at doing things as others, feel that they do not have many good qualities, and are not very proud of themselves. Thus, healthy relationships may not be enough to change the negative self-cognitions of shy individuals. Accordingly, people with greater levels of shyness are going to feel better when in a good relationship (as opposed to in a poor quality relationship), but they are still going to employ more negative and self-conscious cognitive patterns than those who are less shy. However, it must be acknowledged that these assertions remain highly speculative in nature and should be considered as suggested avenues for future research. 
Shyness and Romantic Relationships 88

\section{Caveats \& Future Directions}

The present research contributes to our understanding of the associations between shyness, romantic relationship quality, and well-being in emerging adulthood. However, some caveats must be considered when considering the results. These limitations are presented within the context of suggestions for subsequent research in this area.

Generalizability. Unexpectedly, participant age was significantly (albeit modestly) correlated with shyness in Study 2. This was unexpected since the age range (18-26 years) was quite small and past research does not suggest this finding typically occurs. It is possible that a form of age-related recruitment bias may have occurred. There was such a high proportion of $18-$ 19 year olds participating in the study as compared to older students (20-26 years). The younger participants may well have been interested in participating in the study because it pertained to romantic relationships and sexuality. Alternatively, the older participants may have been drawn to the study because of the focus on shyness. Additionally, older participants may feel more comfortable with themselves and feel they understand their true temperament better than those younger than them. Thus, this would allow these older participants to report higher, and potentially more accurate levels of shyness. Interestingly, this correlation was not found in Study 1.

More generally, participants were recruited from undergraduate classes at Carleton University. Therefore, these findings can potentially be generalized to other undergraduate university populations. However, these same findings may not apply to other people of the same age who are in the workforce or in college. In addition, these findings cannot be generalized to people of different ages or those who are not in the emerging adulthood phase. However, attending school is a key part of the transitional time period of emerging adulthood, so these 
findings may be generalized to other samples of emerging adulthood.

As well, the ethnic diversity of the samples was somewhat limited, with participants predominantly Caucasian (74.7\%). In future studies, effort should be taken to include a wider range of ethnicities and to explore these associations cross-culturally. Indeed, emerging adulthood is a recent transitional phase within Western society. These results may not be generalized to areas outside of western civilization, even for people between the ages 18-26, because in many societies, there is no emerging adulthood phase.

These results are also limited in their ability to further understand more long-term romantic relationships, such as marriage. It would be interesting to explore the negative relation between shyness and both, intimacy and sexual satisfaction, to determine whether this association stays consistent even in married relationships. These findings should be replicated with individuals of the same age who are not attending university, on individual who are of different ages (both younger and older), and in other western cultures to determine if these findings hold in other contexts.

Ceiling effects. Another limitation of this study was the ceiling effects observed for assessments of sexual satisfaction, emotional intimacy, and psychological well-being. That is, most participants reported fairly positive relationship quality and a high level of well-being. There may be a number of reasons for these findings. For one, social desirability may be influencing participants' responses, especially for the two romantic relationship measures. Even though it is an online questionnaire and identification is keep confidential, participants may feel a need to present their relationships in the most attractive light. Also, participants had to be currently in a relationship in order to participate in Study 2, so those that had very poor quality scores may have already broken up and therefore not participating in the study. Alternatively, 
Shyness and Romantic Relationships 90

participants may not have wanted to admit to themselves that their relationship was less than optimal.

In addition, emerging adulthood is an exploratory stage of development, so for many individuals, being in romantic relationships are new experiences, thus making romantic relationships seem exciting. Therefore, they may be reporting the high quality because it is exciting to be in a relationship and they are not focusing on the difficulties that may come along with them. As well, emerging adulthood is characterized as an experiment phase in which people test out different interests, friends, and relationships. Therefore, some relationships in this phase may be less serious than those of older populations. Participants may be less concerned with the negative aspects of their relationships then, because they do not feel stuck in them and can easily find other potential partners if their current relationship fails.

As well, a higher proportion of participants declined to complete the assessment of sexual satisfaction. Potentially, the ceiling effect for this measure was caused by the fact that those who failed to answer did so because their satisfaction was lower than they would like, and those that did answer did so because they are felt they had high sexual satisfaction or were succumbing to social desirability needs.

Causality and directions of effects. The present study was correlational in nature. Therefore, no causal relations can be inferred. It is certainly the case that the "meaning" of the associations between the variables can be interpreted in alternative ways from the ones proposed in this study. For instance, for the present study, the moderating influence of romantic relationship quality and attachment on the association between shyness and well-being were investigated. This was the conceptual framework that was presented prior to collecting and analyzing the data. That being said, there are a number of alternative conceptual models that can 
Shyness and Romantic Relationships 91

be used to interpret this data. For instance, one could explore the potential moderating role of psychological well-being in the associations between shyness and romantic relationship quality. In this regard, it could be suggested that shy individuals with higher self-esteem and better wellbeing might be more likely to form relationships of higher quality.

Additionally, the associations between the study and outcome variables in Study 2 could be considered within a mediation model framework. For instance, shyness could lead to lower relationship quality and attachment, which in turn could lead to more negative well-being outcomes. However, shyness is associated with negative well-being outcomes not only for those in a romantic relationship (Ashbaugh, Antony, McCabe, Schmidt, \& Swinson, 2005; Brunet \& Schmidt, 2007; Cheek \& Melchoir, 1990; Crozier, 1995; Schmidt \& Fox, 1995; Zimbardo, 1990). Longitudinal studies are required to better understand the nature of the associations between shyness, relationship status, and a variety of well-being measures over the emerging adult years. In this regard, links between shyness and well-being can be explored before, during, and after romantic relationships throughout these transitional years. Additionally, a longitudinal study could track emerging adults into adulthood to see if and what the implications of shyness, lack of or decreased dating, and reduced relationship quality on later life outcomes. This will help to determine if shy individuals are at risk for significant negative life outcomes later in life.

Effect size and trends. The predictive ability of shyness and the moderating role of romantic relationship quality were considerably small. As well, findings that were only approaching traditional levels of statistical significance were interpreted. Since these studies are preliminary in nature, it is important to investigate patterns and relationships despite their marginal significance or small effect size. However, the findings of this study must be taken with caution. Replication and further investigation must be conducted to understand these patterns in 
Shyness and Romantic Relationships 92

greater depth.

Self-Report. All questionnaires in this research were self-report in nature. Although this is not uncommon in the contemporary adult personality literature, the reliance on a single informant may have increased associations between variables because of shared-method variance. It would be interesting in future studies to use objective or observational measures of shyness and psychological well-being. As well, the inclusion of partner interpretations of their partner's shyness and well-being, and their subjective perspective of their relationship quality in future studies would provide further insight into the influence of shyness and relationship quality on well-being.

The role of gender. There was an unequal distribution of gender present in both Study 1 and Study 2 . This is a common problem in much psychological research, especially when recruiting students on university campuses (and particularly in psychology classes). In future studies, it would be beneficial to recruit students from other disciplines (not just psychology classes) to attract more male participants, while at the same time getting people from a diverse academic background. A larger sample of males would provide more power, reduce chances of error, and provide more insight into the observed gender differences. With a more equally balanced gender distribution, it would be interesting to see if the gender differences found in this study would be replicated.

Additional variables to consider. The present research did not include measures of life stressors (e.g., death in the family, illness), major life events (e.g., getting married, moving to a new city), or daily hassles (e.g., argument with partner, missing the bus). Such stressors can impact one's physical and mental health (Kanner, Coyne, Schaefer, \& Lazarus, 1981). Therefore, in future studies it would be beneficial to measure these to see how they correlate with the 
Shyness and Romantic Relationships 93

outcome variables of well-being. If they do significantly correlate, then they could then be controlled for in the subsequent hierarchical regression analyses. Potentially, the inclusion of these measures as control variables may significantly change the dynamic observed in this study, between shyness, relationship quality, and the outcome measures. In the least, it would provide greater understanding of well-being within romantic relationships.

As well, despite the importance of romantic relationship for emerging adults and for wellbeing (Arnett, 2000; Berscheid et al., 1989; Birditt \& Antonucci, 2007), other close relationships (e.g., friendships, sibling and parental relationships) significantly impact well-being and have been shown in previous studies to moderate the association between shyness and well-being (Arbeau et al., 2010; Fordham \& Stevenson-Hinde, 1999; Graham, 2009; Hodges et al., 1999). Therefore, it would be beneficial to include measures of friendship quality and parental support into the study. By including these measures, the influence of romantic relationship quality on the associations between shyness and well-being could be compared to that of friendship and parental relationship quality. As well, the quality of friendships and parental support could be controlled in the moderation analyses, to determine what influence romantic relationship quality on the shyness-well-being relation, above and beyond that of other close relationships.

In Study 2, three measures of relationship quality for participants' current relationship were included and one for general relationship quality (attachment). Together these measures provide a significant amount of knowledge about participants' current relationship. However, there are other components of relationship quality that were only touched on within these three measures. In future studies, scales that measure these other aspects of romantic relationship quality (e.g., trust, commitment, and passion) should be included. Study 2 also employed two outcome measures, the General Health Questionnaire and the Rosenberg Self-Esteem Scale. 
Shyness and Romantic Relationships 94

These are both excellent scales for measuring aspects of psychological health. However, in future studies, additional measure could be added to understand the specific aspects of mental health. For instance, the Beck Depression Inventory, Revised UCLA Loneliness Scale and Beck Anxiety Inventory could be added to measure depression, loneliness, and anxiety, respectively. Then the effect of shyness and romantic relationship quality could be tested on these measures as well in order to get a more holistic understanding of their impact on well-being. In the same vein, this research could be extended to include physical health as an outcome variable. It would be interesting to investigate whether similar patterns occur with physical health, as they did with mental health.

Studying couples. The associations reported in this study should be investigated in further depth by studying both partners within a romantic relationship. It would be interesting to examine the influence of the level of shyness of one individual on their own and their partner's perceptions of their relationship as well as both their psychological well-being. This study provided further understanding into the influence of shyness on well-being for people involved in romantic relationships. Another possible avenue to study would be the differences in the relation of shyness and well-being between those in a romantic relationship and those not. A similar study to the current one could be conducted to investigate this, by including both participants who are and are not currently in a relationship. This would allow us to understand the influence of romantic relationship on this relation in further depth.

\section{Conclusion}

Overall, the results from the current study replicated and expanded our understanding of the associations between shyness, romantic relationships, and well-being in emerging adulthood. There were several findings in this study that had not been investigated previously. For instance, 
Shyness and Romantic Relationships 95

shyness was associated with poor intimacy, specifically in a romantic relationship, and low levels of sexual satisfaction. Separately, romantic relationship quality and attachment buffered the negative association between shyness and psychological well-being. In contrast, both romantic relationship quality and attachment failed to buffer the association between shyness and lower self-esteem. Thus, relationship quality helps alleviate the negative well-being outcomes; however, it does not do so for the lower self-esteem that is correlated with shyness.

It is evident that romantic relationships may be of particular importance for shy individuals in emerging adulthood. By forming close, positive romantic relationships in emerging adulthood, shy individuals may be protected from poor well-being. As well, as being protected against reduced well-being at this phase, shy individuals often learn to develop strong social bonds and build a strong social support network. If they are able to develop quality relationships with their romantic partners, then this may flow over into other close relationship (i.e., friends, family, coworkers), which will build an even stronger social support network. Positive relationships may have implications on their ability to develop relationships in the future and their overall well-being later in life. By forming quality relationships at this stage, shy individuals will learn how to be in a high-quality romantic relationship, which will carry over into future relationships.

For shy individuals, having a secure attachment style can be vital and beneficial for their well-being. Secure attachment styles can be pivotal for shy people as it provides them with a constructive view of relationships. Since shyness is associated with being anxious in social interactions, this positive view of relationships may make them associate less stress and anxiety with relationships and be able to trust partners more. Overall, secure attachment style and positive romantic relationships are very important for promoting positive well-being for shy 
emerging adults.

This study provides support for the fact that shyness continues to negatively influence relationship and well-being constructs into later developmental stages. Therefore, it is important for clinicians and researchers to be aware that the detrimental effects of shyness are present not only in childhood, but in emerging adulthood as well. Interventions and programs that work to assist shy emerging adults to develop strong and positive relationships with those close to them are needed. Additionally programs should be directed at promoting positive well-being and selfconfidence, and changing negative self-cognitions for shy emerging adults. Cognitive re-framing and other cognitive therapy techniques directed at improving self-concept views may be necessary to improve the self-esteem of shy individuals. Since post-secondary education is common place for emerging adults to spend a considerable amount of their time, perhaps universities and colleges should set up programs that help shy students through this transitional phase and be successful in their relationship, careers, and life. 
References

Adams, R. G., \& Blieszner, R. (1995). Aging well with friends and family. American Behavioral Scientist, 39, 209-224.

Arbeau, K.A., Coplan, R.J., \& Weeks, M. (2010). Shyness, teacher-child relationships, and socio-emotional adjustment in grade 1. International Journal of Behavioural Development, 34, 259-269.

Arnett, J. J. (2000). Emerging adulthood: A theory of development from the late teens through the twenties. American Psychologist, 55, 469-480.

Arnett, J. J. (2010). Adolescence and emerging adulthood: A cultural approach. Upper Saddle River, NJ: Prentice Hall.

Ashbaugh, A. R., Antony, M. M., McCabe, R. E., Schmidt, L. A., \& Swinson, R. P. (2005). Self evaluative biases in social anxiety. Cognitive Therapy and Research, 29, 387-998.

Asendorpf, J. B., \& Wilpers, S. (1998). Personality effects on social relationships. Journal of Personality and Social Psychology, 74, 1531-1544.

Asendorpf, J. B., Denissen, J. J. A., \& van Aken, M. A. G. (2008). Inhibited and aggressive preschool children at 23 years of age: Personality and social transitions into adulthood. Developmental Psychology, 44, 997-1011.

Bandura, A. (1997). Self-efficacy. The exercise of control. New York: Freeman.

Bartholomew K., \& Horowitz, L. M. (1991). Attachment style among young adutls: A test of a four-category model. Journal of Personality and Social Psychology, 61, 226-44.

Baumeister, R. F., Campbell, J. D., Krueger, J. I., \& Vohs, K. D. (2003). Does high self-esteem cause better performance, interpersonal success, happiness, or healthier lifestyles? Psychological Science in the Public Interest, 4, 1-44. 
Shyness and Romantic Relationships 98

Beinstein Miller, J., \& Hoicowitz, T. (2004). Attachment contexts of adolescent friendship and romance. Journal of Adolescence, 27, 191-206.

Berscheid, E., Snyder, M., \& Omoto, A. M. (1989). Issues in studying relationships:

Conceptualizing and measuring closeness. In C. Hendrick (Ed.), Close relationships: Vol 10. Review of personality and social psychology (pp. 63-91). Newbury Park, CA: Sage.

Birditt, K. S., \& Antonucci, T. C. (2007). Relationship quality profiles and well-being among married adults. Journal of Family Psychology, 21, 595-604.

Bowlby, J. (1969). Attachment and loss. Vol 1. Attachment. New York: Basic Books.

Bowlby, J. (1973). Attachment and loss, separation: Anxiety, and anger. Vol. 2. New York: Basic Books.

Bradshaw, S. D. (2006). Shyness and difficult relationships: Formation is just the beginning. In D. C. Kirkpatrick, S. Duck, \& M. K. Foley (Eds.), Relating difficulty: The process of constructing and managing difficult interaction (pp. 15-41). Mahwah, NJ: Erlbaum.

Bruch, M. A. (2001). Shyness and social interaction. In W. R. Crozier \& L. E. Alden (Eds.), International handbook of social anxiety: Comcepts, research, and interventions relating to the self and shyness (pp. 195-215). Chichester, UK: Wiley.

Bruch, M. A., Gorsky, J. M., Collins, T. M., \& Berger, P. A. (1989). Shyness and sociability re-examined: A multicomponent analysis. Journal of Personality and Social Psychology 57, 904-915.

Brunet, P. M., \& Schmidt, L. A. (2007). Is shyness context specific? Relation between shyness and online self-disclosure with and without a live webcam in young adults. Journal of Research in Personality, 41, 938-945.

Buhrmester, D., \& Furman, W. (1987). The development of companionship and intimacy. Child 
Shyness and Romantic Relationships 99

Development, 58, 1101-1103.

Burgess, K. B., Wojslawowicz, Rubin, K. H., Rose-Krasnor, L., \& Booth-LaForce, C. (2006).

Social information processing and coping strategies of shy/withdrawn and aggressive

Burleson, M. H., Trevathan, W. R., \& Todd, M. (2007). In the mood for love or vise versa?

Exploring the relations among sexual activity, physical affection, affect, and stress in the daily lives of mid-aged women. Archives of Sexual Behavior, 36, 357-368.

Buss, A., \& Plomin, R. (1984). Temperament: Early developing personality traits. Hillsdale, NJ: Erlbaum.

Byers, S. (2005). Relationship satisfaction and sexual satisfaction: a longitudinal study of individuals in long-term relationships. Journal of Sex Research, 42(2), 113-119.

Byers, S., \& Demmons, S. (1999). Sexual satisfaction and self-disclosure within dating relationships. Journal of Sex Research, 36, 180-190.

Byers, S., Demmon, S., \& Lawrance, K. (1998). Sexual satisfaction within dating relationships: A test of the interpersonal exchange model of sexual satisfaction. Journal of Social and Personal Relationships, 15, 257-267.

Campbell, L., Lackenbauer, S. D., \& Muise, A. (2006). When is being known or adored by romantic partners most beneficial? Self-perception, relationship length, and responses to partner's verifying and enhancing appraisals. Personality and Social Psychology Bulletin, $32,1283-1294$.

Carbery, J., \& Buhmeister, D. (1998). Friendship and need fulfillment during three phases of adulthood. Journal of Social and Personal Relationships, 15, 393-409.

Caspi, A., Bem, D. J., \& Elder, G. H. (1988). Moving away from the world: Life-course patterns of shy children. Developmental Psychology, 24, 824-831. 
Caspi, A., \& Silva, P. A. (1995). Temperamental qualities at age three predict personality traits in young adulthood: Longitudinal evidence from a birth cohort. Child Development, 66, 486-498.

Caspi, A., Harrington, H., Milne, B., Amell, J. W., Theodore, R. F., \& Moffitt, T. E. (2003). Children's behavioral styles at age 3 are linked to their adult personality traits at age 26 . Journal of Personality, 71, 495-513.

Caughlin, J. P., \& Afifi, T. D. (2004). When is topic avoidance unsatisfying? Examining moderators of the association between avoidance and dissatisfaction. Human Communication Research, 30, 479-513.

Cheek, J. M., \& Buss, A. H. (1981). Shyness and sociability. Journal of Personality and Social Psychology, 41, 330-339.

Cheek, J. M., \& Melchior, L. A. (1990). Shyness, self-esteem, and self-conciousness. In H. Leitenberg (Ed.), Handbook of social and evaluation anxiety (pp. 47-82). New York: Plenum.

Cheung, P. P. L., \& Hudson, W. W. (1982). Assessment of marital discord in social work practice: A revalidation of the Index of Marital Satisfaction. Journal of Social Service Research, 5, $101-118$.

Collins, N. L., \& Miller, L. C. (1994). Self-disclosure and liking: A meta-analytic review. Psychological Bulletin, 116, 457-475.

Collins, N. L., Ford, M. B., Guichard, A. C., \& Allard, L. M. (2006). Working models of attachment and attribution processes in intimate relationships. Personality and Social Psychology Bulletin, 32, 201-219.

Connolly, J., Furman, W., \& Konarski, R. (2000). The role of peers in the emergence of 
Shyness and Romantic Relationships 101

heterosexual romantic relationships in adolescence. Child Development, 7, 1395-1408.

Coplan, R. J., \& Armer, M. (2007). A "multitude" of solitude: A closer look at social withdrawal and non-social play in early childhood. Child Development Perspectives, 1, 26-32.

Coplan, R.J., Hughes, K., \& Rowsell, H.C. (2009). Once upon a time there was a blushful hippo: A content analysis of shy characters in young children's storybooks. To appear in K.H. Rubin \& R.J. Coplan (Eds.) The development of shyness and social withdrawal in childhood and adolescence. New York: Guilford.

Coplan, R. J., Prakash, K., O’Neil, K., \& Armer, M. (2004). Do you "want" to play?

Distinguishing between conflicted shyness and social disinterest in early childhood. Developmental Psychology, 40(2), 244-258.

Crozier, W. R. (1979). Shyness as a dimension of personality. British Journal of Social \& Clinical Psychology, 18, 121-128.

Crozier, W. R. (1995). Shyness and self-esteem in middle childhood. British Journal of Educational Psychology, 65, 85-95.

Crozier, W. R. (2001). Blushing and the exposed self: Darwin revisited. Journal of the Theory of Social Behavior, 31, 61-72.

Culp, L. N., \& Beach, S. R. H. (1998). Marriage and depressive symptoms: The role and bases of self-esteem differ by gender. Psychology of Women Quarterly, 22, 647-663.

Cupach, W. R., \& Comstock, J. (1990). Satisfaction with sexual communication in marriage. Links to sexual satisfaction and dyadic adjustment. Journal of Social and Personal Relationships, 7, 179-186.

Cupach, W. R., \& Metts, S. (1991). Sexuality and communication in close relationships. In K. 
Shyness and Romantic Relationships 102

McKinney \& S. Sprecher (Eds.) Sexuality in Close Relationships (pp. 93-110). New York: Lawrence Erlbaum.

Davison, S.L., Bell, R., LaChina, M., Holden S.L., \& Davis, S.R. (2009). The relationship between self-reported sexual satisfaction and general well-being in women. Journal of Sexual Medicine, 6, 2690-2697.

Dehle, C., \& Weiss, R. L. (1998). Sex differences in prospective associations between marital quality and depressed mood. Journal of Marriage and the Family, 60, 1002-1011.

DeLongis, A., Folkman, S., \& Lazarus, R. S. (1988). The impact of daily stress on health and mood: Psychological and social resources as mediators. Journal of Personality and Social Psychology, 54, 486-495.

Duggan, E. S., \& Brennan, K. A. (1994). Social avoidance and its relation to Bartholomew's adult attachment typology. Journal of Social and Personal Relationships, 11, 147-153.

Eisenberg, N (Ed.). (2007). Special section: Emerging adulthood around the world. Child Development Perspectives, 1, 65-140.

Eisenberg, N., Fabes, R. A., \& Murphy, B. C. (1995). Relations of shyness and low sociability to regulation and emotionality. Journal of Personality and Social Psychology, $68,505-517$.

Erikson, E. (1950). Childhood and society. New York: Norton.

Erwin, P. G. (2007). The effects of shyness on love styles and relationship status. Psychological Reports, 101, 670-672.

Fehr, B. (1996). Friendship processes. Thousand Oaks, Ca: Sage.

Fincham, F. D., Beach, S. R. H., Harold, G. T., \& Osborne, L. N. (1997). Marital satisfaction and depression: Different causal relationships for men and women? Psychological Science, 8, 
Shyness and Romantic Relationships 103

351-357.

Finkenauer, C., \& Hazam, H. (2000). Disclosure and secrecy in marriage: Do both contribute to marital satisfaction? Journal of Social and Personal Relationships, 17, 245-263.

Fiske, V., \& Peterson, C. (1991). Love and depression: The nature of depressive romantic relationships. Journal of Social and Clinical Psychology, 10, 75-90.

Fletcher, G. J. O., Simpson, J. A., \& Thomas, G. (2000). The measurement of perceived relationship quality components: A confirmatory factor analytic approach. Personality and Social Psychology Bulletin, 26, 340-354.

Fordham, K., \& Stevenson-Hinde, J. (1999). Shyness, friendship quality, and adjustment during middle childhood. Journal of Child Psychology and Psychiatry and Allied Disciplines, 40, 757-768.

Fox, K., R., \& Wilson, P. M. (2008). Self-perceptual systems and physical activity. In Horn, T. S. (Ed.). Advances in Sport Psychology ( $3^{r d}$ Ed.). Champaign, IL: Human Kinetics.

Fraley, R. (2005). Information on the experiences in close relationships-revised (ECR-R) adult attachment questionnaire. Retrieved on July 23, 2009 from: http://wwww.psych.uiuc.edu/ rfraley/measures/eccr.htm

Fraley, R. C., Waller, N. G., \& Brennan, K. A. (2000). An item-response theory analysis of selfreport measures of adult attachment. Journal of Personality and Social Psychology, 78, 350-365.

Furman, W., \& Wehner, E. A. (1997). Adolescent romantic relationships: A developmental perspective. In S. Shulman \& A. Collins (Eds.), Romantic relationships in adolescence: New Directions for Child Development (pp. 21-36). San Francisco: Jossey-Bass.

Garcia-Coll, C., Kagan, J., \& Reznick, J. S. (1984). Behavioral inhibitions in young children. 
Shyness and Romantic Relationships 104

Child Development, 55, $1005-1019$.

Gentile, B., Dolan-Pascoe, B., Twenge, J. M., Grabe, S., Wells, B. E., \& Maitino, A. (2009).

Gender differences in domain-specific self-esteem: A meta-analysis. Review of General Psychology, 13, 34-45.

Giordano, P. C., Manning, W. D., \& Longmore, M. A. (2006). Adolescent romantic relationships: An emerging portrait of their nature and developmental significance. In A. C. Crouter \& A. Booth (Eds.), Romance and sex in emerging adulthood: Risks and opportunities (pp. 127-150). Mahwah, NJ: Erlbaum.

Goldberg, D. P. (1972). The detection of psychiatric illness by questionnaire. London: Oxford University Press.

Graham, A. (2009). Exploring the protective role of siblings in shy children's socio-emotional adjustment. Carleton University.

Griggs, M. S., Gagnon, S. G., Huelsman, T. J., Kidder-Ashley, P., \& Ballard, M. (2009). Studentteacher relationships matter: Moderating influences between temperament and preschool social competence. Psychology in the Schools, 46, 553-567.

Haavio-Mannila, E., \& Kontula, O. (1997). Correlates of increased sexual satisfaction. Journal Archives of Sexual Behaviour, 26, 399-419.

Hartup, W. W. (1995). The three faces of friendship. Journal of Social and Personal Relationships, 12, 569-574.

Hassebrauck, M., \& Fehr, B. (2002). Dimensions of relationship quality. Personal Relationships, 9, 253-270.

Hays, R. B. (1988). Friendship. In S. W. Duck (Ed.), Handbook of personal relationships: Theory, research, and interventions (pp. 391-408). London: Wiley. 
Shyness and Romantic Relationships 105

Hazan C., \& Shaver P. (1987). Romantic love conceptualized as an attachment process. Journal of Personality and Social Psychology, 52, 511-24.

Heiser, N. A, Turner, S. M., \& Beidel, D. C., (2002). Shyness: Relationship to social phobia and other psychiatric disorders. Behavriour Research and Therapy, 41, 209-221.

Henderson, L., \& Zimbardo, P. G. (2008). Encyclopedia of Mental Health. San Diego, CA: Academic Press.

Henderson-King, D. H., \& Veroff, J. (1994). Sexual satisfaction and marital well-being in the first years of marriages. Journal of Social and Personal Relationships, 11, 509-534.

Hodges, E. V. E., Boivin, M., Vitraro, F., \& Bukowski, W. M. (1999). The power of friendship: Protection against an escalating cycle of peer victimization. Developmental Psychology, $35,94-101$.

Hopko, D. R., Stowell, J., Jones, W. H., Armento, M. E. A., \& Cheek, J. M. (2005). Psychometric properties of the Revised Cheek and Buss Shyness Scale. Journal of Personaity Assessment, 84, 185-192.

Johnson, J. E., Aikman, K. G., Danner, C. C., \& Elling, K. A. (1995). Attributions of shy persons in romantic relationships. Journal of Clinical Psychology, 51, 532-538.

Jones, W. H., Briggs, S. R., \& Smith, T. G. (1986). Shyness: Conceptualization and measurement. Journal of Personality and Social Psychology, 51, 629-639.

Kagan, J. (1988). Temperamental contributions to social behavior. American Psychologist, 44(4) $668-674$.

Kagan, J., Reznick, S., \& Snidman, N. (1987). The physiology and psychology of behavioural inhibition in children. Child Development, 58, 1459-1473.

Kagan, J., Snidman, N., \& Arcus, D. (1993). On the temperamental categories of inhibited and 
Shyness and Romantic Relationships 106

uninhibited children. In K. H. Rubin, \& J. B. Asendorpf (Eds.), Social withdrawal, inhibition, and shyness in childhood, pp. 19-28. Hillsdale, NJ: Lawrence Erlbaum Associates.

Kalliopuska, M. (2008). Personality variables related to shyness. Psychological Reports, 102, 4042.

Kan, M. L., \& Cares, A. C. (2006). From "friends with benefits" to "going steady": New directions in understanding romance and sex in adolescence and emerging adulthood. In A. C. Crouter \& A. E. Booth (Eds.), Romance and sex in adolescence and emerging adulthood: Risks and opportunities (pp. 241-258). Mahwah, NJ, US: Lawrence Erlbaum Associates Publishers.

Kanner, A. D., Coyne, J. C., Schaefer, C., \& Lazarus, R. S. (1981). Comparison of two modes of stress management: Daily hassles and uplifts versus major life events. Journal of Behavioral Medicine, 4, 1-39.

Kerr, K., Lambert, W. W., \& Bem, D. J. (1996). Life course sequelae of childhood shyness in Sweden: Comparison with the United States. Developmental Psychology, 32, 1100-1105.

Kirkpatrick, L., \& Hazan, C. (1994). Attachment styles and close relationships: A four year prospective study. Personal Relationships, 1, 123-142.

Kling, K. C., Hyde, J. S., Showers, C. J., \& Buswell, B. N. (1999). Gender differences in selfesteem: A meta-analysis. Psychological Bulletin, 125, 470-500.

Koydemir, S., \& Demir, A. (2008). Shyness and cognitions: An examination of Turkish university students. The Journal of Psychology, 142, 633-644.

Ladd, G. W., \& Burgess, K. B. (1999). Charting the relationship trajectories of aggressive, withdrawn, and aggressive/withdrawn children during early grade school. Child 
Development, 70, 910-929.

Lanz, M., \& Tagliabue, S. (2007). Do I really need someone in order to become an adult? Romantic relationships during emerging adulthood in Italy. Journal of Adolescent Research, 22, 531-549.

Last, C. G. (1991). Somatic complaints in anxiety disordered children. Journal of Anxiety Disorders, 5, 125-138.

Laurenceau, J., Rivera, L. M., Schaffer, A. R., \& Pietromonaco, P. R. (2004). Intimacy as an interpersonal process: Current status and future directions. In D. J. Mashek \& A. Aron (Eds.), Handbook of closeness and intimacy (pp. 81-101). Mahwah, NJ: Erlbaum.

Leary, M. R., \& Kowalski, R. M. (1995). Social Anxiety. New York: Guilford Press.

Leary, M. R., \& Tangney, J. P. (2003). Handbook of self and identity. New York: Guildford. Leck, K. (2006). Correlates of minimal dating. The Journal of Social Psychology, 146, $549-567$.

Maltby, J., \& Day, L. (2000). Romantic acts and depression. Psychological Medicine, 28, 13891401.

Martin, R. P. (1994). Child temperament and common problems in schooling: Hypothesis about causal connections. Journal of School Psychology, 32(2), 119-134.

Miller, R. S. (2001). Shyness and embarrassment compared: Siblings in the service of social evaluation. In W. R. Crozier \& L. E. Alden (Eds.), International handbook of social anxiety: Concepts, research and interventions relating to the self and shyness (pp. 281300). Chichester, England: Wiley.

Miller, R. S., \& Perlman, D. (2009). Intimate Relationships ( $5^{\text {th }}$ Ed.). New York, NY: McGrawHill Higher Education. 
Montgomery, M. J. (2005). Psychosocial intimacy and identity: From early adolescence to emerging adulthood. Journal of Adolescent Research, 20, 346-374.

Mortimer, J. T (Ed.). (2009). Special issue: Social class and transitions to adulthood. New Directions for Child and Adolescent Development, 2008, 1-98.

Murray, S. L., Holmes, J. G., Griffin, D. W., Bellavia, G., \& Rose, P. (2001). The mismeasure of love: How self-doubt contaminates relationship beliefs. Personality and Social Psychology Bulletin, 27, 423-436.

Myers, D. (2000). The funds, friends, and faith of happy people. American Psychologist, 55, 5667.

Nelson, L. J., Padilla-Walker, L. M., Badger, S., McNamara, B. C., Carroll, J. S., Madsen, S. D (2008). Associations between shyness and internalizing behaviors, externalizing behaviors, and relationships during emerging adulthood. Journal of Youth and Adolescence, 37, 605-615.

Noftle, E. E., \& Shaver, P. R. (2006). Attachment dimensions and the big five personality traits: Associations and comparative ability to predict relationship quality. Journal of Research in Personality, 40, 179-208.

Ornish, D. (1998). Love \& survival: The scientific basis for the healing power of intimacy. New York: HarperCollins.

Parker, J. G., \& Asher, S. R. (1993). Friendship and friendship quality in middle childhood: Links with peer group acceptance and feelings of loneliness and social dissatisfaction. Developmental Psychology, 29, 611-621.

Parker, J. G., \& Gottman, J. M. (1989). Social and emotional development in a relational context: Friendship interaction from early childhood to adolescence. In T. J. Berndt \& G. W. Ladd 
Shyness and Romantic Relationships 109

(Eds.), Peer relationships in child development (pp. 95-131). New York: Wiley.

Parker, J. G., \& Seal, J. (1996). Forming, loving, renewing, and replacing friendships: Applying temporal parameters to the assessment of children's friendship experiences. Child Development, 67, 2248-2268.

Penhollow, T. M., \& M. Young, (2008). Predictors of sexual satisfaction: The role of body image and fitness. Electronic Journal of Human Sexuality, 12.

Perlman, D., \& Fehr, B. (1987). The development of intimate relationships. In D. Perlman \& S. Duck (Eds.), Intimate relationships: Development, dynamics, and deterioration (pp. 1342). Newbury Park, CA: Sage.

Pietromonaco, P. R., \& Barrett, L. F. (1997). Working models of attachment and daily social interactions. Journal of Personality and Social Psychology, 73, 1409-23.

Pilkonis, P. A. (1997a). Shyness, private and public, and its relation to other measures of social behavior. Journal of Personality, 45, 585-595.

Pilkonis, P. A. (1997b). The behavioral consequences of shyness. Journal of Personality, 45, $596-611$.

Prakash, K., \& Coplan, R. J. (2003). Shy skaters? Shyness, coping, and adjustment outcomes in female adolscent figure skaters. Athletic Insight: The Online Journal of Sport Psychology, 5.

Preacher, K. J., Curran, P. J., \& Bauer, D. J. (2006). Computational tools for probing interaction effects in multiple linear regression, multilevel modeling, and latent curve analysis. Journal of Educational and Behavioral Statistics, 31, 437-448.

Rathus, S. A., Nevid, J. S., Fichner-Rathus, L., Herold, E.S., \& McKenzie, S. W. (2007). Human Sexuality In a World of Diversity ( $2^{\text {nd }}$ ed.). Toronto: Pearson Education Canada Inc. 
Shyness and Romantic Relationships 110

Reis, H. T. (2007). Steps toward the ripening of relationship science. Personal Relationships, 14, $1-23$.

Reis, H. T., Lin, Y., Bennett, M. E., \& Nezlek, J. B. (1993). Change and consistency in social participation during early adulthood. Developmental Psychology, 29, 633-645.

Reis, H. T., Collins, W. A., \& Berscheid, E. (2000). The relationship context of human behavior and development. Psychological Bulletin, 126, 844-872.

Renaud, C., Byers, S., \& Pan, S. (1997). Sexual and relationship satisfaction in mainland China. Journal of Sex Research, 34(4), 399-417.

Rogers, C. R. (1951). Client-centered therapy. Boston, MA: Houghton Mifflin.

Roisman, G. I., Masten, A. S., Coatsworth, J. D., \& Tellegen, A. (2004). Salient and emerging developmental tasks in the transition to adulthood. Child Development, 75, 123-133.

Rosenberg, M. (1965). Society and The Adolescent Self-Image. Princeton, N.J.: Princeton University Press.

Rubin, K. H., \& Asendorpf, J. B. (1993). Social withdrawal, inhibition and shyness in childhood. Hillsdale, NJ: Lawrence Erlbaum Associates, Inc.

Rubin, K. H., \& Coplan, R. J. (2004). Paying attention to and not neglecting social withdrawal and social isolation. Merill-Palmer Quarterly, 50, 506-534.

Rubin, K. H., Daniels-Beirness, T., \& Bream, L. (1984). Social isolation and social problem solving: A longitudinal study. Journal of Consulting and Clinical Psychology, 52, 17-25.

Rubin, K. H., Dwyer, K. M., Booth-LaForce, C., Kim, A. H., Burgess, K. B., \& Rose-Krasnor, L. (2004). Attachment, friendship, and psychosocial functioning in early adolescence. Journal of Early Adolescence, 24, 326-356. 
Shyness and Romantic Relationships 111

Rubin, K. H., Wojslawowicz, J. C., Rose-Krasnor, L., Booth-LaForce, C., \& Burgess, K.

B. (2006). The best friendships of shy/withdrawn children: Prevalence, stability, and relationship quality. Journal of Abnormal Child Psychology, 34, 143-157.

Schmidt, L. A., \& Fox, N. A. (1995). Individual differences in young adults' shyness and sociability: Personality and health correlates. Personality and Individual Differences, 19, $455-462$.

Schmidt, L. A., Fox, N. A., Schulkin, J., \& Gold, P. W. (1999). Behavioral and psychophysiological correlates of self-presentation in temperamentally shy children. Developmental Psychobiology, 35, 119-135.

Segrin, C., Powell, H. L., Givertz, M., \& Brackin, A. (2003). Symptoms of depression, relational quality, and loneliness in dating relationships. Personal Relationships, 10, 25-36.

Seiffge-Krenke, I. (2003). Testing theories of romantic development from adolescence to young adulthood: Evidence of a developmental sequence. International Journal of Behavioral Development, 27, 519-531.

Simons, K. J., Paternite, C. E., \& Shore, C. (2001). Quality of parent/adolescent attachment and aggression in young adolescents. Journal of Early Adolescence, 17, 800-808.

Sinclair, V. G., \& Dowdy, S. W. (2005). Development and validation of the emotional intimacy scale. Journal of Nursing Management, 13, 193-206.

Spanier, G. B., \& Lewis, R. A. (1980). Marital quality: A review of the seventies. Journal of Marriage and the Family, 42, 825-839.

Sprecher, S. (2002). Sexual satisfaction in premarital relationships: Associations with satisfaction, love, commitment, and stability. Journal of Sex Research, 39, 190-196. 
Shyness and Romantic Relationships 112

Sprecher, S., \& Hendrick, S. S. (2004). Self-disclosure in intimate relationships: Associations with individual and relationship characteristics over time. Journal of Social and Clinical Psychology, 23, 857-877.

Sternberg, R. J. (1987). The triangle of love: Intimacy, passion, commitment. New York: Basic Books.

Stordal, E., Bjelland, I., Dahl, A. A., \& Mykletun, A. (2003). Anxiety and depression in individuals with somatic health problems. The Nord-Trondelag Health Study (HUNT). Scandinavian Journal of Primary Health Care, 21, 136-141.

Tabachnick, B. G., \& Fidell, L. S. (2007). Experimental Design Using ANOVA. Belmont; CA: Thomson Brooks/Cole.

Taleporos, G., Dip, G., McCabe, M. P. (2002). The impact of sexual esteem, body esteem, and sexual satisfaction on psychological well-being in people with physical disability. Sexuality and Disability, 20, 177-183.

Tanner, J. L. (2006). Recentering during emerging adulthood: A critical turning point in life span human development. In J. J. Arnett \& J. L. Tanner (Eds.), Emerging adults in America. Coming of age in the $21^{\text {st }}$ century (pp. 21-55). Washington, DC: American Psychological Association.

Thomas, J. J., \& Daubman, K. A. (2001). The relationship between friendship quality and selfesteem in adolscent girls and boys. Sex Roles, 45, 53-65.

Touliatos, J., Perlmutter, B. F., \& Straus, M. A. (2001). Handbook of family measurement techniques, Volume 1. California: Sage Publications.

Turner, R. J. (1981). Social support as a contingency in psychological well-being. Journal of Health and Social Behavior, 22, 357-367. 
Shyness and Romantic Relationships 113

Tweng, J. M., \& Campbell, W. K. (2001). Age and birth cohort differences in self-esteem: A cross-temporal meta-analysis. Personality and Social Psychology Review, 5, 321-344.

Vartanian, L. R. (in press). Book review: Adolescence and emerging adulthood: A cultural approach. Journal of Adolescence.

Ward, C. C., \& Tracey, T. J. G. (2004). Relation of shyness with aspects of online relationships involvement. Journal of Social and Personal Relationships, 21, 611-623.

Weiss, R. S. (1974). The provision of social relationships. In Z. Rubin (Ed.), Doing unto others (pp. 17-26). Englewood Cliffs, NJ: Prentice-Hall.

Werner, E. E. (1990). Protective factors and individual resilience. In S. J. Meisels, \& J. P. Shonkoff (Eds.), Handbook of early childhood intervention (pp. 97-116). New York, NY: Cambridge University Press.

Whiffen, V. E. (2006). A secret sadness: The hidden relationship patterns that make women depressed. Oakland, CA: New Harbinger Publications, Inc.

Wichmann, C., Coplan, R. J., Daniels, T. (2004). The social cognitions of socially withdrawn children. Social Development, 13, 377-392.

Wood, J. J., Emmerson, N. A., \& Cowan, P. A. (2004). Is early attachment security carried forward into relationships with preschool peers? British Journal of Developmental Psychology, 22, 245-253.

Young, M., Denny, G., Luquis, R., \& Young, T. (1998). Correlates of sexual satisfaction in marriage. The Canadian Journal of Human Sexuality, 72, 115-127.

Zimbardo, P. G. (1990). Shyness: What it is, what to do about it. Reading, MA: Addison-Wesley. 


\author{
Appendix A \\ The Relationship Study \\ Informed Consent Form
}

Thank you for signing up to participate in this study on romantic relationships. We are interested in better understanding individual functioning in personal life and in relationships.

Participation in this study involves completing one 25-minute questionnaire about shyness, selfesteem, intimacy, sexual satisfaction, and romantic relationship quality. This questionnaire is done on-line, so you are able to complete it in your own home.

\title{
Time
}

The questionnaires will take approximately 30 minutes, but there is no time limit. You will be given a total 1\% towards your Psyc 1001, 1002, 2001 or 2002 grade for your completion of the questionnaire. If you participated in the mass testing questionnaire earlier in the semester, the percentage that you receive in the current study will be in addition to those that you received from mass testing.

\section{Potential Risks}

There are no anticipated risks associated with this research. We are asking questions about your personal life, romantic relationship, and sexuality. You may prefer not to answer some questions if they make you uncomfortable. If you would like to talk to a qualified counselor about your personal situation, you can contact Student Health and Counseling Services at (613) 520-6674.

\section{Your Rights}

Participation in this study is voluntary. There is no obligation for you to participate. If there are questions that you do not wish to answer or that are not relevant to you, you may choose to skip these questions. You have the right to withdraw from the study at any point with no penalties if you feel you are not able to continue.

\section{Anonymity and Confidentiality}

All information will be kept confidential. To ensure confidentiality, the data will only be shared with research personnel and consent forms and questionnaires will be kept in separate places. In any publications using the data from this study, will use the data of the group together, ensuring that no information about a single individual is given.

\section{For more information}

If you have questions about this study or would like more information you may contact Claire 
Rowsell (hcrowsel@connect.carleton.ca), or Dr. Robert Coplan in the Department of Psychology at Carleton University (613) 520-2600 ext. 8691 (robert_coplan@ carleton.ca).

If you are interested in finding out more about your rights as a participant, please contact the Chair of the Department of Psychology Ethics Chair, Monique Sénéchal, at (613) 520-2600 ext.1155 (monique sénéchal@carleton.ca). This study has been approved by the Carleton University Ethics Committee for Psychological Research.

Consent By clicking on the "I agree" button, it will mean that you have consented to participate in this study.

I Agree Quit 


\section{Appendix B}

Debriefing

Thank you for participating in this study. The purpose of this research is to examine the influence of shyness on romantic relationship quality and psychological well-being. It is expected that people who are more shy are going to experience lower relationship quality, well-being and selfesteem.

In addition, an objective is to determine the potential protective role of romantic relationship quality on the well-being of people who are shy. It is predicted that high quality romantic relationships will help shy individuals to experience less stress and anxiety. This research will further our understanding of shyness and individual functioning within romantic relationships.

If you are interested in finding out more about this specific study you may contact Claire Rowsell (hcrowsel@connect.carleton.ca) or Dr. Robert Coplan in the Department of Psychology at Carleton University (613) 520-2600 ext. 8691 (robert_coplan@ @arleton.ca).

If you are interested in finding out more about your rights as a participant, please contact the Department of Psychology Ethics Chair, Monique Sénéchal, at (613) 520-2600 ext.1155 (monique sénéchal@carleton.ca).

If after participating in this research, you feel distressed, or if you are feeling depressed or anxious for any other reason, please contact your family physician or the Carleton University Student Health and Counseling Services at (613) 520-6674. 


\section{Appendix C}

Recruitment Notice

Study Name: A Relationship Study

Description: This is an online questionnaire that you can do from home or wherever you choose. We are investigating the link between shyness, romantic relationship quality, and psychological well-being.

Eligibility: In order to participate in this study you must currently be involved in a romantic relationship and must be between 18-26 years old.

Duration: 30 minutes

Percentage: $.25 \%$

Researcher:

Claire Rowsell: hcrowsel@ connect.carleton.ca

A404 Loeb Building, Carleton University

This study has been approved by the Carleton University Ethics Committee for Psychological Research. 
Appendix D

Relationship Measures for Study 1

(items from the Social Provisions Questionnaire, Carbery \& Buhmeister, 1998;

Nelson et al., 2008)

Please circle the answer that is most appropriate for you currently.

1. Are you currently involved in a romantic relationship?

$\begin{array}{ll}1 & 2 \\ \text { Yes } & \text { No }\end{array}$

2. How long have you been in this current romantic relationship?
1
2
3
4

$1=$ less than 3 months $\quad 2=3-$ to -6 months $\quad 3=6-12$ months $\quad 4=$ over 1 year.

If you are currently involved in a romantic relationship (answered yes to question 1) then please answer the following questions. These questions ask about your relationships with your romantic partner. Please answer each question using the following scale.

$$
\begin{aligned}
& 1=\text { Not at all } \\
& 2=\text { A little } \\
& 3=\text { Somewhat } \\
& 4=\text { Very } \\
& 5=\text { Extremely }
\end{aligned}
$$

3. How satisfied are you with your relationship with this person?

4. How happy are you with the way things are between you and this person?

5. How good is your relationship with this person? 
Appendix E

Demographics for Study 2

Please mark the appropriate response.

1. Your age:

2. You are:
A)
Male
B)
Female

3. How would you describe yourself? (optional)
A)
B)
African
C)
American Indian/Native American
D)
Asian or Pacific Islander
E)
Caucasian
F)
Hispanic/Latino
Mixed/Biracial
G)
Other (specify)

4. What year of university are you in?
A) $1^{\text {st }}$ year of undergraduate
B) $2^{\text {nd }}$ year of undergraduate
C) $3^{\text {rd }}$ year of undergraduate
D) $4^{\text {th }}$ year of undergraduate
E) $5^{\text {th }}$ or higher year of undergraduate

Please mark the appropriate response.

1. Which best describes your current dating status?
A) Married
B) Have a boy/girlfriend (in an exclusive relationship), Engaged, or Committed to marry
C) Casual/occasional dating
D) Not dating at all

2. How long have you been in a relationship with your boy/girlfriend, fiancé(e), or spouse?
A) Less than 2 weeks
B) More than 2 weeks, but less than 2 months
C) More than 2 months, but less than 6 months
D) More than 6 months, but less than 1 year
E) More than 1 year, but less than 5 years
F) More than 5 years
G) Does not apply, I am not in a relationship 
3. What are your living arrangements?
A) Currently living with romantic partner
B) Currently living in the same city as romantic partner
C) Currently do not live in the same city as romantic partner. 


\section{Appendix F \\ Revised Cheek and Buss Shyness Scale (Cheek \& Buss, 1983)}

Read each item carefully and decide to what extent it is characteristic of your feelings and behaviour. Answer each question by choosing the most appropriate number from the scale below.

$1=$ very uncharacteristic or untrue, strongly disagree

$2=$ uncharacteristic $\quad 3=$ neutral $\quad 4=$ characteristic

$5=$ very characteristic or true, strongly agree

1. I feel tense when I'm with people I don't know well.

$\begin{array}{llll}1 & 2 & 3 & 4\end{array}$

2. I am socially somewhat awkward.
1
2
3
4

3. I find it difficult to ask other people for information.
1 2
3
4

4. I am often uncomfortable at parties and other social events.
1
2
3
4

5. When in a group of people, I have trouble thinking of the right thing to say.
1
2
3
4

6. It takes me a long time to overcome my shyness in new situations.
1
2
3
4

7. It is hard for me to act natural when I am meeting new people.

$\begin{array}{lllll}1 & 2 & 3 & 4\end{array}$

8. I feel nervous when speaking to someone in authority.

1 2
4 5

9. I have doubts about my social competence.

1 2 3 4 5

10. I have trouble looking someone right in the eye.

1 2

11. I feel inhibited in social situations. 
Shyness and Romantic Relationships 122

12. I find it hard to talk to strangers.

1

2

3

13. I am more shy with members of the opposite sex.

1

2

3

4

5 


\section{Appendix G \\ Index of Marital Satisfaction}

(Cheung \& Hudson, 1982)

This questionnaire is designed to measure the degree of satisfaction you have with your present marriage. It is not a test, so there are no right or wrong answers. Answer each item as carefully and accurately as you can by placing a number beside each one as follows:

$1=$ Rarely or none of the time

$2=$ A little of the time

$3=$ Sometimes

$4=$ A good part of the time

$5=$ Most or all of the time

1. My partner is affectionate enough.

$$
123
$$

2. My partner treats me badly.

12

3. My partner really cares for me.

1

4. I feel that I would not choose the same partner if I had it to do over again.

1

$$
2
$$

3

4

5. I feel that I can trust my partner.

6. I feel that our relationship is breaking up.

1

7. My partner really doesn't understand me.

8. I feel that our relationship is a good one.

9. Ours is a very happy relationship.

10. Our life together is dull.

11. We have a lot of fun together. 
12. My partner does not confide in me.

$\begin{array}{lllll}1 & 2 & 3 & 4 & 5\end{array}$

13. Ours is a very close relationship.

14. I feel that I cannot rely on my partner.

$1 \quad 2 \quad 3 \quad 4 \quad 5$

15. I feel that we do not have enough interests in common. 1

16. We manage arguments and disagreements very well.

123

17. We do a good job of managing our finances.
1
2
3
4

18. I feel that I should never have dated my partner.
1 2
3
4

19. My partner and I get along very well together.

123

4

5

20. Our relationship is very stable.

123

4

21. My partner is a real comfort to me.

12

34

5

22. I feel that I no longer care for my partner.

$\begin{array}{llll}1 & 2 & 3 & 4\end{array}$

23. I feel that the future looks bright for our relationship.

1 2 3

4

24. I feel that our relationship is empty.
1
2
3
4

25. I feel there is no excitement in our relationship. 


\section{Appendix $\mathrm{H}$ \\ The Experiences in Close Relationships-Revised (ECR-R) Questionnaire \\ (Fraley, Waller, \& Brennan, 2000)}

The statements below concern how you feel in emotionally intimate relationships. We are interested in how you generally experience relationships, not just in what is happening in a current relationship. Respond to each statement by clicking a circle to indicate how much you agree or disagree with the statement.

$1=$ strongly disagree

$2=$ disagree

$3=$ disagree somewhat

$4=$ neutral

$5=$ agree somewhat

$6=$ agree

$7=$ strongly agree

1. I'm afraid that I will lose my partner's love.
1
2
3
4
5
6

2. I often worry that my partner will not want to stay with me.
1
2
34
5
6
7

3. I often worry that my partner doesn't really love me.
1
2
3
4
5
6

4. I worry that romantic partners won't care about me as much as I care about them.
1
2
3
4
5
6

5. I often wish that my partner's feelings for me were as strong as my feelings for him or her.
1
2
3
4
5
6

6. I worry a lot about my relationships.
1
2
3
4
5
6

7. When my partner is out of sight, I worry that he or she might become interested in someone else.
1
2
3
45
6

8. When I show my feelings for romantic partners, I'm afraid they will not feel the same about me. 1 2 3 4 5 6 7

9. I rarely worry about my partner leaving me.

1

2 3 4 5 6

10. My romantic partner makes me doubt myself. 

1
2
3
4
5
6
7

11. I do not often worry about being abandoned.
1
2
3
4
5
6
7

12. I find that my partner(s) don't want to get as close as I would like.
1
2
3
4
5
6

13. Sometimes romantic partners change their feelings about me for no apparent reason.
1
2
3
4
5
6

14. My desire to be very close sometimes scares people away.
1
2
3
4
5
6
7

15. I'm afraid that once a romantic partner gets to know me, he or she won't like who I really am.
1
2
3
4
5
6
7

16. It makes me mad that I don't get the affection and support I need from my partner.
1 2 3
4
5
6

17. I worry that I won't measure up to other people.
1
2
3
4
5
6

18. My partner only seems to notice me when I'm angry.

$\begin{array}{lllllll}1 & 2 & 3 & 4 & 5 & 6 & 7\end{array}$

19. I prefer not to show a partner how I feel deep down.
1
2
3
4
5
6

20. I feel comfortable sharing my private thoughts and feelings with my partner.
12
3
4
5

6

21. I find it difficult to allow myself to depend on romantic partners.
1
2
3
4
5
6

22. I am very comfortable being close to romantic partners.
1 2 3 4 5
6

23. I don't feel comfortable opening up to romantic partners.
1
2
3
4
5
6
7

24. I prefer not to be too close to romantic partners. 1
2
3
4
5
6

25. I get uncomfortable when a romantic partner wants to be very close. 
26. I find it relatively easy to get close to my partner.
1
2
3
4
5
6
7

27. It's not difficult for me to get close to my partner.
1
2
3
4
5
6
7

28. I usually discuss my problems and concerns with my partner.
1
2
3
4
5
6
7

29. It helps to turn to my romantic partner in times of need.
1
2
3
4
5
6
7

30. I tell my partner just about everything.

$\begin{array}{llllllll}1 & 2 & 3 & 4 & 5 & 6 & 7\end{array}$

31. I talk things over with my partner.

$\begin{array}{lllllll}1 & 2 & 3 & 4 & 5 & 6 & 7\end{array}$

32. I am nervous when partners get too close to me.
1
2
3
4
5
6
7

33. I feel comfortable depending on romantic partners.

$\begin{array}{llllllll}1 & 2 & 3 & 4 & 5 & 6 & 7\end{array}$

34. I find it easy to depend on romantic partners.
1
2
3
4
5
6
7

35. It's easy for me to be affectionate with my partner.
12
$3 \quad 4$
5
6

36. My partner really understands me and my needs. 


\section{Appendix I \\ Emotional Intimacy Scale \\ (Sinclair \& Dowdy, 2005)}

Complete the following questions with your current romantic partner in mind. Please, answer the questions as carefully and accurately as you can using the following scale.

$1=$ strongly disagree

$2=$ disagree

$3=$ undecided

$4=$ agree

$5=$ strongly agree

1. This person completely accepts me as I am.

123

Strongly Disagree Disagree Undecided
4

Agree
5

Strongly Agree

2. I can openly share my deepest thoughts and feelings with this person.

1

2

Strongly Disagree

Disagree
4

Agree
5

Strongly Agree

3. This person cares deeply for me.

1 2

Strongly Disagree
3

Undecided
4

Agree
5

Strongly Agree

4. This person would willingly help me in any way.

1 2

Disagree
3

Undecided
4

Agree
5

Strongly Agree

5. My thoughts and feelings are understood and affirmed by this person.

1 2

Strongly Disagree

Disagree

3

Undecided
4

Agree
5

Strongly Agree 


\section{Appendix J \\ Sexual Satisfaction Scale \\ (Young, Denny, Luquis, \& Young, 1998)}

The following questions evaluate your degree of sexual satisfaction in your present marriage/relationship. Please, answer the questions as carefully and accurately as you can using the following scale.

$1=$ strongly disagree

$2=$ disagree

$3=$ undecided

$4=$ agree

$5=$ strongly agree

1. I am satisfied with my partner as a sexual partner

1

Strongly Disagree
2

Disagree
3

Undecided
4

Agree

4

4

Agree

4

Agree

Strongly Disagree Disagree Undecided $\quad$ Agree $\quad$ Strongly Agree

5

Strongly Agree

3. I have satisfying orgasms

12

3

Undecided

3

Undecided

4. I feel that foreplay with my partner is very arousing

1

Strongly Disagree

Disagree

5. I have very good communication with my partner about sex

1

Strongly Disagree
2

Disagree
3

Undecided
4

Agree
5

Strongly Agree

6. I am satisfied with the variety of sexual positions and activities in which my partner and I participate

1

Strongly Disagree
2

Disagree
3

Undecided
4

Agree
5

Strongly Agree

7. I am pleased with the frequency with which my partner and I engage in sexual activity 
Shyness and Romantic Relationships 130

$\begin{array}{llll}\text { Strongly Disagree } & \text { Disagree } & \text { Undecided } & \text { Strongly Agree }\end{array}$

8. My partner makes me feel sexually desirable

123

Strongly Disagree Disagree Undecided

9. I am sexually attracted to my partner

1

2

Strongly Disagree Disagree

1

2

Disagree

Undecided

3

3

4

Agree

Agree

Strongly Agree

5

4

10. My partner makes it clear that I provide him/her with a great deal of sexual satisfaction

Strongly Disagree Disagree Undecided $\quad$ Agree $\quad$ Strongly Agree




\section{Appendix K \\ Rosenberg Self-Esteem Scale \\ (Rosenberg, 1965)}

Below is a list of statements dealing with your general feelings about yourself. If you strongly agree, circle SA. If you agree with the statement, circle A. If you disagree, circle D. If you strongly disagree, circle SD.

1. On the whole, I am satisfied with myself.
SA
A
D
SD

2.* At times, I think I am no good at all.
SA
A
D
SD

3. I feel that I have a number of good qualities.

$\begin{array}{llll}\text { SA } & \text { A } & \text { D } & \text { SD }\end{array}$

4. I am able to do things as well as most other people.
$\mathrm{SA}$
A
D
SD

5. * I feel I do not have much to be proud of.
SA
A
D
SD

6. * I certainly feel useless at times.
SA
A
D
SD

7. I feel that I'm a person of worth, at least on an equal plane with others.
SA
A
D
SD

8. * I wish I could have more respect for myself.
SA
A
D
SD

9. * All in all, I am inclined to feel that I am a failure.
SA
A
D
SD

10. I take a positive attitude toward myself.
SA
A
D
SD 
Appendix L

General Health Questionnaire

(Goldberg, 1972)

Circle the best response to each of the following items.

During the past few weeks, have you:

1. been able to concentrate on whatever you're doing?

better than usual same as usual less than usual much less than usual

2. lost much sleep over worry?

not at all no more than usual rather more than usual much more than usual

3. felt that you were playing a useful part in things?

more so than usual same as usual less useful than usual much less useful

4. felt capable of making decisions about things?

more so than usual same as usual less so than usual much less capable

5. felt constantly under strain?

not at all no more than usual rather more than usual much more than usual

6. felt you couldn't overcome your difficulties?

not at all no more than usual rather more than usual much more than usual

7. been able to enjoy your normal day-to-day activities?

more so than usual same as usual less so than usual much less than usual

8. been able to face up to you problems?

more so than usual same as usual less so than usual much less able

9. been feeling unhappy and depressed?

not at all no more than usual rather more than usual much more than usual 
10. been losing confidence in yourself? not at all no more than usual rather more than usual much more than usual

11. been thinking of yourself as a worthless person? not at all no more than usual rather more than usual much more than usual

12. been feeling reasonably happy, all things considered? more so than usual about the same as usual less so than usual much less than usual 